\title{
Guía de Práctica Clínica de Prevención y Tratamiento de la Conducta Suicida
}

La GPC ha sido revisada en septiembre 2020. La revisión ha concluido que las recomendaciones y otros contenidos clínicos relevantes continúan siendo vigentes. El procedimiento para la revisión de la GPC puede consultarse en: https:// bit.ly/2ZEyBJx

Está previsto valorar la necesidad de actualización de la GPC transcurridos 5 años desde la última revisión.

Versión resumida

GUÍAS DE PRÁCTICA CLÍNICA EN EL SNS

MINISTERIO DE SANIDAD, POLITICA SOCIAL E IGUALDAD
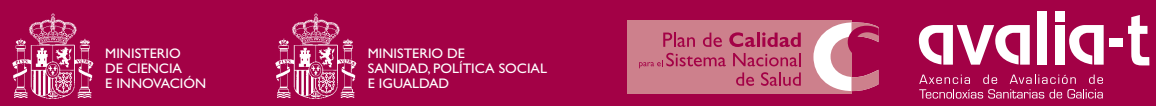


\section{Guía de Práctica Clínica de Prevención y Tratamiento de la Conducta Suicida}

Versión resumida 
Esta GPC es una ayuda a la toma de decisiones en la atención sanitaria. No es de obligatorio cumplimiento ni sustituye el juicio clínico del personal sanitario.

Edición: 2012

Edita: Agencia de Evaluación de Tecnologías Sanitarias de Galicia, avalia-t. Consellería de Sanidad. NIPO MICINN: 477-11-053-8

NIPO MSPSI: 860-11-161-2

ISBN: 978-84-453-5052-2

Depósito Legal: C 1504-2012

Nombre de la imprenta: Tórculo Artes Gráficas, S.A. 
"Esta GPC ha sido financiada mediante el convenio suscrito por el Instituto de Salud Carlos III, organismo autónomo del Ministerio de Ciencia e Innovación, y la Agencia de Evaluación de Tecnologías Sanitarias de Galicia (avalia-t), en el marco de colaboración previsto en el Plan de Calidad para el Sistema Nacional de Salud del Ministerio de Sanidad, Política Social e Igualdad".

Esta guía debe citarse:

Grupo de trabajo de la Guía de Práctica Clínica de Prevención y Tratamiento de la Conducta Suicida. Guía de Práctica Clínica de Prevención y Tratamiento de la Conducta Suicida. Plan de Calidad para el Sistema Nacional de Salud del Ministerio de Sanidad, Política Social e Igualdad. Agencia de Evaluación de Tecnologías Sanitarias de Galicia (avalia-t); 2012. Guías de Práctica Clínica en el SNS: Avalia-t 2010/02. 


\section{Índice}

$\begin{array}{ll}\text { Presentación } & 11\end{array}$

$\begin{array}{ll}\text { Autoría y colaboraciones } & 13\end{array}$

Niveles de evidencia y grados de recomendación del SIGN 21

1. Introducción 23

1.1. La conducta suicida 23

1.2. Conceptualización $\quad 23$

1.3. Epidemiología del suicidio 26

$\begin{array}{ll}\text { I. EVALUACIÓN Y TRATAMIENTO } & 29\end{array}$

2. Factores asociados con la conducta suicida y evaluación del riesgo suicida $\quad 31$

2.1. Factores de riesgo 31

2.2. Evaluación del riesgo suicida 33

3. Evaluación y manejo de la ideación y conducta suicidas en atención primaria 39

3.1. Abordaje de la ideación suicida en atención primaria 39

3.2. Evaluación de la conducta suicida en atención primaria 41

3.3. Criterios de derivación de pacientes desde atención primaria 42

4. Evaluación y manejo del paciente con conducta suicida en el $\begin{array}{ll}\text { servicio de urgencias } & 47\end{array}$

4.1. La clasificación de pacientes (triaje) en los servicios de urgencias 47

4.2. Evaluación del paciente con conducta suicida en el servicio de urgencias 49

4.3. Formación del médico de los servicios de urgencias 51

4.4. Criterios de ingreso hospitalario del paciente con conducta suicida 52

5. Tratamiento de la conducta suicida en atención especializada

(Salud Mental)

5.1. Las intervenciones psicoterapéuticas en el tratamiento de la conducta suicida

5.1.1. Terapias de corte cognitivo-conductual 54

5.1.2. Terapia interpersonal 55

5.1.3. Terapia familiar $\quad 56$

5.1.4. Terapia psicodinámica 56 
5.2. Tratamiento farmacológico de la conducta suicida 57

5.2.1. Antidepresivos 57

5.2.2. Litio 59

5.2.3. Anticonvulsivantes 59

5.2.4. Antipsicóticos 60

5.3. Terapia electroconvulsiva 61

II. ASPECTOS PREVENTIVOS 65

6. Medidas generales de prevención de la conducta suicida 67

6.1. Programas de prevención de la conducta suicida a nivel internacional 67

6.2. Potenciación de factores protectores y resiliencia 70

6.3. Restricción del acceso a medios letales 72

6.4. Medios de comunicación y suicidio 73

6.4.1. Medios de comunicación 73

6.4.2. Internet 75

6.5. Programas formativos de prevención de la conducta suicida $\quad 77$

$\begin{array}{ll}\text { 6.5.1. Profesionales sanitarios } & 78\end{array}$

6.5.2. Profesionales no sanitarios 80

7. El cribado del riesgo de suicidio 83

7.1. Cribado de riesgo de suicidio en adultos 83

7.2. Cribado de riesgo de suicidio en la infancia y la adolescencia 84

7.3. Cribado de riesgo de suicidio en personas mayores 86

7.4. Cribado de riesgo de suicidio en centros penitenciarios 87

7.5. Posibles efectos adversos del cribado 88

8. La conducta suicida en grupos de riesgo 89

8.1. La conducta suicida en la infancia y la adolescencia 89

8.1.1. Factores de riesgo y protectores 89

8.1.2. Detección y valoración del riesgo suicida 91

8.1.3. Instrumentos psicométricos 92

8.1.4. Intervenciones preventivas 93

8.2. La conducta suicida en personas mayores 97

8.2.1. Factores de riesgo y protectores 98

8.2.2. Detección y valoración del riesgo suicida 99

8.2.3. Instrumentos psicométricos 100

8.2.4. Intervenciones preventivas 101

8.3. Prevención de la conducta suicida en otros grupos de riesgo 104

8.3.1. Pacientes con gran dependencia o enfermedad somática grave 104

8.3.2. Cuidadores no profesionales de enfermos 106 
8.3.3. En situaciones laborales consideradas de riesgo 107

8.3.4. Personas que sufren violencia doméstica 108

8.3.5. Población penitenciaria 109

9. Intervenciones en familiares, allegados y profesionales después de un suicidio 111

9.1. Necesidades y expectativas de la familia y allegados tras un suicidio 111

9.2. Intervenciones preventivas en familiares y allegados 113

9.3. Intervenciones comunitarias 115

9.4. Intervenciones en profesionales de la salud tras el suicidio de un paciente 115

10. Programas clínicos de intervención sobre la conducta suicida en España

11. Aspectos legales del suicidio en España 125

12. Estrategias diagnósticas y terapéuticas 127

$\begin{array}{ll}\text { Anexos } & 131\end{array}$

Anexo 1. Aspectos a recoger en urgencias hospitalarias ante una conducta suicida

Anexo 2. Objetivos de las intervenciones preventivas de suicidio

Anexo 3. Información para pacientes y familiares sobre la ideación y conducta suicidas

Anexo 4. Información para familiares y allegados sobre el duelo tras un suicidio 153

Anexo 5. Abreviaturas 173

Anexo 6. Glosario 175

Anexo 7. Declaración de intereses 183

$\begin{array}{ll}\text { Bibliografía } & 185\end{array}$ 


\section{Presentación}

Documentar la variabilidad de la práctica clínica, analizar sus causas y adoptar estrategias orientadas a eliminarla han demostrado ser iniciativas que inducen mejoras sustanciales en la práctica profesional y que fomentan la calidad. Entre dichas estrategias destaca la elaboración de guías de práctica clínica (GPC), conjunto de recomendaciones claves basadas en una profunda revisión sistemática de estudios científicos relevantes con el propósito de dar respuesta a las incertidumbres existentes en la práctica clínica diaria.

El Plan de Calidad 2010 para el Sistema Nacional de Salud (SNS) pretende responder a los retos que tiene planteados el SNS, incrementando la cohesión del sistema, garantizando la equidad en la atención sanitaria a los ciudadanos, con independencia del lugar en el que residan y asegurando que esta atención sea de la máxima calidad. Entre sus objetivos figura el impulso a la elaboración y uso de GPC vinculadas a las Estrategias de salud, consolidando y extendiendo el Proyecto Guía-Salud.

El Consejo Interterritorial del SNS aprobó en el año 2003 el Proyecto Guía-Salud con el objeto final de mejorar la calidad en la toma de decisiones clínicas basadas en la evidencia, a través de la articulación de un sistema de actividades formativas y la configuración de un registro de GPC en el SNS accesibles de forma gratuita vía Internet. En este contexto se enmarca la presente GPC de Prevención y Tratamiento de la Conducta Suicida.

El suicidio representa un grave problema de Salud Pública con alrededor de un millón de muertes anuales en todo el mundo, siendo la décima causa de muerte en Europa. En España se suicidan nueve personas al día, hecho de gran repercusión emocional, social y económica en el entorno de las personas fallecidas.

Es por ello de gran importancia la adopción de medidas y el desarrollo de estrategias encaminadas a la disminución de la conducta suicida como se recoge en la Estrategia de Salud Mental del SNS que contempla entre sus objetivos la prevención del suicidio y la evaluación de acciones específicas para disminuir las tasa de suicidio en grupos de riesgo.

El propósito de esta GPC es contribuir a reducir la variabilidad de la práctica clínica en el manejo de la conducta suicida, ayudando a la toma de decisiones por parte de los profesionales sanitarios implicados y favoreciendo la mejora en la salud y la calidad de vida de la población.

Pretende además mejorar la información de pacientes y familiares favoreciendo su participación en la toma de decisiones y mejorar la información de toda la ciudadanía de manera que se logre reducir el estigma asociado a este problema de salud. 
Esta guía es el resultado del gran esfuerzo realizado por profesionales expertos en metodología y profesionales sanitarios de los distintos ámbitos clínicos relacionados con el manejo de la conducta suicida, tanto en Atención Primaria como en Atención Especializada. Desde la Agencia de Calidad agradecemos a todos ellos el trabajo realizado y les felicitamos por esta GPC que esperamos permita mejorar el trato y la atención sanitaria que reciben estos pacientes.

CARMEN MOYA GARCÍA

DG. de la Agencia de Calidad del SNS 


\section{Autoría y colaboraciones}

Grupo de trabajo de la Guía de Práctica Clínica de Prevención y Tratamiento de la Conducta Suicida*

María Álvarez Ariza ${ }^{1,2}$. Doctora en Medicina. Especialista en Psiquiatría. Complejo Hospitalario Universitario de Vigo

(Pontevedra).

Gerardo Atienza Merino ${ }^{\mathbf{1}, \mathbf{2}}$. Doctor en Medicina. Técnico de la Agencia de Evaluación de Tecnologías Sanitarias de Galicia. Consellería de Sanidad.

María José Ávila González² ${ }^{2}$ Licenciada en Medicina. Especialista en Psiquiatría. Complejo Hospitalario Universitario de Santiago

(A Coruña).

Celia Canedo Magariños ${ }^{1}$. Doctora en Medicina. Especialista en Psiquiatría. Hospital Lucus Augusti de Lugo.

Manuel Castro Bouzas ${ }^{1}$. Licenciado en Psicología. Especialista en Psicología Clínica. Área Sanitaria de Ferrol (A Coruña).

Jesús Combarro Mato ${ }^{1}$. Licenciado en Medicina. Especialista en Medicina Familiar y Comunitaria. Centro de Salud de Culleredo

(A Coruña).

Elena de las Heras Liñero ${ }^{\mathbf{1}, 2}$. Doctora en Medicina. Especialista en Psiquiatría. Complejo Hospitalario Universitario de Vigo

(Pontevedra).

Rafael Fernández Martínez ${ }^{2}$. Doctor en Psicología. Especialista en Psicología Clínica. Complejo Hospitalario Universitario de Vigo (Pontevedra).

Ernesto Ferrer Gómez del Valle1,2. Doctor en Medicina. Especialista en Psiquiatría. Complejo Hospitalario de Ourense.

Alejandro García Caballero ${ }^{1}$. Doctor en Medicina. Especialista en Psiquiatría. Complejo Hospitalario de Ourense.

\footnotetext{
* Los autores han participado en la primera parte de la guía (evaluación y tratamiento, capítulos 2 a 5) ${ }^{1}$, en la segunda (aspectos preventivos, capítulos 6 a 10) ${ }^{2}$, o en ambas ${ }^{1,2}$.
} 
Amparo González García ${ }^{\mathbf{1}, 2}$. Enfermera Especialista en Salud Mental. Complejo Hospitalario de Ourense.

Delia Guitián Rodríguez ${ }^{\mathbf{1} 2}$. Licenciada en Psicología. Especialista en Psicología Clínica. Hospital Lucus Augusti de Lugo.

Ekaterina Kokoulina Cherevach ${ }^{2}$. Licenciada en Psicología. Psicóloga interna residente. Complejo Hospitalario Universitario de Vigo (Pontevedra).

Cristina Losada Pérez ${ }^{2}$. Licenciada en Medicina. Médica interna residente (Psiquiatría). Complejo Hospitalario Universitario de Vigo

(Pontevedra).

María del Carmen Maceira Rozas ${ }^{\mathbf{1}, \mathbf{2}}$. Licenciada en Farmacia. Técnica de la Agencia de Evaluación de Tecnologías Sanitarias de Galicia. Consellería de Sanidad.

Belén Martínez Alonso ${ }^{1}$. Licenciada en Medicina. Especialista en Psiquiatría. USM. Infanto-Juvenil. Complejo Hospitalario Universitario de Vigo (Pontevedra).

José Mazaira Castro ${ }^{1}$. Licenciado en Medicina. Especialista en Psiquiatría. USM Infanto-Juvenil. Complejo Hospitalario Universitario de Santiago (A Coruña).

Mª Luisa Mosteiro Álvarez ${ }^{1}$. Licenciada en Medicina. Médico de Urgencias. Complejo Hospitalario de Pontevedra.

Laura Pérez Méndez ${ }^{1}$. Licenciada en Psicología. Especialista en Psicología Clínica. Complejo Hospitalario de Pontevedra.

Teresa Reijas Ruiz ${ }^{1}$. Doctora en Psicología. Especialista en Psicología Clínica. Complejo Hospitalario de Ourense.

Águeda Rojo Pantoja ${ }^{2}$. Doctora en Medicina. Especialista en Psiquiatría. Complejo Hospitalario de Pontevedra.

Henar Sancho Díaz ${ }^{2}$. Licenciada en Medicina. Especialista en Psiquiatría. Complejo Hospitalario Universitario de Vigo

(Pontevedra).

Margarita Tovar Bobo ${ }^{2}$. Licenciada en Medicina. Especialista en Medicina Familiar y Comunitaria. Centro de Salud de Culleredo

(A Coruña).

Yolanda Triñanes Pego ${ }^{1,2}$. Licenciada en Psicología. Técnica de la Agencia de Evaluación de Tecnologías Sanitarias de Galicia. Consellería de Sanidad. 


\section{Coordinación}

Ernesto Ferrer Gómez del Valle. Coordinador general. Doctor en

Medicina. Especialista en Psiquiatría. Complejo Hospitalario de

Ourense.

María Álvarez Ariza. Coordinadora clínica. Doctora en Medicina. Especialista en Psiquiatría. Complejo Hospitalario

Universitario de Vigo (Pontevedra).

Gerardo Atienza Merino. Coordinador metodológico. Doctor en Medicina. Técnico de la Agencia de Evaluación de Tecnologías Sanitarias de Galicia. Consellería de Sanidad.

\section{Colaboración}

Beatriz Casal Acción. Documentalista. Agencia de Evaluación de Tecnologías Sanitarias de Galicia. Consellería de Sanidad.

\section{Colaboración experta*}

Jose Teo Andrés González² ${ }^{2}$ Licenciado en Derecho. Subdirector del Diario Atlántico. Vigo (Pontevedra).

Enrique Baca-García ${ }^{1}$. Psiquiatra. Profesor Asociado de Psiquiatría, Universidad Autónoma de Madrid. Jefe del Servicio de Psiquiatría, Fundación Jiménez Díaz, Madrid.

Jose Antonio Couceiro Gianzo ${ }^{2}$. Especialista en Pediatría. Jefe del Servicio de Pediatría del Complejo Hospitalario de Pontevedra.

Manuel A. Franco Martín ${ }^{2}$. Psiquiatra. Jefe del Servicio de Psiquiatría del Complejo Asistencial de Zamora.

Susana García-Baquero Borrell ${ }^{1}$. Fiscal de la Fiscalía de Área de Vigo (Pontevedra).

José Ramón García Palacios ${ }^{1}$. Fiscal delegado de protección de menores e incapaces de la Fiscalía de Área de Vigo (Pontevedra).

Ana Goicoechea Castaño ${ }^{2}$. Especialista en Pediatría. Centro de Salud de Tui (Pontevedra).

* Los colaboradores expertos han participado en la primera parte de la guía (capítulos 2 a 5) en la segunda (capítulos 6 a 10)², o en ambas ${ }^{1,2}$. 
Belén Martínez Alonso ${ }^{2}$. Licenciada en Medicina. Especialista en Psiquiatría. USM. Infanto-Juvenil. Complexo Hospitalario Universitario de Vigo (Pontevedra).

José Mazaira Castro ${ }^{2}$. Licenciado en Medicina. Especialista en Psiquiatría. USM Infanto-Juvenil. Complejo Hospitalario Universitario de Santiago (A Coruña).

Marta Medrano Varela ${ }^{1}$. Médico Forense. Especialista en Medicina Legal y Forense. Jefa de Sección Clínica. Instituto de Medicina Legal de Galicia.

María Teresa Olcoz Chiva ${ }^{2}$. Licenciada en Medicina. Servicio de Geriatría. Complejo Hospitalario Universitario de Vigo (Pontevedra).

Daniel Portela Orjales ${ }^{2}$. Médico. Subdirección Médica de Atención Especializada. Complejo Hospitalario Universitario de Vigo (Pontevedra).

Carmen Senra Rivera ${ }^{1,2}$. Doctora en Psicología. Profesora titular de Universidad. Departamento de Psicología Clínica y Psicobiología. Universidad de Santiago de Compostela.

\section{Revisión externa*}

Enric Aragonés Benaiges ${ }^{1,2,3}$. Médico de Familia. Centro de Atención Primaria de Constantí, Tarragona. Institut Catalá de la Salut. En representación de SEMFYC.

Tiburcio Angosto Saura ${ }^{2}$. Psiquiatra. Jefe del Servicio de Psiquiatría del Complejo Hospitalario Universitario de Vigo (Pontevedra).

Manuel Arrojo Romero ${ }^{1,2,3}$. Psiquiatra. Jefe del Servicio de Salud Mental y Asistencia a Drogodependencias. Servizo Galego de Saúde. Consellería de Sanidade. Xunta de Galicia.

Germán E. Berrios ${ }^{1,2,3}$. Profesor de Epistemología de la Psiquiatría (emérito). Life Fellow Robinson College. Departamento de Psiquiatría. Universidad de Cambridge, Reino Unido.

Julio Bobes García ${ }^{\mathbf{1} 3}$. Psiquiatra. Catedrático de Psiquiatría. Universidad de Oviedo.

* Los revisores externos han participado en la primera parte de la guía (capítulos 2 a 5) ${ }^{1}$, en la segunda (capítulos 6 a 10) ${ }^{2}$, en la parte de información a pacientes y familiares ${ }^{3}$, o en todas ellas ${ }^{1,2,3}$. 
Mercedes Borda Más $\mathbf{1}^{\mathbf{1 2 , 3}}$. Psicóloga clínica. Profesora Titular del Departamento de Personalidad, Evaluación y Tratamiento Psicológico. Universidad de Sevilla. En representación de AEPCP.

Rosendo Bugarín González ${ }^{1,2,3}$. Médico de Familia. Centro de Salud de Folgueiras-Calo (A Coruña). En representación de SEMES.

Alfredo Calcedo Barba ${ }^{1,3}$. Psiquiatra. Servicio de Psiquiatría. Hospital Gregorio Marañón (Madrid). En representación de SEPL.

María Consuelo Carballal Balsa ${ }^{1,2,3}$. Coordinadora de Enfermería. Servicio de Salud Mental y Asistencia a Drogodependencias. Servizo Galego de Saúde. Consellería de Sanidade. Xunta de Galicia. En representación de ANESM.

Ana Díaz Pérez ${ }^{1,2,3}$. Psiquiatra. Departamento de Psiquiatría. Hospital de la Santa Creu i Sant Pau. Barcelona.

Juan L. Fernández Hierro ${ }^{1,3}$. Psiquiatra. Unidad de Hospitalización Psiquiátrica "Nicolás Peña". Complexo Hospitalario Universitario de Vigo (Pontevedra).

$\mathbf{M}^{\mathrm{a}}$ Dolores Franco Fernández ${ }^{1,2,3}$. Psiquiatra. Departamento de Psiquiatría. Facultad de Medicina. Sevilla. En representación de SEP.

Lucas Giner Jiménez ${ }^{1,2,3}$. Psiquiatra. Departamento de Psiquiatría. Universidad de Sevilla. En representación de SEP.

Mariano Hernández Monsalve ${ }^{1,2,3}$. Psiquiatra. Jefe de los servicios de Salud Mental del distrito de Tetuán (Madrid). En representación de AEN.

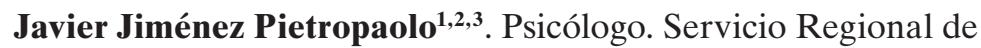
Atención Jurídica y Psicosocial de la Comunidad de Madrid. En representación de AIPIS y FEMASAM.

Raquel León Lamela ${ }^{3}$. Licenciada en Psicología Clínica. Servicio de Información y Atención Socio-Familiar. FEAFES Galicia

(A Coruña).

Germán López Cortacáns ${ }^{1,2,3}$. Enfermero de Salud Mental. Centro de Salud de Salou, Tarragona. En representación de FAECAP.

Raimundo Mateos Álvarez ${ }^{1,2,3}$. Psiquiatra. Unidad de Psicogeriatría. Complexo Hospitalario Universitario de Santiago (CHUS), (A Coruña). En representación de SEPG. 
Berta Moreno Küstner ${ }^{\mathbf{1}, 3}$. Psicóloga clínica. Departamento de Personalidad, Evaluación y Tratamiento Psicológico. Universidad de Málaga. En representación de SEEP.

Teresa Pacheco Tabuenca ${ }^{2}$. Licenciada en Psicología. SAMUR-Protección Civil. Madrid.

Mario Páramo Fernández ${ }^{1,2,3}$. Psiquiatra. Servicio Psiquiatría. Complexo Hospitalario Universitario de Santiago (CHUS), (A Coruña).

Pablo Pascual Pascual ${ }^{1,2,3}$. Médico de Familia. Centro de Salud Azpilagaña. Pamplona (Navarra). En representación de SEMFYC.

Víctor Pérez Solá, ${ }^{1,2,3}$. Psiquiatra. Director de la Unidad de Psiquiatría. Hospital de la Santa Creu i Sant Pau, Barcelona.

Manuel Portela Romero ${ }^{1,3}$. Médico de Familia. Centro de Salud de Padrón (A Coruña). En representación de SEMERGEN.

Francisco Rodríguez Pulido ${ }^{1,2,3}$. Psiquiatra. Profesor Titular de Psiquiatría. Universidad de La Laguna (Tenerife).

En representación de AEN.

Pilar Alejandra Saiz Martínez ${ }^{1,3}$. Psiquiatra. Profesora Titular del Área de Psiquiatría. Universidad Oviedo. En representación de SEPB.

Carmen Senra Rivera ${ }^{1,2,3}$. Psicóloga. Profesora titular de Universidad. Departamento de Psicología Clínica y Psicobiología. Universidad de Santiago de Compostela.

Gustavo Turecki ${ }^{\mathbf{1}, 3}$. Psiquiatra. Departamento de Psiquiatría del Douglas Mental Health University Institute y profesor de la McGill University. Montreal (Canadá).

\section{Agradecimientos}

A José Luis Iglesias Diz y Luis Iglesias Fernández, por las ilustraciones realizadas para el apartado de información a pacientes, familiares y allegados.

A Noemí Raña Villar, de la Agencia de Evaluación de Tecnologías Sanitarias de Galicia, por su labor administrativa y de gestión.

A todos los pacientes y familiares que han participado en la revisión externa del apartado de información para pacientes y familiares. 


\section{Sociedades colaboradoras}

Miembros de estas sociedades y asociaciones han participado en la revisión externa de la GPC:

Asociación de Investigación, Prevención e Intervención del Suicidio (AIPIS).

Asociación Española de Neuropsiquiatría (AEN).

Asociación Española de Psicología Clínica y Psicopatología (AEPCP).

Asociación Madrileña de Amigos y Familiares de personas con Esquizofrenia (AMAFE).

Asociación Nacional de Enfermería de Salud Mental (ANESM).

Federación de Asociaciones de Enfermería Comunitaria y Atención Primaria (FAECAP).

Federación de Asociaciones de Familiares y Personas con Enfermedad Mental de Galicia (FEAFES Galicia).

Federación Madrileña de Asociaciones Pro Salud Mental (FEMASAM).

Sociedad Española de Epidemiología Psiquiátrica (SEEP).

Sociedad Española de Medicina de Familia y Comunitaria (SEMFYC).

Sociedad Española de Medicina de Urgencias y Emergencias (SEMES).

Sociedad Española de Médicos de Atención Primaria (SEMERGEN).

Sociedad Española de Psicogeriatría (SEPG).

Sociedad Española de Psiquiatría (SEP).

Sociedad Española de Psiquiatría Biológica (SEPB).

Sociedad Española de Psiquiatría Legal (SEPL).

Declaración de interés. Todos los miembros del grupo de trabajo, así como las personas que han participado como colaboradores expertos o en la revisión externa, han realizado la declaración de interés que se presenta en el anexo 7. 


\section{Niveles de evidencia y grados de recomendación del SIGN}

\begin{tabular}{|c|c|}
\hline \multicolumn{2}{|c|}{ Niveles de evidencia } \\
\hline $1^{++}$ & $\begin{array}{l}\text { Metanálisis, revisiones sistemáticas de ensayos clínicos o ensayos clínicos de alta calidad con } \\
\text { muy poco riesgo de sesgo. }\end{array}$ \\
\hline $1^{+}$ & $\begin{array}{l}\text { Metanálisis, revisiones sistemáticas de ensayos clínicos o ensayos clínicos bien realizados con } \\
\text { poco riesgo de sesgo. }\end{array}$ \\
\hline $1^{-}$ & $\begin{array}{l}\text { Metanálisis, revisiones sistemáticas de ensayos clínicos o ensayos clínicos con alto riesgo de } \\
\text { sesgo. }\end{array}$ \\
\hline $2^{++}$ & $\begin{array}{l}\text { Revisiones sistemáticas de estudios de cohortes o de casos y controles o estudios de } \\
\text { pruebas diagnósticas de alta calidad, estudios de cohortes o de casos y controles de pruebas } \\
\text { diagnósticas de alta calidad con riesgo muy bajo de sesgo y con alta probabilidad de establecer } \\
\text { una relación causal. }\end{array}$ \\
\hline $2^{+}$ & $\begin{array}{l}\text { Estudios de cohortes o de casos y controles o estudios de pruebas diagnósticas bien realizadas } \\
\text { con bajo riesgo de sesgo y con una moderada probabilidad de establecer una relación causal. }\end{array}$ \\
\hline $2^{-}$ & Estudios de cohortes o de casos y controles con alto riesgo de sesgo. \\
\hline 3 & Estudios no analíticos, como informes de casos y series de casos. \\
\hline 4 & Opinión de expertos. \\
\hline
\end{tabular}

\begin{tabular}{|c|l|}
\hline \multicolumn{2}{|l|}{ Fuerza de las recomendaciones } \\
\hline A & $\begin{array}{l}\text { Al menos un metanálisis, revisión sistemática de ECA, o ECA de nivel 1++, directamente aplicables } \\
\text { a la población diana, o evidencia suficiente derivada de estudios de nivel 1+, directamente } \\
\text { aplicable a la población diana y que demuestren consistencia global en los resultados. }\end{array}$ \\
\hline B & $\begin{array}{l}\text { Evidencia suficiente derivada de estudios de nivel 2++, directamente aplicable a la población } \\
\text { diana y que demuestren consistencia global en los resultados. Evidencia extrapolada de } \\
\text { estudios de nivel 1++ o 1+. }\end{array}$ \\
\hline C & $\begin{array}{l}\text { Evidencia suficiente derivada de estudios de nivel 2+, directamente aplicable a la población diana } \\
\text { y que demuestren consistencia global en los resultados. Evidencia extrapolada de estudios de } \\
\text { nivel 2++. }\end{array}$ \\
\hline D & Evidencia de nivel 3 o 4. Evidencia extrapolada de estudios de nivel 2+. \\
\hline
\end{tabular}

Los estudios clasificados como 1- y 2- no deben usarse en el proceso de elaboración de recomendaciones por su alta posibilidad de sesgo. Las recomendaciones adaptadas de una GPC se señalan con el superíndice "GPC"

Q Evidencia extraída de estudios cualitativos relevantes y de calidad. Esta categoría no está contemplada por el SIGN.

\begin{tabular}{|c|l|}
\hline \multicolumn{2}{|l|}{ Buena práctica clínica } \\
\hline $\mathfrak{S}^{1}$ & Práctica recomendada basada en la experiencia clínica y el consenso del equipo redactor. \\
\hline
\end{tabular}

Fuente: Scottish Intercollegiate Guidelines Network. SIGN 50: A guideline developers' handbook (Section 6: Forming guideline recommendations), SIGN publication $n^{\circ} 50,2001$.

1. En ocasiones el grupo elaborador se percata de que existe algún aspecto práctico importante sobre el que se quiere hacer énfasis y para el cual no existe, probablemente, ninguna evidencia científica que lo soporte. En general estos casos están relacionados con algún aspecto del tratamiento considerado buena práctica clínica y que no se cuestionaría habitualmente. Estos aspectos son valorados como puntos de buena práctica clínica. Estos mensajes no son una alternativa a las recomendaciones basadas en la evidencia científica sino que deben considerarse únicamente cuando no existe otra manera de destacar dicho aspecto. 


\section{Introducción}

Este documento es la versión resumida de otro más amplio, la versión completa, disponible en la página web de GuiaSalud (http://www.guiasalud.es) y de la Agencia de Evaluación de Tecnologías Sanitarias de Galicia (avalia-t) (http://avalia-t.sergas.es). En la versión completa se añade información y apartados sobre metodología, indicadores de calidad, difusión e implementación y recomendaciones de investigación futura.

\subsection{La conducta suicida}

El suicidio representa un grave problema de salud pública con alrededor de un millón de muertes anuales en todo el mundo (2) y se ha estimado que cada año se suicidan 14,5 personas de cada 100000 (3). Las repercusiones en el entorno son muy importantes, ya que las vidas de los allegados se ven profundamente afectadas a nivel emocional, social y económico. En este sentido, los costes económicos asociados al suicidio se han estimado en EE.UU. en unos 25000 millones de dólares anuales, entre gastos directos e indirectos $(3,4)$.

Es por ello de gran importancia la adopción de medidas y el desarrollo de estrategias encaminadas a la disminución de la conducta suicida. Desde la Unión Europea se han promovido iniciativas, como la Mental Health Promotion and Mental Disorder Prevention (5), donde la prevención del suicidio se considera una de las áreas de intervención. En España, la Estrategia de Salud Mental elaborada para el periodo 2009-2013 (6) contempla entre sus objetivos la prevención del suicidio y la evaluación de acciones específicas para disminuir las tasas de suicidio en grupos de riesgo.

\subsection{Conceptualización}

En 1986, la Organización Mundial de la Salud (OMS) definió el suicidio como "un acto con resultado letal, deliberadamente iniciado y realizado por el sujeto, sabiendo o esperando su resultado letal y a través del cual pretende obtener los cambios deseados" y el parasuicidio, como "un acto sin resultado fatal mediante el cual, sin ayuda de otros, una persona se autolesiona o ingiere sustancias con la finalidad de conseguir cambios a través de las consecuencias actuales o esperadas sobre su estado físico" (7).

La conceptualización de la conducta suicida es compleja y algunos de los términos utilizados resultan poco operativos, por lo que ha sido necesaria 
la elaboración de definiciones más precisas que intentan concretar diferentes aspectos $(8,9)$. Los criterios de clasificación de la conducta suicida de Diekstra (10) diferencian entre suicidio, intento de suicidio y parasuicidio, en función de si el resultado de la conducta es mortal o no y de la gravedad de dicha conducta. Por su parte, $\mathrm{O}^{\prime} \mathrm{Carroll}$ et al. (11) plantearon una nomenclatura de los pensamientos y conductas relacionadas con el suicidio, adoptada por el National Institute of Mental Health (NIMH) de EE.UU. y considerada como una de las más operativas. En ella se diferencia entre ideación suicida, conducta instrumental, intento de suicidio y suicidio consumado.

En 2007, Silverman et al. $(12,13)$ realizaron una revisión de la nomenclatura de $\mathrm{O}^{\prime}$ Carroll et al. en la que intentaron incluir aquellos aspectos clave de diferentes definiciones propuestas con anterioridad, como: el resultado de la conducta, la entidad del acto, el grado de intencionalidad y el conocimiento o conciencia de los resultados de dicha conducta (14). En esta nueva propuesta se añadió una categoría denominada comunicación suicida, que incluye la amenaza y el plan suicida, y además, el término conducta instrumental se cambió por el de amenaza suicida. Además añadieron los tipos I, II y III con el fin de intentar simplificar la terminología e incluir todas las combinaciones posibles de las diferentes variables clínicas (tabla 1).

Las definiciones de esta nomenclatura son las siguientes:

- Ideación suicida: pensamientos sobre el suicidio (cogniciones)

- Comunicación suicida: acto interpersonal en el que se transmiten pensamientos, deseos o intencionalidad de acabar con la propia vida, sin que exista evidencia implícita o explícita de que este acto de comunicación suponga por sí mismo una conducta suicida. La comunicación suicida es un punto intermedio entre la ideación suicida (cogniciones) y la conducta suicida. En esta categoría se incluyen aquellas comunicaciones verbales o no verbales, que pueden tener intencionalidad, pero no producen lesiones. Existen dos tipos de comunicación suicida:

- Amenaza suicida: acto interpersonal, verbal o no verbal, que podría predecir una posible conducta suicida en el futuro cercano

- Plan suicida: es la propuesta de un método con el que llevar a cabo una conducta suicida potencial. 
Tabla 1. Nomenclatura y clasificación de la conducta suicida.

\begin{tabular}{|c|c|c|}
\hline $\begin{array}{l}\text { Ideación } \\
\text { suicida }\end{array}$ & $\begin{array}{l}\text { a. Sin intencionalidad suicida } \\
\text { b. Con grado indeterminado de intencionalidad } \\
\text { c. Con alguna intencionalidad suicida }\end{array}$ & $\begin{array}{l}\text { 1. Casual } \\
\text { 2. Transitoria } \\
\text { 3. Pasiva } \\
\text { 4. Activa } \\
\text { 5. Persistente }\end{array}$ \\
\hline & \multicolumn{2}{|c|}{$\begin{array}{l}\text { a. Sin intencionalidad suicida: } \\
\text { 1. Verbal o no verbal, pasiva o activa (amenaza suicida, tipo I) } \\
\text { 2. Propuesta de un método con el que llevar a cabo una autolesión } \\
\text { (plan suicida, tipo I) } \\
\text { b. Con grado indeterminado de intencionalidad } \\
\text { 1. Verbal o no verbal, pasiva o activa (amenaza suicida, tipo II) } \\
\text { 2. Propuesta de un método con el que llevar a cabo una autolesión } \\
\text { (plan suicida, tipo II) } \\
\text { c. Con alguna intencionalidad suicida } \\
\text { 1. Verbal o no verbal, pasiva o activa (amenaza suicida, tipo III) } \\
\text { 2. Propuesta de un método con el que llevar a cabo una autolesión } \\
\text { (plan suicida, tipo III) }\end{array}$} \\
\hline & \multicolumn{2}{|c|}{$\begin{array}{l}\text { a. Sin intencionalidad suicida } \\
\text { 1. Sin lesiones (autolesión, tipo I) } \\
\text { 2. Con lesiones (autolesión, tipo II) } \\
\text { 3. Con resultado fatal (muerte autoinfligida no intencionada) } \\
\text { b. Con grado indeterminado de intencionalidad } \\
\text { 1. Sin lesiones (conducta suicida no determinada, tipo I) } \\
\text { 2. Con lesiones (conducta suicida no determinada, tipo II) } \\
\text { 3. Con resultado fatal (muerte autoinfligida con intencionalidad } \\
\text { indeterminada) } \\
\text { c. Con alguna intencionalidad suicida } \\
\text { 1. Sin lesiones (intento de suicidio, tipo I) } \\
\text { 2. Con lesiones (intento de suicidio, tipo II) } \\
\text { 3. Con resultado fatal (suicidio consumado) }\end{array}$} \\
\hline \multicolumn{3}{|c|}{$\begin{array}{l}\text { *Clasificación adicional para comunicación y conducta suicida: } \\
\text { - Foco intrapersonal: obtención de cambios en el estado interno (evasión/liberación) } \\
\text { - Foco interpersonal: obtención de cambios en el estado externo (afecto/control) } \\
\text { - Foco mixto }\end{array}$} \\
\hline
\end{tabular}

Fuente: elaboración propia a partir de Silverman et al. (12, 13). 
- Conducta suicida: conducta potencialmente lesiva y autoinflingida, en la que hay evidencia implícita o explícita de que:

a. La persona desea utilizar la aparente intención de morir con alguna finalidad.

b. La persona presenta algún grado, determinado o no, de intención de acabar con su vida.

La conducta suicida puede no provocar lesiones, provocarlas de diferente gravedad e, incluso, producir la muerte. Se considera conducta suicida:

- Autolesión/gesto suicida: conducta potencialmente lesiva autoinfligida para la que existe evidencia, implícita o explícita, de que la persona no tiene la intención de matarse. La persona desea utilizar la aparente intencionalidad de morir con alguna finalidad. Este tipo de conducta puede no provocar lesiones, provocar lesiones o provocar la muerte (muerte autoinfligida no intencionada)

- Conducta suicida no determinada: conducta con grado indeterminado de intencionalidad suicida que puede resultar sin lesiones, con lesiones o causar la muerte (muerte autoinfligida con grado indeterminado de intencionalidad)

- Intento de suicidio: conducta potencialmente lesiva autoinfligida y sin resultado fatal, para la que existe evidencia, implícita o explícita, de intencionalidad de provocarse la muerte. Dicha conducta puede provocar o no lesiones, independientemente de la letalidad del método

- Suicidio: muerte autoinfligida con evidencia implícita o explícita de que la persona tenía intencionalidad de autoprovocarse la muerte.

En esta Guía de Práctica Clínica (GPC) se adoptará la nomenclatura propuesta por Silverman et al. $(12,13)$.

\subsection{Epidemiología del suicidio}

En la actualidad, el suicidio se sitúa entre las quince primeras causas de muerte en el mundo. Su tendencia es ascendente, estimándose que en 2020 la cifra de suicidios consumados será de 1,53 millones (15).

En los estudios de autopsia psicológica, la presencia de trastornos mentales se objetiva en alrededor del $90 \%$ de las personas que consuman el suicidio $(2,16-18)$, siendo los trastornos más frecuentemente asociados, la depresión, el abuso de sustancias, los trastornos psicóticos, los trastornos 
de la personalidad y los trastornos de ansiedad, entre otros $(2,19)$. En este sentido es importante destacar las previsiones del estudio ESEMeD (European Study of the Epidemiology of Mental Disorders) que nos muestra que un $14,7 \%$ de la población europea presentará un trastorno afectivo a lo largo de su vida (casi un 20\% en el caso de España), el 14,5\% un trastorno de ansiedad y un $5,2 \%$ un trastorno por abuso de alcohol $(20,21)$.

\section{Factores sociodemográficos}

- Región o país: las tasas más altas de suicidio a nivel mundial se encuentran en Lituania y Rusia (51,6 y 43,1 por 100000 habitantes), y las más bajas en Azerbaiyán, Kuwait y Filipinas (1,1, 2,0 y 2,1 por 100000 habitantes). En Europa, el suicidio es la décima causa de muerte, siendo los países de Europa Oriental los que presentan mayores tasas (22). También se observan altas tasas en los países nórdicos (2).

- Género: la proporción de suicidios hombre/mujer es de 4:1 en países occidentales (3) y entre 3:1 y 7,5:1 en el resto del mundo (17). Dos excepciones serían India y China, en donde no hay claras diferencias respecto al género (1,3:1 en la India y 0,9:1 en China) (17).

- Edad: aunque proporcionalmente las tasas de suicidio son más altas entre las personas de edad, dada la distribución demográfica, el número absoluto de casos registrados es mayor entre los menores de 45 años, fenómeno que parece existir en todos los continentes y que no está relacionado con los niveles de industrialización o riqueza (15). En Europa, el suicidio en jóvenes ha ido aumentando entre los años 1980 y 2000, multiplicándose por cuatro su tasa (22). Sin embargo, tanto el suicidio consumado como el intento de suicidio son raros antes de la pubertad (23).

- $\underline{\text { Raza: }}$ parecen existir patrones de suicidio según la raza, con menores tasas entre los hispanos y afroamericanos que entre los europeos, especialmente los caucásicos que doblan las tasas observadas en otras razas. Sin embargo, en la actualidad se observa un aumento en las tasas de suicidio de los afroamericanos de EE.UU. $(2,3)$.

- Religión: podría actuar como factor protector, ya que las tasas más elevadas de suicidio se encuentran entre los ateos (24).

Si los suicidios consumados representan alrededor de un millón de casos al año, se ha estimado que los intentos de suicidio podrían ser 10 o 20 veces más numerosos (3). Respecto a la edad y al sexo, existen importantes 
diferencias entre el suicidio consumado y los intentos de suicidio. Así, mientras el primero suele producirse en hombres, los intentos son más habituales entre las mujeres jóvenes $(15,25)$.

\section{El suicidio en España}

Según datos del Instituto Nacional de Estadística (INE) (26) del 2010, en España se suicidan nueve personas al día, siendo el suicidio en los varones $(78,09 \%)$ más del triple que en las mujeres $(21,90 \%)$. Aunque las tasas de suicidio se sitúan entre las más bajas de Europa (3), hasta el año 2003 parecía existir una evolución ascendente; sin embargo, a partir de 2004 la tendencia es estable o descendente, al igual que en el resto de Europa $(22,27)$.

En Europa mueren cada año 58000 personas por suicidio, 7000 más que por accidentes de tráfico (28). Si en España comparamos ambas causas de muerte a lo largo de los últimos años, podemos comprobar una disminución importante de los fallecimientos por accidentes de tráfico, mientras que las tasas de suicidio se mantuvieron similares, llegando a ser desde el 2008 la primera causa de muerte no natural (29).

Los datos recogidos por el INE (30) muestran que la conducta suicida en España sigue las pautas del resto del mundo (3), produciéndose la mayoría de los suicidios en la población de sexo masculino y aumentando su tasa conforme aumenta la edad. Analizando los datos por comunidades autónomas, las que presentan mayores tasas por 100000 habitantes son Asturias y Galicia (13,74 y 9,83), mientras que Madrid y Melilla presentan las tasas más bajas $(1,89$ y 1,32$)$.

Respecto a los intentos de suicidio, en España se cifran entre 50-90 por 100000 habitantes/año, aunque las cifras reales son difíciles de estimar por la dificultad de la recogida de datos (28). El método más frecuente es la intoxicación medicamentosa, con una incidencia anual de intoxicaciones agudas en medio extrahospitalario de 28/100 000 habitantes (31) y de 170/100 000 habitantes en medio hospitalario (32). 


\section{EVALUACIÓN Y TRATAMIENTO}




\section{Factores asociados con la conducta suicida y evaluación del riesgo suicida}

\subsection{Factores de riesgo}

La identificación de los factores que aumentan o disminuyen el nivel de riesgo suicida es de gran importancia por la estrecha relación que guardan con dicha conducta (33). El nivel de riesgo aumenta proporcionalmente con el número de factores presentes, si bien algunos de ellos tienen un peso específico mayor que otros $(2,33)$.

La estimación del riesgo de suicidio se realiza mediante el juicio clínico del profesional, valorando los factores que concurren de modo particular en cada persona, en un momento determinado de su vida y ante eventos estresantes específicos $(33,34)$.

\section{Preguntas para responder:}

- ¿Cuáles son los factores de riesgo más importantes asociados con la conducta suicida?

\section{Resumen de la evidencia}

Factores de riesgo individuales

- Intentos de suicidio previos: son el predictor más importante de conducta suicida (35).

- Abuso de alcohol u otras sustancias tóxicas: ejerce un papel muy significativo, y no es sólo un factor de riesgo, sino también un factor precipitante (35).

- Depresión mayor: es el trastorno mental que de forma más común se asocia con la conducta suicida, suponiendo un riesgo de suicidio 20

Metanálisis 1+ veces mayor respecto a la población general (36).

- Otros trastornos mentales: trastorno bipolar y esquizofrenia (36). 
- Factores psicológicos: desesperanza y rigidez cognitiva (36).

- Edad: los momentos con más riesgo de intentos y de suicidios consumados a lo largo de la vida son la adolescencia y la edad avanzada (36).

- Sexo: los hombres presentan mayores tasas de suicidios consumados y las mujeres mayor número de intentos de suicidio (36).

- Presencia de enfermedad crónica o discapacitante $(2,17)$.

Factores de riesgo familiares y contextuales

- Historia familiar de suicidio: aumenta el riesgo

RS de distintos de conducta suicida $(2,36,37)$, especialmente en tipos de estudios el género femenino $(2,17)$ y cuando se produce $2++$ en un familiar de primer grado (37).

- Factores sociales y ambientales: falta de apoyo social $(36,38)$, nivel socioeconómico y situación laboral $(17,36,38)$.

- Historia de maltrato físico o abuso sexual: en concreto, los producidos durante la infancia presentan una asociación consistente con la conducta suicida $(2,23,36,37)$.

\section{Preguntas para responder:}

- ¿Qué factores pueden actuar como precipitantes de la conducta suicida y cuáles son factores protectores?

Factores de riesgo que pueden actuar como precipitantes de una conducta suicida

- Eventos vitales estresantes: pérdidas personales (divorcio, separación, muertes), pérdidas financieras (económicas o laborales), problemas RS de distintos legales y acontecimientos negativos (conflictos tipos de estudios $2++$ y relaciones interpersonales), pueden ser desencadenantes de una conducta suicida en personas que presentan otros factores de riesgo $(2,17,36)$. 
- Fácil acceso a armas de fuego, medicamentos o tóxicos: aumenta el riesgo del mismo, al facilitar el paso de la ideación a la conducta suicida (2, 17).

- Acoso por parte de pares (iguales): en adolesSerie de casos 3 centes, se ha asociado con altos niveles de estrés, así como con ideación y conducta suicidas (23).

Factores protectores

Personales $(36,39,40)$ :

- Habilidad en la resolución de conflictos o problemas

- Confianza en uno mismo

RS de distintos tipos de estudios $2++$

- Habilidad para las relaciones sociales e interpersonales.

Sociales o medioambientales $(17,36,37,39)$

- Apoyo familiar y social, no sólo la existencia del apoyo sino su fuerza y calidad

- Integración social

RS de distintos tipos de estudios $2++$

- Poseer creencias y prácticas religiosas, espiritualidad o valores positivos.

\subsection{Evaluación del riesgo suicida}

\section{Resumen de la evidencia}

La evaluación del riesgo suicida es una parte fundaSerie de casos 3 mental en el manejo y la prevención de la conducta suicida, tanto en atención primaria como en atención especializada (41).

El porcentaje de pacientes a los que se les realiza Serie de casos 3 una adecuada evaluación tras un intento de suicidio varía entre el 60\% (42) y el 95\% (43). 


\section{Preguntas para responder:}

- ¿Cuál es el papel de la entrevista clínica en la valoración del riesgo suicida?

\section{Resumen de la evidencia}

La entrevista clínica es el instrumento esencial en la valoración del riesgo de suicidio. Supone el inicio de la interacción entre el paciente y el profesional, por lo que puede jugar un papel relevante en la reducción del riesgo suicida (44).

Se han encontrado diferentes factores que influyen en la entrevista clínica, como son: el escenario, las circunstancias, el tiempo disponible, las condiciones y la disponibilidad de la persona entrevistada, además del estilo, experiencia y preparación del entrevistador (45).

El programa SUPRE (Suicide Prevention) de la OMS publicó algunas recomendaciones para los profesionales sobre la forma de preguntar acerca de los diferentes aspectos de la ideación y la conducta suicidas (15).

Los pacientes expresan mayor satisfacción cuando en la entrevista clínica, los profesionales los implican en las decisiones sobre el tratamiento y les explican los objetivos y la finalidad de la evaluación (46).

La información necesaria para la valoración del riesgo de suicidio puede provenir del paciente directamente o de otras fuentes, como familiares, allegados y otros profesionales sanitarios o cuidadores $(33,47)$.

Opinión de expertos 4

Opinión de expertos 4

Opinión de expertos 4

RS de distintos tipos de estudios $3, \mathrm{Q}$

Opinión de expertos 4

\section{Recomendaciones}

\begin{tabular}{|l|l|}
\hline $\mathbf{D}^{\mathbf{G P C}}$ & $\begin{array}{l}\text { Tras una conducta suicida se recomienda realizar siempre una ade- } \\
\text { cuada evaluación psicopatológica y social que incluya las carac- } \\
\text { terísticas psicológicas y contextuales del paciente, así como una } \\
\text { evaluación de los factores de riesgo y de protección de conducta } \\
\text { suicida. }\end{array}$ \\
\hline
\end{tabular}




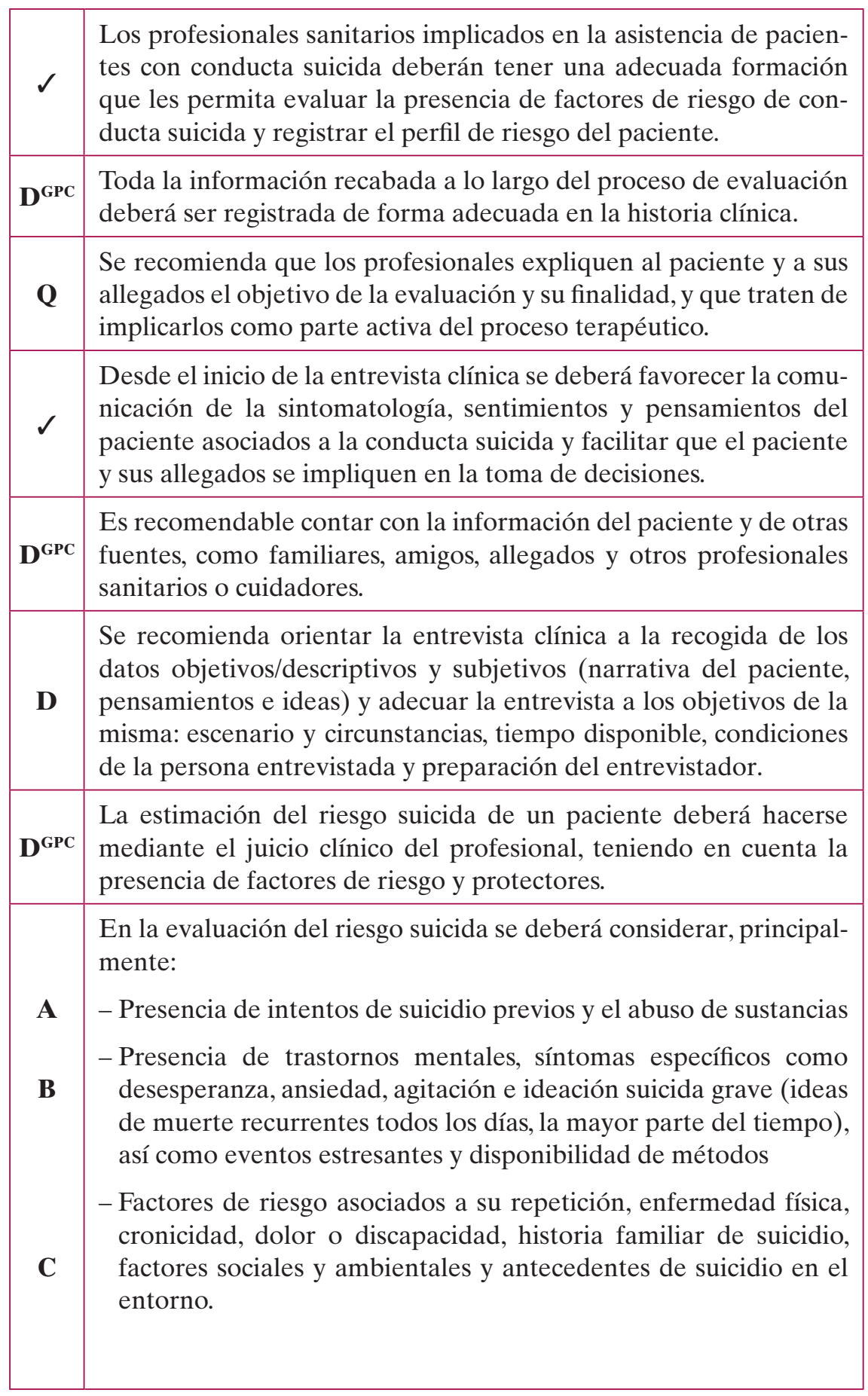


Escalas de evaluación auto y heteroaplicadas

Existe una gran diversidad de instrumentos psicométricos diseñados para evaluar el riesgo de suicidio que suelen basarse, bien en la valoración directa de ideas/conductas suicidas y factores de riesgo, bien en síntomas o síndromes asociados al suicidio, como la desesperanza, la depresión, etc.

\section{Preguntas para responder:}

- ¿Existe algún instrumento psicométrico que permita predecir el riesgo de futuros episodios de conducta suicida?

\section{Resumen de la evidencia}

Los instrumentos psicométricos pueden ser una ayuda complementaria a la entrevista y al juicio clínico, pero nunca deben sustituirlos (9).

De las escalas revisadas, aquellas que han demosOpinión de expertos 4 trado adecuadas propiedades para la valoración del riesgo suicida son (48):

- Escala de desesperanza de Beck (49)

- Escala de ideación suicida de Beck (50)

- Escala de intencionalidad suicida de Beck (51)

- Ítem de conducta suicida de la Escala de depresión de Beck (52)

- Ítem sobre conducta suicida de la Escala de valoración de la depresión de Hamilton (53).

Aunque no validados en España y sin estudios que demuestren sus propiedades psicométricas, los acró-

Opinión de expertos 4 nimos SAD PERSONS (54) e IS PATH WARM (55) pueden ser útiles por su facilidad de aplicación en la evaluación del paciente con conducta suicida.

\section{Recomendaciones}

\begin{tabular}{l|l} 
D & $\begin{array}{l}\text { Se recomienda no sustituir la entrevista clínica por el uso de esca- } \\
\text { las auto y heteroaplicadas, aunque estas aportan una información } \\
\text { complementaria en la evaluación. }\end{array}$
\end{tabular} 


\begin{tabular}{|c|c|}
\hline $\mathbf{C}$ & $\begin{array}{l}\text { Dentro de las diferentes escalas, se recomiendan las escalas } \\
\text { de desesperanza, ideación suicida e intencionalidad suicida de } \\
\text { Beck. También se recomiendan los ítems de conducta suicida del } \\
\text { Inventario de depresión de Beck y de la Escala de valoración de la } \\
\text { depresión de Hamilton. }\end{array}$ \\
\hline D & $\begin{array}{l}\text { Aunque no validadas en España, también se recomiendan las esca- } \\
\text { las SAD PERSONS o la IS PATH WARM por su facilidad de apli- } \\
\text { cación. }\end{array}$ \\
\hline C & $\begin{array}{l}\text { Al valorar a un paciente con varios intentos de suicidio, se reco- } \\
\text { mienda evaluar las causas o precipitantes de cada uno de ellos de } \\
\text { forma independiente. }\end{array}$ \\
\hline$\checkmark$ & $\begin{array}{l}\text { Se recomienda evitar todo tipo de actitudes negativas hacia las per- } \\
\text { sonas con conducta suicida reiterada, favoreciendo una atención } \\
\text { profesional basada en el respeto y la comprensión hacia este tipo } \\
\text { de pacientes. }\end{array}$ \\
\hline
\end{tabular}




\section{Evaluación y manejo de la ideación y conducta suicidas en atención primaria}

Los profesionales de atención primaria tienen una extraordinaria importancia a la hora de la evaluación y manejo de la conducta suicida, debido a la relación de confianza que habitualmente tienen con sus pacientes y que en la mayoría de las ocasiones han desarrollado a lo largo de los años (56). Antes de un suicidio es frecuente el contacto previo con el médico de atención primaria. Así, el 75\% de las personas han contactado con su médico en el año anterior a dicho episodio y el $45 \%$ en el mes anterior, mientras que sólo uno de cada tres lo han hecho con su servicio de salud mental en el año anterior y uno de cada cinco en el mes anterior $(57,58)$.

La tipología de los pacientes que se evalúan en este ámbito puede ser de tres tipos: 1) aquellos que han sobrevivido a un intento de suicidio;2) los que acuden a la consulta manifestando ideación suicida y 3) los que tienen ideación suicida pero aún no la han manifestado verbalmente (59).

Por otra parte, la atención sanitaria proporcionada en atención primaria dependerá de factores como el ámbito asistencial (zona rural o urbana), la experiencia de los profesionales sanitarios implicados y el conocimiento previo del propio paciente (60).

\subsection{Abordaje de la ideación suicida en atención primaria}

\section{Preguntas para responder:}

- ¿Cómo abordar la ideación suicida en atención primaria?

\section{Resumen de la evidencia}

Una forma efectiva de reducir las tasas de suicidio es mejorar la capacidad de los médicos de atención primaria en reconocer y tratar los trastornos mentales (61).

Hablar de suicidio con los pacientes en los que se detecte o que comuniquen ideación suicida puede
Opinión de expertos 4

Opinión de expertos 4 
aliviar su ansiedad y contribuir a que se sientan mejor comprendidos, sin que ello aumente el riesgo de desencadenar una conducta suicida. También hay que tener en cuenta que el que un paciente hable sobre el suicidio no elimina la posibilidad de que lo cometa (62).

Distintos organismos han elaborado recomendaciones acerca de las principales acciones a realizar o evitar ante una situación de ideación suicida $(15,63)$, así como sobre la forma de evaluar el riesgo de suicidio de forma empática $(62,64)$.

Si el paciente presenta ideación y/o planificación suicida será necesario graduar el nivel de riesgo (15).

Los puntos más importantes a evaluar en un paciente con ideación suicida son $(59,64)$ :

Opinión de expertos 4

Opinión de expertos 4

Opinión de expertos 4

- Factores sociodemográficos

- Trastornos mentales asociados

- Existencia de intentos previos

- Antecedentes familiares de conducta suicida y de trastorno mental.

\section{Recomendaciones}

\begin{tabular}{|c|l|}
\hline D & $\begin{array}{l}\text { Se recomienda la capacitación de los médicos de atención primaria } \\
\text { en la evaluación y tratamiento de la ideación y conducta suicidas, } \\
\text { implementando, en caso necesario, programas específicos acerca de } \\
\text { su abordaje diagnóstico y psicoterapéutico. }\end{array}$ \\
\hline$\checkmark$ & $\begin{array}{l}\text { Se recomienda explorar pensamientos suicidas en los pacientes en } \\
\text { los que se sospeche ideación suicida y presenten factores de riesgo } \\
\text { de suicidio. Esto no aumenta el riesgo de suicidio. }\end{array}$ \\
\hline D & $\begin{array}{l}\text { Se recomienda que las preguntas a los pacientes sobre sus ideas de } \\
\text { suicidio se formulen de forma gradual: no deberán ser exigentes ni } \\
\text { coercitivas, sino plantearlas de manera cálida y empática. }\end{array}$ \\
\hline$\checkmark$ & $\begin{array}{l}\text { Si se confirma la presencia de ideación suicida será preciso realizar } \\
\text { preguntas específicas dirigidas a valorar la posibilidad real de suici- } \\
\text { dio (frecuencia y gravedad de las ideas, grado de planificación...). }\end{array}$ \\
\hline
\end{tabular}




\begin{tabular}{|c|c|}
\hline En pacientes con ideación suicida y riesgo de suicidio se recomienda: \\
- Prescribir fármacos potencialmente seguros en caso de sobre- \\
dosis \\
- Prescribir envases con el menor número de comprimidos \\
posible \\
- Explicar a los familiares la necesidad de control y administración \\
de la medicación así como de su custodia \\
- Acompañamiento constante por parte de familiares así como \\
restricción de acceso a métodos letales \\
- Aceptación por parte del paciente y su familia del seguimiento \\
y derivación a servicio de salud mental.
\end{tabular}

\subsection{Evaluación de la conducta suicida en atención primaria}

\section{Preguntas para responder:}

- ¿Cómo realizar la evaluación de la conducta suicida en atención primaria?

\section{Resumen de la evidencia}

Tras un intento de suicidio deberán valorarse, en primer lugar, las condiciones físicas del paciente y decidir sobre la necesidad de derivación a un centro hospitalario para el tratamiento de sus lesiones (60).

Los puntos más importantes en la evaluación de un episodio de conducta suicida en atención primaria son $(59,64)$ :

- Características del intento: peligrosidad objetiva y percibida por el paciente, objetivo de la conducta, planificación, posibilidad de rescate, deseos de morir, apoyos externos y actitud

- Intentos autolíticos previos

- Factores sociodemográficos

Opinión de expertos 4

Opinión de expertos 4 
- Trastornos mentales asociados

- Antecedentes familiares (intentos de suicidio y/o suicidios consumados en la familia, trastornos mentales familiares).

\section{Recomendaciones}

\begin{tabular}{|c|l|}
\hline D & $\begin{array}{l}\text { Tras un intento de suicidio en el ámbito de la atención prima- } \\
\text { ria deberá valorarse, en primer lugar, las condiciones físicas del } \\
\text { paciente y decidir sobre la necesidad de derivación a un centro } \\
\text { hospitalario para el tratamiento de sus lesiones. }\end{array}$ \\
\hline D & $\begin{array}{l}\text { Tras un intento de suicidio en el ámbito de la atención primaria se } \\
\text { recomienda realizar, siempre que sea posible, una valoración que } \\
\text { incluya: }\end{array}$ \\
& - Características del intento \\
& - Intentos autolíticos previos \\
& - Factores sociodemográficos \\
& - Trastornos mentales asociados \\
& - Antecedentes familiares.
\end{tabular}

\subsection{Criterios de derivación de pacientes desde atención primaria}

\section{Preguntas para responder:}

- ¿Cuándo derivar a un paciente con ideación o intento de suicidio desde atención primaria a otro nivel asistencial?

\section{Resumen de la evidencia}

En general, la derivación urgente desde atención Opinión de primaria al servicio de salud mental de un paciente con expertos 4 ideación suicida se realizará en los casos de $(60,63)$ :

- Presencia de enfermedad mental grave

- Conducta suicida grave reciente 
- Plan de suicidio elaborado

- Expresión de intencionalidad suicida

- Situación sociofamiliar de riesgo o falta de soporte

- En casos de duda sobre la gravedad de la ideación o riesgo de intento inmediato.

Ante un episodio de conducta suicida, la derivación desde atención primaria será urgente, y al servicio de urgencias del hospital de referencia, en los siguientes casos $(60,63)$ :

- Necesidad de tratamiento médico de las lesiones producidas, no susceptibles de ser atendidas en atención primaria

- Intoxicación voluntaria con disminución del nivel de conciencia (previa estabilización del paciente).

La derivación será urgente, desde atención Opinión de primaria al servicio de salud mental ${ }^{2}$, en los siguientes casos $(60,63)$ :

- Alta letalidad del plan, independientemente de su resultado

- Presencia de enfermedad mental grave

- Conducta autolítica grave reciente

- Repetidas tentativas previas

- Situación sociofamiliar de riesgo o de falta de soporte

- En casos de duda sobre la gravedad del episodio o riesgo de repetición.

2 Dependiendo de su organización funcional, la atención urgente por parte del servicio de salud mental podrá ser en el servicio de urgencias del hospital de referencia o en otra ubicación. 


\section{Recomendaciones}

\begin{tabular}{|c|c|}
\hline D & $\begin{array}{l}\text { En caso de ideación suicida se recomienda la derivación urgente al } \\
\text { servicio de salud mental, si: } \\
\text { - Presencia de trastorno mental grave } \\
\text { - Conducta autolítica grave reciente } \\
\text { - Plan de suicidio elaborado } \\
\text { - Expresión de intencionalidad suicida que se mantenga al final } \\
\text { de la entrevista } \\
\text { - Situación sociofamiliar de riesgo o falta de apoyo } \\
\text { - Duda sobre la gravedad de la ideación o riesgo de intento } \\
\text { inmediato. }\end{array}$ \\
\hline D & $\begin{array}{l}\text { En caso de intento de suicidio se recomienda la derivación urgente } \\
\text { a un servicio de urgencias hospitalario, si: } \\
\text { - Necesidad de tratamiento médico de las lesiones producidas, } \\
\text { no susceptibles de ser atendidas en atención primaria } \\
\text { - Intoxicación voluntaria con disminución del nivel de concien- } \\
\text { cia o agitación (previa estabilización del paciente). } \\
\text { En caso de intento de suicidio, y en ausencia de los puntos ante- } \\
\text { riores, se recomienda la derivación urgente al servicio de salud } \\
\text { mental, si: } \\
\text { - Alta letalidad del plan, independientemente de su resultado } \\
\text { - Presencia de enfermedad mental grave } \\
\text { - Conducta autolítica grave reciente } \\
\text { - Intentos de suicidio previos } \\
\text { - Situación sociofamiliar de riesgo o de falta de apoyo } \\
\text { - Duda sobre la gravedad del intento o riesgo de repetición. }\end{array}$ \\
\hline
\end{tabular}




\begin{tabular}{|c|l|}
\hline$\checkmark$ & $\begin{array}{l}\text { En caso de ideación o conducta suicida se podría considerar la } \\
\text { derivación preferente al servicio de salud mental (en el plazo de } \\
\text { una semana) cuando no estén presentes ninguno de los criterios } \\
\text { anteriores de derivación inmediata y se cumplan todas las circuns- } \\
\text { tancias siguientes: } \\
\quad-\text { Alivio tras la entrevista } \\
\quad \text { Intención de control de impulsos suicidas } \\
\quad-\text { Aceptación del tratamiento y medidas de contención pactadas } \\
\quad-\text { Apoyo sociofamiliar efectivo. }\end{array}$ \\
\hline$\checkmark$ & $\begin{array}{l}\text { Toda la información del paciente será recogida en la historia clí- } \\
\text { nica, así como la justificación razonada del tipo de derivación. }\end{array}$ \\
\hline$\checkmark$ & $\begin{array}{l}\text { Se recomienda, una vez producido un episodio de conducta suicida, } \\
\text { una adecuada comunicación entre el servicio de salud mental y el } \\
\text { médico de atención primaria. }\end{array}$ \\
\hline
\end{tabular}




\section{Evaluación y manejo del paciente con conducta suicida en el servicio de urgencias}

Los servicios de urgencias, tanto hospitalarios como extrahospitalarios, tienen una gran relevancia en relación al suicidio debido a que en muchas ocasiones son los primeros lugares en los que el paciente con ideación o conducta suicida toma contacto con el sistema sanitario $(65,66)$.

En estos servicios pueden verse tres grupos diferentes de pacientes con riesgo significativo de conducta suicida:

- Aquellos que acuden con ideación suicida manifiesta o después de un intento de suicidio

- Aquellos que acuden con trastornos mentales, aunque sin intencionalidad suicida conocida

- Aquellos que acuden con una patología física específica pero que presentan un riesgo de suicidio oculto o silente.

Un importante desafío para los servicios de urgencias, como proveedores de asistencia sanitaria, es el de participar activamente en la integración de estos pacientes en un proceso terapéutico, favoreciendo los procedimientos de vigilancia, cribado, tratamiento y derivación de aquellos pacientes con alto riesgo de suicidio y tratar de involucrarlos en programas de prevención y de manejo ambulatorio. Para ello sería necesaria una colaboración más estrecha entre los servicios de urgencias y los de salud mental (67).

\subsection{La clasificación de pacientes (triaje) en los servicios de urgencias}

\section{Pregunta para responder:}

- ¿Cómo se estratifica el nivel de riesgo de los pacientes que acuden a un servicio de urgencias por una conducta suicida? 


\section{Resumen de la evidencia}

El triaje se define como la revisión clínica y sistemática de todos los pacientes llegados al servicio de urgencias, con el objetivo de asignar evaluaciones y prioridades de tratamiento mediante una serie de criterios predeterminados y con un método de clasificación para determinar el nivel de urgencia (68).

El Cuestionario de riesgo de suicidio (Risk of Suicide Questionnaire, RSQ) (69) ha demostrado ser un instrumento con alta sensibilidad y especificidad en la detección de riesgo de conducta suicida en niños y adolescentes por parte de personal no especializado, aunque también ha sido utilizado en adultos (70). Su versión en castellano obtuvo una moderada consistencia interna y una correlación moderada-alta con constructos como la desesperanza (71).

La versión breve del RSQ (72) podría ayudar a conocer el grado de necesidad de una atención inmediata en aquellas personas que acuden por conducta suicida a un servicio de urgencias y en las que no existe una afectación grave de su condición física. Las preguntas a formular serían las siguientes:

- ¿Acude usted porque ha tratado de lesionarse a sí mismo?

- ¿En la semana pasada ha tenido ideas relacionadas con suicidarse?

- ¿Ha tratado de lesionarse a sí mismo en el pasado?

- ¿Le ha sucedido algo muy estresante en las últimas semanas?

\section{Recomendaciones}

\begin{tabular}{|c|l|}
\hline$\checkmark$ & $\begin{array}{l}\text { Se recomienda que todos los pacientes que acudan a un servicio de } \\
\text { urgencias por una conducta suicida sean catalogados en el triaje de } \\
\text { tal forma que se asegure su atención dentro de la primera hora desde } \\
\text { su llegada. }\end{array}$ \\
\hline \multirow{4}{*}{} & $\begin{array}{l}\text { Se propone la versión breve del Cuestionario de riesgo de suicidio de } \\
\text { Horowitz para ser empleado por el personal encargado del triaje en el } \\
\text { servicio de urgencias con aquellas personas que acuden por conducta } \\
\text { suicida y en las que no existe una afectación grave de su condición física. }\end{array}$ \\
\hline
\end{tabular}




\subsection{Evaluación del paciente con conducta suicida en el servicio de urgencias}

\section{Preguntas para responder:}

- En un paciente que acude a un servicio de urgencias por una conducta suicida, ¿qué otros aspectos deberían ser evaluados, además de los físicos, con el fin de tomar decisiones inmediatas?

\section{Resumen de la evidencia}

A pesar de que cualquier persona que habla de suicidio debe ser siempre tomada en serio, se ha descrito la existencia de una posible actitud negativa o ambivalente de los profesionales de los servicios de urgencias y unidades de cuidados intensivos hacia los pacientes atendidos por intento de suicidio (46).

El médico de urgencias hospitalarias, además de valorar las alteraciones de la condición física, deberá realizar siempre una evaluación psicopatológica y social básicas, incluyendo una evaluación de las necesidades y del riesgo de suicidio (73).

La identificación de factores de riesgo de suicidio es de gran importancia ya que el nivel de riesgo aumenta con el número de factores presentes, si bien existen algunos con mayor peso específico que otros $(2,33)$.

Una forma de mejorar la recogida de información y con ello la evaluación del paciente con conducta suicida sería a través de la cumplimentación sistemática de formularios estandarizados (ver anexo 1) (74).

En la evaluación del riesgo de suicidio en el servicio de urgencias la escala SAD PERSONS es utilizada ampliamente a pesar de no haber sido validada en España ni existir estudios que evalúen sus propiedades psicométricas (54).

El test de Manchester Cooper, aunque con alta sensibilidad en la identificación de pacientes con riesgo de repetición de la conducta suicida, podría, aunque no

Estudio cualitativo Q

Opinión de expertos 4

Opinión de expertos 4

Serie de casos 3

Opinión de expertos 4

Estudio cualitativo Q 
en todos los casos, ser válido para un primer intento de suicidio (tipos I-II) $(75,76)$.

Se han identificado áreas de mejora en la atención de la conducta suicida: comunicación entre pacientes y

Estudio cualitativo Q profesionales, formación de los profesionales, empatía hacia las personas afectadas, acceso a la asistencia sanitaria especializada e información sobre la conducta suicida a pacientes, cuidadores y público en general (46).

\section{Recomendaciones}

\begin{tabular}{|c|c|}
\hline$\checkmark$ & $\begin{array}{l}\text { La evaluación del paciente con conducta suicida deberá realizarse } \\
\text { en un ambiente de privacidad, confidencialidad y respeto. }\end{array}$ \\
\hline$\checkmark$ & $\begin{array}{l}\text { Durante su estancia en el servicio de urgencias deberán adoptarse } \\
\text { todas aquellas medidas disponibles de seguridad que impidan la } \\
\text { fuga y la auto o heteroagresividad. }\end{array}$ \\
\hline$\checkmark$ & $\begin{array}{l}\text { El médico de urgencias hospitalarias, además de valorar la altera- } \\
\text { ción de la condición física del paciente con conducta suicida, deberá } \\
\text { realizar siempre una evaluación psicopatológica y social básica. }\end{array}$ \\
\hline D & $\begin{array}{l}\text { En la valoración de un paciente con conducta suicida se reco- } \\
\text { mienda la evaluación sistemática de la presencia de factores de } \\
\text { riesgo y la recogida de las características más relevantes del intento } \\
\text { de suicidio, preferiblemente mediante formatos estandarizados y } \\
\text { documentando correctamente toda la información en la historia } \\
\text { clínica. }\end{array}$ \\
\hline$\checkmark$ & $\begin{array}{l}\text { Se recomienda que los pacientes con un intento de suicidio sean } \\
\text { valorados por un psiquiatra, cuando así lo considere el médico de } \\
\text { urgencias hospitalarias. }\end{array}$ \\
\hline$\checkmark$ & $\begin{array}{l}\text { La derivación al psiquiatra por parte del médico de urgencias } \\
\text { deberá realizarse cuando el paciente esté plenamente consciente } \\
\text { y pueda llevarse a cabo una adecuada valoración psicopatológica. }\end{array}$ \\
\hline$\checkmark$ & $\begin{array}{l}\text { En ocasiones podrá diferirse la evaluación psiquiátrica del } \\
\text { paciente, derivándose con carácter preferente a una consulta de } \\
\text { salud mental. }\end{array}$ \\
\hline
\end{tabular}




\begin{tabular}{|c|l|}
\hline \multirow{4}{*}{} & $\begin{array}{l}\text { Se recomienda la mejora de las siguientes áreas de atención a las } \\
\text { personas con conducta suicida: }\end{array}$ \\
& - Comunicación entre pacientes y profesionales \\
& - Actitud empática de los profesionales \\
& - Acceso a la asistencia sanitaria especializada \\
& - Información sobre la conducta suicida a pacientes y familiares. \\
\hline
\end{tabular}

\subsection{Formación del médico de los servicios de urgencias}

\section{Preguntas para responder:}

- ¿Cuál debe ser la formación del médico de urgencias en el reconocimiento, evaluación y manejo de personas con conducta suicida?

\section{Resumen de la evidencia}

La formación de los profesionales, tanto en evaluación Serie de casos 3 como en el manejo de pacientes con conducta suicida, mejora sus actitudes e incrementa las habilidades y la seguridad en la atención a estos pacientes, correlacionándose la calidad de la evaluación con los cuidados proporcionados (77).

\section{Recomendaciones}

\begin{tabular}{|l|l|}
\hline D & $\begin{array}{l}\text { Los profesionales no especializados en salud mental deberían } \\
\text { recibir una adecuada formación en la evaluación de pacientes que } \\
\text { acuden por una conducta suicida. }\end{array}$ \\
\hline
\end{tabular}




\begin{tabular}{|l|l|}
\hline$\checkmark$ & $\begin{array}{l}\text { La formación del médico de urgencias en la atención a pacientes } \\
\text { con conducta suicida debería incluir aquellos aspectos considera- } \\
\text { dos de su competencia, entre otros: }\end{array}$ \\
& - Evaluación del estado y capacidad mental del paciente y de \\
& su estado de ánimo \\
& - Habilidades en la detección de riesgo de suicidio inmediato \\
& - Conocimiento básico de las condiciones médico-legales de las \\
situaciones de urgencia.
\end{tabular}

\subsection{Criterios de ingreso hospitalario del paciente con conducta suicida}

\section{Preguntas para responder:}

- ¿Cuáles son los criterios de ingreso hospitalario psiquiátrico de un paciente con conducta suicida?

\section{Resumen de la evidencia}

En general, la decisión de ingresar o no al paciente Opinión de dependerá de tres factores principales: la repercusión expertos 4 médico-quirúrgica de la conducta suicida, el riesgo suicida inmediato del paciente, la necesidad de tratamiento del trastorno mental de base y la falta de apoyo sociofamiliar efectivo $(33,78)$.

\section{Recomendaciones}

\begin{tabular}{|c|c|}
\hline $\mathbf{D}^{\mathbf{G P C}}$ & $\begin{array}{l}\text { La decisión de hospitalizar o no a un paciente tras una conducta } \\
\text { suicida es habitualmente un proceso complejo. Se recomienda } \\
\text { tener en cuenta principalmente los siguientes factores: } \\
\text { - Repercusión médico-quirúrgica de la conducta suicida } \\
\text { - Riesgo suicida inmediato del paciente } \\
\text { - Necesidad de un tratamiento más intensivo del trastorno } \\
\text { mental de base } \\
\text { - Falta de apoyo social y familiar efectivo. }\end{array}$ \\
\hline
\end{tabular}




\section{Tratamiento de la conducta suicida en atención especializada (Salud Mental)}

Una de las mayores dificultades en el estudio del tratamiento de la conducta suicida, es que el suicidio consumado es un hecho excepcional, por lo que se necesita una muestra muy amplia para mostrar diferencias estadísticamente significativas cuando se comparan distintos tratamientos. A esta dificultad hay que añadir que muchos estudios excluyen a los pacientes de alto riesgo suicida y que los periodos de seguimiento no suelen ser largos. Debido a esto, una estrategia alternativa para analizar el efecto de un tratamiento sobre el suicidio es seleccionar variables de resultado altamente asociadas a la conducta suicida (79).

\section{Recomendaciones}

\begin{tabular}{|c|l|}
\hline$\checkmark$ & $\begin{array}{l}\text { Se recomienda abordar la conducta suicida desde una perspectiva } \\
\text { amplia, en la que se valoren de forma integral las intervenciones } \\
\text { farmacológicas, psicoterapéuticas y psicosociales de las que el } \\
\text { paciente pueda beneficiarse y contar con la implicación de los pro- } \\
\text { fesionales sanitarios de los distintos niveles asistenciales. }\end{array}$ \\
\hline & $\begin{array}{l}\text { Es recomendable promover la formación de una alianza terapéu- } \\
\text { tica sólida entre el paciente y el profesional y contar con el apoyo } \\
\text { del entorno del paciente, como parte fundamental del proceso } \\
\text { terapéutico. }\end{array}$ \\
\hline
\end{tabular}

\subsection{Las intervenciones psicoterapéuticas en el tratamiento de la conducta suicida}

\section{Preguntas para responder:}

- En un paciente con conducta suicida ¿existe alguna técnica psicoterapéutica indicada para su tratamiento? 


\section{Resumen de la evidencia}

\subsubsection{Terapias de corte cognitivo-conductual}

Las terapias cognitivo-conductuales son efectivas en adultos con conducta suicida cuando se comparan con "no tratamiento" o "tratamiento habitual". Cuando se comparan con otras formas de psicoterapia no existen diferencias significativas en la efectividad comparada (80).

Las terapias cognitivo-conductuales son más efectivas cuando se orientan a reducir algún aspecto concreto de la conducta suicida que cuando tratan de disminuir ésta de forma indirecta centrándose en otros síntomas o signos asociados (80).

En adultos, los tratamientos cognitivo-conductuales de carácter individual o combinados con sesiones grupales obtienen mejores resultados que en formato grupal. Sin embargo, en adolescentes, la terapia grupal parece más eficaz que la terapia individual (80).

En pacientes con trastorno límite de la personalidad y conducta suicida, la terapia dialéctico-conductual (TDC) muestra una efectividad comparable al resto de tratamientos cognitivo-conductuales (80).

Sobre la terapia cognitivo-conductual (TCC) en formato grupal para adolescentes con conducta suicida previa, aunque en el metanálisis de Tarrier et al. (80) se concluyó que era más efectiva que el tratamiento habitual basándose en un estudio realizado por Wood et al. (81), dos ECA posteriores no encontraron diferencias estadísticamente significativas entre los dos grupos $(82,83)$.

En personas mayores de 60 años con depresión mayor e ideación suicida, el tratamiento antidepresivo o terapia de resolución de problemas (TRP) y seguimiento telefónico obtuvo una reducción significativa de la ideación suicida en comparación con el tratamiento habitual (84).

En adolescentes con depresión mayor, la terapia combinada de fluoxetina y TCC produjo una mejoría

Metanálisis de ECA $1+$

Metanálisis de ECA $1+$

Metanálisis de ECA $1+$

Metanálisis de ECA $1+$

ECA $1+$

ECA $1+$

ECA $1++$ 
más rápida en comparación con fluoxetina y TCC de forma independiente, lo que representa un efecto protector de la conducta suicida (85). Sin embargo en adolescentes con depresión moderada-grave, la TCC en combinación con fluoxetina y cuidados estándar amplios no fue más efectiva que la fluoxetina combinada con dichos cuidados (86).

La terapia cognitivo-conductual redujo de forma significativa la conducta suicida en pacientes con trastorno límite de la personalidad (87), en pacientes con conducta suicida recurrente (88) y en pacientes con esquizofrenia crónica resistente a la medicación (89).

Tanto la TDC como la psicoterapia basada en la transferencia propiciaron una mejoría estadísticamente significativa de la conducta suicida en pacientes con trastorno límite de la personalidad (90).

En adolescentes con depresión y riesgo suicida, la TRP redujo de forma significativa las puntuaciones de las escalas de depresión, disminuyó el riesgo de suicidio y aumentó significativamente la autoestima y la asertividad (91).

En adolescentes con trastorno límite de la personalidad y trastorno bipolar, la terapia dialéctico-conductual podría ser efectiva en la reducción de la conducta e ideación suicidas (92).

\subsubsection{Terapia interpersonal}

La terapia interpersonal psicodinámica breve realizada en adultos tras un episodio de intoxicación medicamentosa voluntaria obtuvo a los 6 meses mejores resultados (menor frecuencia de autolesiones autoinformadas, menores puntuaciones en el Inventario de depresión de Beck y mayor satisfacción con el tratamiento) que el tratamiento habitual (93).

En mayores de 60 años con depresión e ideación suicida, tras 24 meses de tratamiento con terapia interpersonal (TIP) y/o citalopram, se redujo de forma significativa la ideación suicida en comparación con el grupo que recibió tratamiento habitual (94).

ECA $1+$

ECA $1+$

ECA $1+$

Serie de casos 3

ECA $1+$

ECA $1+$ 
Una intervención intensiva de TIP en adolescentes con riesgo suicida fue más efectiva que el tratamiento habitual en la disminución de depresión, ideación suicida, ansiedad y desesperanza (95).

\subsubsection{Terapia familiar}

No existe evidencia suficiente para determinar si en menores de 16 años con ideación y conducta suicidas, la terapia familiar es un tratamiento eficaz (96).

\subsubsection{Terapia psicodinámica}

En pacientes con trastorno límite de la personalidad y ECA $1+$ abuso de alcohol, la terapia psicodinámica deconstructiva fue eficaz en la disminución de la conducta suicida, el abuso de alcohol y la necesidad de cuidado institucional, en comparación con el tratamiento habitual (97).

En pacientes con trastornos de la personalidad, la combinación de terapia psicodinámica y cognitivoconductual en hospital de día (formato grupal durante 18 semanas) no obtuvo mejores resultados que el tratamiento ambulatorio habitual (98).

\section{Recomendaciones}

\begin{tabular}{|c|l|}
\hline$\checkmark$ & $\begin{array}{l}\text { Las técnicas psicoterapéuticas juegan un importante papel en el } \\
\text { tratamiento de los pacientes con conducta suicida, por lo que se } \\
\text { recomienda garantizar su disponibilidad para aquellas personas } \\
\text { que las necesiten. }\end{array}$ \\
\hline B & $\begin{array}{l}\text { De modo general, en los pacientes con conducta suicida se recomien- } \\
\text { dan los tratamientos psicoterapéuticos de corte cognitivo-conduc- } \\
\text { tual con una frecuencia semanal, al menos al inicio del tratamiento. }\end{array}$ \\
\hline B & $\begin{array}{l}\text { La psicoterapia empleada debería incidir siempre sobre algún } \\
\text { aspecto concreto del espectro suicida (ideación suicida, desespe- } \\
\text { ranza, autolesiones u otras formas de conducta suicida). }\end{array}$ \\
\hline B & $\begin{array}{l}\text { En adultos con ideación o conducta suicida se recomiendan los tra- } \\
\text { tamientos cognitivo-conductuales basados en sesiones individua- } \\
\text { les, aunque puede valorarse la inclusión de sesiones grupales como } \\
\text { complemento del tratamiento individual. }\end{array}$ \\
\hline
\end{tabular}




\begin{tabular}{|c|l|}
\hline B & $\begin{array}{l}\text { En adultos con diagnóstico de trastorno límite de la personalidad } \\
\text { se debe considerar de forma preferente la terapia dialéctico-con- } \\
\text { ductual, aunque también podrían valorarse otras técnicas psicote- } \\
\text { rapéuticas. }\end{array}$ \\
\hline B & $\begin{array}{l}\text { En adolescentes, se recomienda el tratamiento psicoterapéutico } \\
\text { específico (terapia dialéctico-conductual en trastorno límite de la } \\
\text { personalidad y terapia cognitivo conductual en depresión mayor). }\end{array}$ \\
\hline B & $\begin{array}{l}\text { La terapia interpersonal se recomienda en adultos con conducta } \\
\text { suicida, en mayores de } 60 \text { años con depresión e ideación suicida y } \\
\text { en adolescentes con riesgo suicida. }\end{array}$ \\
\hline
\end{tabular}

\subsection{Tratamiento farmacológico de la conducta suicida}

Como ya se ha comentado anteriormente, la conducta suicida es un fenómeno complejo mediado por factores biológicos, psicológicos y sociales (99, 100). La correcta evaluación, el diagnóstico y el tratamiento de la patología de base del paciente es el mecanismo más efectivo a la hora de abordar la conducta suicida. Su tratamiento farmacológico deberá incluir tanto la patología subyacente como aquellos síntomas que puedan actuar como factores de riesgo adicional (ansiedad, insomnio, impulsividad,...).

Existen escasos estudios específicos del tratamiento de la conducta suicida, ya que la mayoría analizan aquellos fármacos empleados en el abordaje de las patologías subyacentes a dicha conducta.

\section{Pregunta para responder:}

- ¿Existe algún fármaco eficaz en el tratamiento de la conducta suicida?

\section{Resumen de la evidencia}

\subsubsection{Antidepresivos}

En pacientes con depresión mayor, el tratamiento con RS de ECA $1+$ inhibidores selectivos de la recaptación de serotonina (ISRS) reduce la ideación suicida cuando se compara con placebo, si bien no está demostrado en estudios de 
larga duración. No se ha demostrado que el tratamiento con antidepresivos aumente el riesgo de suicidio (101).

En adolescentes con depresión mayor e ideación suicida, la terapia combinada (ISRS-fluoxetina + TCC) redujo la ideación suicida de forma significativa (85).

En pacientes mayores de 60 años con depresión mayor e ideación suicida, el seguimiento mantenido $\mathrm{y}$ el tratamiento con terapia combinada (citalopram $\mathrm{u}$ otro antidepresivo + TIP), redujo la ideación suicida y aumentó las tasas de remisión de la depresión a largo plazo (94).

En pacientes con trastorno bipolar se observó que los intentos de suicidio fueron más frecuentes en aquellos que recibieron tratamiento con antidepresivos en monoterapia (102). En pacientes con trastorno bipolar tipo I se ha observado riesgo de desestabilización psicopatológica si los antidepresivos no se acompañan de estabilizadores del ánimo (103).

ECA $1++$

ECA 1+

Estudio de

cohortes $2+$

\section{Recomendaciones}

\begin{tabular}{|c|l|}
\hline $\mathbf{A}$ & $\begin{array}{l}\text { En adultos con depresión mayor que presentan ideación suicida } \\
\text { se recomienda preferentemente el tratamiento con antidepresivos } \\
\text { del grupo de inhibidores selectivos de la recaptación de serotonina. }\end{array}$ \\
\hline $\mathbf{A}$ & $\begin{array}{l}\text { En mayores de } 60 \text { años con depresión mayor y conducta suicida se } \\
\text { recomienda el seguimiento mantenido en el tiempo junto con el } \\
\text { empleo de terapia combinada (Inhibidores selectivos de la recap- } \\
\text { tación de serotonina + terapia interpersonal). }\end{array}$ \\
\hline $\mathbf{A}$ & $\begin{array}{l}\text { En adolescentes con depresión mayor e ideación suicida se reco- } \\
\text { mienda el empleo de la terapia combinada (fluoxetina + terapia } \\
\text { cognitivo-conductual). }\end{array}$ \\
\hline $\mathbf{D}$ GPC & $\begin{array}{l}\text { Se recomienda el empleo de ansiolíticos al inicio del tratamiento } \\
\text { con antidepresivos en pacientes con depresión mayor e ideación } \\
\text { suicida que además experimenten ansiedad o agitación. }\end{array}$ \\
\hline $\mathbf{C}$ & $\begin{array}{l}\text { En pacientes con trastorno bipolar e ideación suicida no se reco- } \\
\text { mienda el uso de antidepresivos en monoterapia, sino acompaña- } \\
\text { dos de un estabilizador del ánimo. }\end{array}$ \\
\hline
\end{tabular}




\subsubsection{Litio}

El tratamiento con litio a largo plazo reduce cinco veces

Metanálisis 1+ el riesgo de conducta suicida (intentos y suicidios consumados) en pacientes con trastorno bipolar y otros trastornos afectivos. Este efecto se atribuye a la disminución de la agresividad e impulsividad (104).

Aunque en menor proporción que el litio, el ácido valproico y la carbamazepina se han mostrado también eficaces en la reducción de la conducta suicida (intentos y/o suicidios consumados) en pacientes con trastorno bipolar (105).

Un ensayo clínico observó una asociación entre el tratamiento con litio y un menor riesgo de suicidios consumados en pacientes con trastorno del espectro depresivo e intento de suicidio reciente (106).

En pacientes con trastorno bipolar, la retirada rápida del litio se asocia con un aumento de la conducta suicida (107).

Metanálisis 1+

ECA $1+$

Opinión de expertos 4

\section{Recomendaciones}

\begin{tabular}{|c|l|}
\hline A & $\begin{array}{l}\text { Se recomienda el tratamiento con litio en pacientes adultos con } \\
\text { trastorno bipolar que presentan conducta suicida, ya que además } \\
\text { de su efecto estabilizador de ánimo añade una potencial acción } \\
\text { antisuicida. }\end{array}$ \\
\hline B & $\begin{array}{l}\text { En pacientes adultos con depresión mayor y conducta suicida } \\
\text { reciente se recomienda valorar la asociación de litio al tratamiento } \\
\text { antidepresivo. }\end{array}$ \\
\hline D & $\begin{array}{l}\text { Cuando se considere necesario finalizar el tratamiento con litio } \\
\text { deberá hacerse de forma gradual, al menos durante dos semanas. }\end{array}$ \\
\hline
\end{tabular}

\subsubsection{Anticonvulsivantes}

En pacientes con trastorno bipolar, el riesgo de conducta suicida (intentos y/o suicidios consumados) es menor cuando éstos son tratados con litio que con carbamazepina o ácido valproico $(105,108,109)$.

Metanálisis 1+ Estudio de cohortes $2+$ 
En pacientes con trastorno límite de la personalidad existe un efecto favorable del tratamiento con carbamazepina sobre el control de la impulsividad y la conducta suicida (101).

Los pacientes con trastorno bipolar a tratamiento continuado con anticonvulsivantes (ácido valproico, lamotrigina y oxcarbazepina) presentan una reducción de las tasas de conducta suicida, si bien los resultados sugieren una superioridad del tratamiento continuado con litio en la prevención del suicidio (110). Existe controversia sobre si los fármacos anticonvulsivantes incrementan o no el riesgo de conducta suicida. Mientras que la Food and Drug Administration (FDA) avisa de un posible aumento, estudios posteriores no encuentran asociación significativa entre el empleo de anticonvulsivantes y la conducta suicida (111-113).
Estudio de

cohortes $2+$

Estudio de cohortes $2+$ Estudio caso control $2+$

\section{Recomendaciones}

\begin{tabular}{|c|l|}
\hline $\mathbf{C}$ & $\begin{array}{l}\text { En el tratamiento con anticonvulsivantes del trastorno límite de } \\
\text { la personalidad se recomienda utilizar como fármaco de primera } \\
\text { elección la carbamazepina para controlar el riesgo de conducta } \\
\text { suicida. }\end{array}$ \\
\hline $\mathbf{C}$ & $\begin{array}{l}\text { En pacientes con trastorno bipolar y riesgo de suicidio que pre- } \\
\text { cisen tratamiento con anticonvulsivantes, se recomienda el trata- } \\
\text { miento con ácido valproico o carbamazepina de forma continuada. }\end{array}$ \\
\hline$\checkmark$ & $\begin{array}{l}\text { En pacientes con epilepsia y factores de riesgo de suicidio a trata- } \\
\text { miento antiepiléptico se mantendrá especial atención a la presen- } \\
\text { cia de ideación o conducta suicida. }\end{array}$ \\
\hline
\end{tabular}

\subsubsection{Antipsicóticos}

Antipsicóticos convencionales o de primera generación

Una revisión sistemática de antipsicóticos de primera RS de distintos generación resaltaba la alta variabilidad de los estudios tipos de estudios publicados hasta ese momento respecto al tratamiento, 2+ dosis, duración, medicación concomitante y diagnósticos, lo que limitaba poder realizar conclusiones generalizadas sobre su eficacia en la conducta suicida (101). 
Para algunos autores, los antipsicóticos de primera Opinión de generación tendrían un efecto limitado sobre el riesgo de conducta suicida (33).

Antipsicóticos atípicos o de segunda generación

La clozapina ha mostrado una reducción significativa de ECA $1++$ la conducta suicida en pacientes adultos diagnosticados de esquizofrenia (114).

En pacientes adultos con esquizofrenia, la olanzapina ha mostrado una reducción de la conducta y del ECA $1++$ pensamiento suicida, aunque en menor grado que la clozapina (114).

La risperidona como coadyuvante en pacientes ECA $1+$ adultos con depresión mayor y conducta suicida podría ser beneficiosa y reducir el riesgo suicida (115).

\title{
Recomendaciones
}

\author{
ECA $1++$
}

ECA $1++$

Recomendaciones

Se recomienda el uso de clozapina en el tratamiento de pacientes

adultos con diagnóstico de esquizofrenia o trastornos esquizoafec-
tivos y con alto riesgo de conducta suicida, para reducir el riesgo de comportamientos suicidas.

\subsection{Terapia electroconvulsiva}

La terapia electroconvulsiva (TEC) consiste en provocar una crisis comicial generalizada mediante la estimulación eléctrica de áreas cerebrales. Aunque su mecanismo de acción no está completamente dilucidado, ha demostrado ser efectiva en el tratamiento de ciertos trastornos mentales, como la depresión mayor grave, la manía y la esquizofrenia (33,116-119).

\section{Preguntas para responder:}

- ¿Cuál es la eficacia y seguridad de la terapia electroconvulsiva en el tratamiento de la conducta suicida? 


\section{Resumen de la evidencia}

Estudios observacionales realizados en pacientes con Serie de casos 3 esquizofrenia, trastorno depresivo o esquizoafectivo muestran resultados positivos respecto a un posible efecto de la terapia electroconvulsiva sobre la conducta suicida (120).

Un estudio caso-control realizado en 30 pacientes con trastorno mental grave asociado o no a abuso de sustancias, mostró una mejoría en las puntuaciones relativas a las áreas de depresión y de suicidio de la escala Brief Psychiatric Rating Scale. Los resultados se compararon con controles pareados que no recibieron TEC aunque sí tratamiento farmacológico, siendo más favorables en el grupo que recibió TEC y que presentaba también abuso de sustancias (121).

En un estudio caso-control realizado con pacientes con depresión mayor grave (ingresados entre 1956 y 1969 y seguidos hasta 1998), los intentos de suicidio fueron menos frecuentes en los tratados con terapia electroconvulsiva que en los que recibieron fármacos antidepresivos (122).

En pacientes diagnosticados de depresión mayor unipolar, la terapia electroconvulsiva redujo la intencionalidad suicida, alcanzando cero puntos en la escala de Hamilton el $38 \%$ de los pacientes al cabo de una semana, el $61 \%$ tras dos semanas y el $76 \%$ a las tres semanas (123).

\section{Recomendaciones}

\begin{tabular}{|c|l|}
\hline$\checkmark$ & $\begin{array}{l}\text { La decisión de utilizar terapia electrocovulsiva debería tomarse } \\
\text { de forma compartida con el paciente, teniendo en cuenta facto- } \\
\text { res como el diagnóstico, tipo y gravedad de los síntomas, historia } \\
\text { clínica, balance riesgo/beneficio, opciones alternativas y preferen- } \\
\text { cias del paciente. En todos los casos se deberá obtener el consenti- } \\
\text { miento informado por escrito. }\end{array}$ \\
\hline \multirow{\checkmark}{*}{$\begin{array}{l}\text { Se recomienda que la terapia electroconvulsiva sea administrada } \\
\text { siempre por un profesional experimentado, tras una evaluación } \\
\text { física y psiquiátrica y en un entorno hospitalario. }\end{array}$} \\
\hline
\end{tabular}




\begin{tabular}{|c|l|}
\hline $\mathbf{C}$ & $\begin{array}{l}\text { Se recomienda la terapia electroconvulsiva en aquellos pacientes } \\
\text { con depresión mayor grave en los que exista la necesidad de una } \\
\text { rápida respuesta debido a la presencia de alta intencionalidad sui- } \\
\text { cida. }\end{array}$ \\
\hline $\mathbf{D}^{\mathbf{G P C}}$ & $\begin{array}{l}\text { La terapia electroconvulsiva estaría indicada también en adoles- } \\
\text { centes con depresión mayor grave y persistente, con conductas que } \\
\text { pongan en peligro su vida o que no respondan a otros tratamientos. }\end{array}$ \\
\hline
\end{tabular}




\section{ASPECTOS PREVENTIVOS}




\section{Medidas generales de prevención de la conducta suicida}

\subsection{Programas de prevención de la conducta suicida a nivel internacional}

Desde hace más de 40 años la OMS recomienda la elaboración y aplicación de estrategias de prevención del suicidio, y así, en 1969 publicó un documento donde reconocía la importancia de encuadrar la prevención del suicidio en el campo de la salud pública y la necesidad de establecer centros de prevención del suicidio a nivel nacional y local (124). En 1984, los países de la oficina regional para Europa de la OMS incluyeron la reducción del suicidio dentro de sus objetivos de política sanitaria (125).

\section{Preguntas para responder:}

- ¿Qué programas sobre prevención de la conducta suicida podemos encontrar a nivel internacional?

\section{Resumen de la evidencia}

El proyecto SUPRE es una iniciativa de la OMS Opinión de (126) con el objetivo de reducir la progresiva mortalidad expertos 4 debida al suicidio. Para ello elaboró una serie de documentos dirigidos a profesionales y grupos sociales relevantes en la prevención del suicidio (profesionales de atención primaria $(15,63)$, medios de comunicación (127), docentes (128, 129), funcionarios de prisiones (130), trabajadores (131), supervivientes de un suicidio ${ }^{3}$ (132), bomberos, policías y socorristas (133); no se han encontrado datos de efectividad de esta iniciativa.

3 El término superviviente de un suicidio se emplea para referirse a los allegados de una persona que ha realizado un suicidio y, aunque tradicionalmente el concepto se ha reservado para la familia, en la actualidad se ha extendido también a los allegados (amigos, compañeros de trabajo o de clase y vecinos). 
La OMS realizó una serie de recomendaciones sobre las intervenciones preventivas del suicidio (134):

- Deben partir desde la salud pública con participación del gobierno

- Deben incluir programas específicos para grupos de riesgo

- Los profesionales sanitarios deben estar capacitados para identificar grupos de riesgo, por lo que la formación debe centrarse en factores de riesgo y protección

- Es necesario implementar políticas de evaluación de los programas

- Los medios de comunicación deben estar implicados en la prevención del suicidio.

Mann et al.(135) propusieron un modelo de prevención basado en las intervenciones que han demostrado efectividad en pacientes con trastornos mentales y otros factores de riesgo (formación y concienciación sobre el suicidio, detección de personas de alto riesgo, tratamiento farmacológico y psicoterapéutico, seguimiento preventivo de los intentos de suicidio, restricción del acceso a medios letales e implicación de los medios de comunicación) (anexo 2).

Posteriormente, diferentes revisiones sistemáticas de prevención del suicidio destacan las siguientes recomendaciones $(66,125,136-138)$ :

- Limitación del acceso a medios letales

- Mejora en el acceso a los servicios sanitarios y proporción de apoyo a personas en riesgo de suicidio

- Identificación, tratamiento y seguimiento adecuados de personas con depresión y otros trastornos mentales

- Desarrollo de intervenciones comunitarias en jóvenes, mayores y minorías étnicas

- Mejora de la formación del personal sanitario

- Eliminación de tabúes y estigmas sobre el trastorno mental y el suicidio, tanto en personal sanitario como en la población general
RS de estudios $2+$

RS de estudios $2+$

RS de estudios $2+$ 
- Implicación de los medios de comunicación y centros educativos en la prevención de la conducta suicida.

A nivel europeo, el programa multinivel de Nuremberg (Nuremberg Alliance Against Depression), llevado a cabo durante dos años y con 4 líneas de intervención (formación a médicos de atención primaria, sensibilización de los medios de comunicación y de la población general, entrenamiento de figuras clave e intervención en grupos de riesgo), obtuvo una reducción significativa de las tasas de intentos de suicidio y de suicidios consumados en relación a las tasas iniciales y a las de una región de referencia, y esta reducción se mantuvo al año del programa $(139,140)$.

En comparación con otros países europeos, en España existe una muy escasa implementación de programas de tipo preventivo. No existe un plan nacional de prevención del suicidio específico y hasta ahora solo se han desarrollado iniciativas locales (141).
Estudio cuasiexperimental $2+$
Opinión de expertos 4

\section{Recomendaciones}

\begin{tabular}{|c|c|}
\hline Se recomienda a las autoridades sanitarias la puesta en marcha de \\
líneas de acción específicas para la prevención de la conducta sui- \\
cida mediante: \\
- Desarrollo de programas preventivos en poblaciones de riesgo \\
- Formación de los profesionales sanitarios en la detección del \\
riesgo suicida e identificación de factores de riesgo y protectores \\
- Educación a la población general y medios de comunicación \\
- Mejorar los procedimientos de identificación, tratamiento y \\
seguimiento de personas en riesgo de suicidio \\
- Mejorar el acceso a los servicios de salud y proporcionar el \\
tratamiento indicado a las personas con conducta suicida \\
- Eliminar tabúes y estigmas sobre el trastorno mental y el suici- \\
dio tanto en el personal sanitario como en la población general \\
- Promover la investigación sobre la prevención del suicidio. \\
\hline
\end{tabular}




\subsection{Potenciación de factores protectores y resiliencia}

El interés por los factores protectores radica en que su potenciación podría ayudar a prevenir el suicidio. Sin embargo, pocos estudios se han centrado en su evaluación, que presenta ciertas dificultades: algunos de los factores propuestos han sido extrapolados de la investigación en otros campos, no existe homogeneidad en la terminología empleada y en ocasiones algunos factores protectores propuestos son la descripción en positivo de un factor de riesgo (36).

Respecto a la resiliencia, a pesar de que su fomento es una de las bases de la prevención en salud mental, sobre todo en la infancia y la adolescencia (142) y en personas mayores (143), la mayoría de estudios se han centrado en los factores de riesgo (depresión y otros trastornos mentales, aislamiento social, etc.), siendo muy limitada la investigación sobre el efecto de la potenciación de factores protectores.

\section{Preguntas para responder:}

- ¿Qué intervenciones clínicas son eficaces en la prevención de la conducta suicida mediante la potenciación de los factores de protectores y la resiliencia?

\section{Resumen de la evidencia}

Los factores protectores del riesgo de suicidio se pueden clasificar en personales (habilidad en la solución de problemas, autoestima, flexibilidad cognitiva, hábitos de vida saludables, entre otros) $(36,39,40,144-146)$ y sociales/medioambientales (como contar con apoyo familiar y social, integración social, disponer de ayuda y recursos) $(17,18,36,37,39,47,145,147)$ (ver apartado 2).

Los factores protectores relacionados con la resiliencia que más se han asociado a la prevención de la conducta suicida son (148):

RS de distintos tipos de estudios $2++, 2+, 3$

- Capacidades y procesos cognitivos: el estilo atribucional podría tener un papel central en la conducta suicida, de forma que si es positivo podría moderar el riesgo de suicidio. También cuenta con cierta evidencia la confianza en la capacidad de solución de problemas.

RS de distintos tipos de estudios 3 
- Creencias y actitudes: el alto nivel de autonomía es la variable que cuenta con mayor evidencia, y podría ejercer una función preventiva. Otras variables que podrían estar implicadas y moderar el riesgo de suicidio son el apoyo social percibido, el apego y las creencias relacionadas con el suicidio.

En el ámbito escolar, un programa basado en la potenciación de factores protectores a través de iguales (peer leaders) mejoró en los estudiantes la percepción de apoyo por parte de los adultos y consiguió mayor aceptación a pedir ayuda. También se encontró en los peer leaders un aumento significativo de la información en relación con el suicidio, conexión con los adultos e implicación escolar (149).

En Australia se llevó a cabo un programa de prevención del suicidio de adolescentes aborígenes, basado en la potenciación de factores protectores y dirigido a profesionales, familias y los propios adolescentes (4 módulos de 10 semanas, 1 sesión semanal). Al final de su implementación se encontró un incremento significativo en los niveles de empoderamiento (empowerment), autoestima, resiliencia, habilidades de solución de problemas y bienestar (150).

Un programa de adaptación a la jubilación en el que se empleó terapia TCC grupal obtuvo una disminución de los niveles de depresión y de distrés psicológico. También se observó un aumento significativo de variables como esperanza, objetivos, serenidad, flexibilidad y actitud positiva frente a la jubilación, y la mejoría se mantuvo a los 6 meses (151).

La TIP (16 sesiones semanales) orientada a mejorar el funcionamiento social y las habilidades en personas mayores de 60 años con elevado riesgo de suicidio, obtuvo una reducción significativa en los niveles de síntomas depresivos, ideación suicida e ideas de muerte, en comparación con el nivel basal (152).
ECA $1+$

Estudio cualitativo Q

RS de distintos tipos de estudios 3

RS de distintos tipos de estudios 3 


\section{Recomendaciones}

\begin{tabular}{|l|l|}
\hline$\checkmark$ & $\begin{array}{l}\text { Se recomienda el desarrollo y puesta en marcha de programas de } \\
\text { prevención del suicidio basados en la potenciación de factores pro- } \\
\text { tectores y factores asociados a la resiliencia. }\end{array}$ \\
\hline
\end{tabular}

\subsection{Restricción del acceso a medios letales}

Distintos estudios han puesto de manifiesto que los suicidios llevados a cabo con un determinado método se reducen cuando este es menos accesible (125), si bien en algunos casos, las tasas de suicidio global se compensan con un aumento de suicidios por otro método $(135,137)$.

\section{Preguntas para responder:}

- ¿Qué medidas se pueden tomar para la restricción de medios letales?

\section{Resumen de la evidencia}

Existe evidencia sobre una disminución de la conducta RS de estudios suicida cuando se realiza una restricción del acceso $2++$ a determinados medios letales (acceso a sustancias tóxicas, armas de fuego...), aunque es necesario tener en cuenta que la restricción del tipo de método depende del país $(66,125,135,137,138)$.

\section{Recomendaciones}

Se recomienda reducir la disponibilidad o limitar el acceso a medios letales de suicidio, principalmente de aquellos más utilizados en cada país:

- Restricción de la venta de psicotrópicos

- Reducción del tamaño de los envases de fármacos en general

- Uso de antidepresivos de menor toxicidad

B

- Reducción de las emisiones de monóxido de carbono de los vehículos

- Menor toxicidad del gas de uso doméstico

- Instalación de barreras en lugares elevados

- Restricción sobre posesión y control de armas de fuego

- Control de plaguicidas. 


\subsection{Medios de comunicación y suicidio}

Parece existir una asociación entre la aparición de noticias sobre suicidio, el tratamiento que le dan los medios de comunicación y un efecto imitativo del mismo, denominado suicidio por contagio o efecto Werther (153). Por el contrario, la forma y el contenido de las noticias sobre suicidio también puede ejercer un efecto preventivo, conocido como efecto Papageno (154). Debido a esta compleja interacción, diferentes países han elaborado directrices para los medios de comunicación sobre cómo deben enfocar las noticias sobre suicidios, aunque existen pocos estudios que hayan evaluado posteriormente la efectividad de estas medidas sobre la reducción de sus tasas.

\subsubsection{Medios de comunicación}

\section{Preguntas para responder:}

- ¿Qué medidas pueden adoptar los medios de comunicación para prevenir la conducta suicida?

\section{Resumen de la evidencia}

Existe evidencia consistente sobre la relación entre el RS de distintos tratamiento inadecuado de la información sobre el suicidio y un incremento del mismo. Las noticias que idealizan o dramatizan los suicidios y las que implican a personas famosas se relacionan especialmente con conductas imitativas. Sobre el efecto de las guías con recomendaciones para los medios, su evidencia no es concluyente (153).

La OMS publicó un documento en el que se ofrecen una serie de recomendaciones para los medios de comunicación sobre cómo enfocar las noticias sobre suicidios (155).

Distintos países (Australia, Nueva Zelanda, EE.UU., Canadá, Reino Unido, Hong Kong y Sri Lanka, entre otros) han desarrollado recomendaciones para los tipos de estudios $2+, 3$

Opinión de expertos 4 medios de comunicación basadas en las directrices de la RS de distintos tipos de estudios 3,4 OMS. Las más importantes son (156): 
- No tratar las noticias sobre suicidios de forma sensacionalista

- Evitar especificar detalles sobre sus características y circunstancias

- Aportar información precisa, responsable y ética

- Aprovechar la oportunidad para educar a la población

- Ofrecer información sobre los recursos de ayuda disponibles

- Tras un suicidio, tener siempre en cuenta a los familiares y allegados.

Otros aspectos que también se han relacionado Serie de casos 3 con un aumento de la conducta suicida son la repetición de noticias sobre un mismo suicidio y la referencia a los mitos que existen sobre el mismo (154).

En Austria, tras la implementación de medidas dirigidas a los medios de comunicación, se observó una reducción significativa de la tasa anual de suicidios a nivel nacional y especialmente en las regiones donde la prensa colaboró de forma más activa. También se puso de manifiesto una mejora en la calidad de la información ofrecida (157).

En Hong Kong, tras la implementación de las recomendaciones de la OMS para los medios, se observó una disminución de las tasas de suicidio y se publicaron menos imágenes y titulares sobre suicidios (158).

Los periodistas reconocen la necesidad de su implicación en la prevención del suicidio y su papel en la promoción de la salud. Una de las principales barreras para la adopción de las recomendaciones sobre el tratamiento de la información sobre el suicidio fue el escepticismo sobre el efecto contagio (159).

Estudio cuasiexperimental $2+$

Estudio cuasiexperimental $2+$

\section{Estudio} cualitativo Q 


\section{Recomendaciones}

\begin{tabular}{|l|l|}
\hline D & $\begin{array}{l}\text { Se recomienda que los medios de comunicación sigan las directri- } \\
\text { ces de la OMS para la publicación de noticias sobre suicidios, entre } \\
\text { las que destacan: } \\
\text { - No tratar las noticias sobre suicidios de forma sensacionalista } \\
\text { - Evitar especificar detalles sobre sus características y circuns- } \\
\text { tancias } \\
\text { - Aportar información precisa, responsable y ética } \\
\text { - Aprovechar la oportunidad para educar a la población } \\
\text { - Ofrecer información sobre los recursos de ayuda disponibles } \\
\text { - Tras un suicidio, tener siempre en cuenta el impacto que la } \\
\text { información pueda producir en los familiares y allegados. }\end{array}$ \\
$\checkmark$ & $\begin{array}{l}\text { Se recomiendan acciones, a nivel nacional o autonómico, encami- } \\
\text { nadas a promover la puesta en marcha de las directrices de la OMS } \\
\text { y de otras similares que favorezcan un adecuado tratamiento del } \\
\text { suicidio en los medios de comunicación. }\end{array}$ \\
\hline
\end{tabular}

\subsubsection{Internet}

\section{Preguntas para responder:}

- ¿Cuál es el papel de Internet en la conducta suicida?

\section{Resumen de la evidencia}

El uso patológico de Internet se ha asociado con la presencia de ideación y conducta suicidas (160).

Se ha constatado que gran parte de la información de Internet sobre el suicidio podría clasificarse como contenido prosuicidio y que los jóvenes son especialmente vulnerables a esta información (160-163).

En jóvenes de 14 a 24 años, se ha puesto de manifiesto que aunque la información sobre el suicidio provenía en la mayoría de los casos de fuentes tradi-
RS de estudios

$2+$

RS de distintos tipos de estudios $2+$

Serie de casos 3 
cionales (familia, amigos o prensa), las redes sociales y foros fueron cada vez más frecuentes (164).

Los pactos de suicidio en Internet son un fenómeno que adquiere cada día mayor importancia. También se pueden encontrar en la red variantes de este fenómeno como los suicidios narrados online y la simulación del propio suicidio en la red (160).

Internet podría ser una buena herramienta para la promoción de la salud mental y la prevención del suicidio. Algunas de las ventajas que presenta son (160):

- Facilita la interacción social

- Presenta un fácil acceso y rápida diseminación de la información

- Ha demostrado ser un buen medio para ofrecer información sobre aspectos relacionados con la salud, por lo que podría ser una buena plataforma para la educación

- Puede proporcionar apoyo mediante el uso adecuado de redes sociales y chats.

Un estudio realizado con estudiantes universitarios que habían participado en un cribado de depresión y de riesgo suicida online, y posterior entrevista personal, comparó aquellos que mantuvieron contacto online con el terapeuta con los que no lo hicieron. Se encontró que los estudiantes que mantuvieron contacto con el terapeuta a través de Internet tuvieron mayor probabilidad de comenzar un tratamiento (165).

En otro estudio se analizó la proporción de contactos relacionados con el suicidio en una línea telefónica de ayuda, en un chat y en un grupo de autoayuda online asincrónico. Las amenazas de suicidio fueron más frecuentes en el grupo de ayuda online, que en la línea telefónica y el chat (166).

Algunas medidas que han sido propuestas para intentar regular el contenido de la información sobre suicidios en Internet son (161):
Opinión de expertos 4

Opinión de expertos 4

Serie de casos 3

Serie de casos 3

Opinión de expertos 4 
- El uso de programas de filtrado por parte de los familiares para impedir el acceso a determinados foros o blogs

- Intentar que las páginas con información útil para los pacientes (encaminada a la prevención o a ofrecer apoyo), aparezcan situadas en un lugar prioritario cuando se realiza una búsqueda con palabras clave

- Regularizar el control de los contenidos de Internet (mediante su legislación, implicación de organizaciones o servicios proveedores).

\section{Recomendaciones}

\begin{tabular}{|c|c|}
\hline Se recomienda la implantación de medidas dirigidas a favorecer \\
que Internet sea un instrumento que promueva la salud mental y la \\
prevención del suicidio. Entre estas medidas estarían: \\
- Intentar que las páginas con información útil para los pacien- \\
tes, encaminadas a la prevención o a ofrecer apoyo, aparezcan \\
situadas en un lugar prioritario cuando se realiza una bús- \\
queda con términos clave \\
- Regularizar el control de los contenidos de Internet mediante \\
su legislación, implicación de organizaciones o servicios pro- \\
veedores \\
- Uso de programas de filtrado para impedir el acceso a deter- \\
minados foros o blogs.
\end{tabular}

\subsection{Programas formativos de prevención de la conducta suicida}

La OMS recomienda, ya desde 1969, la formación sobre prevención del suicidio en las facultades de medicina con el fin de que los alumnos adquieran conocimientos sobre la ideación y la conducta suicidas (124). Posteriormente, la guía elaborada por el NICE (National Institute for Health and Clinical Excellence) en 2004 (60) recomienda que todo el personal, sanitario y no sanitario, con posibilidad de estar en contacto con personas con conducta suicida tenga un entrenamiento apropiado para tratar y entender a este tipo de pacientes. La actualización en 2011 de esta guía (167) dedica 
un capítulo a la formación del profesional sanitario de atención primaria, salud mental, urgencias y de otros profesionales del campo de la salud. Así mismo, la guía de la EPA (European Psychiatric Association) de tratamiento y prevención del suicidio, también del 2011 (168), dedica asimismo un apartado a la mejora de las habilidades del personal médico.

\section{Recomendaciones}

\begin{tabular}{|c|l|}
\hline C & $\begin{array}{l}\text { Se recomienda que todo profesional, tanto sanitario como no sani- } \\
\text { tario, que pueda estar en contacto con personas en riesgo de suici- } \\
\text { dio adquiera los conocimientos, actitudes y habilidades adecuados } \\
\text { para su manejo. }\end{array}$ \\
\hline
\end{tabular}

\subsubsection{Profesionales sanitarios}

\section{Preguntas para responder:}

- Los programas formativos de sensibilización, detección y abordaje de la ideación y la conducta suicida llevados a cabo en profesionales sanitarios ise han mostrado efectivos a la hora de reducir las tasas de suicidio consumado?

\section{Resumen de la evidencia}

Los programas de formación para la prevención del suicidio dirigidos a profesionales de la salud deben incluir aspectos relacionados con los factores de riesgo, la evaluación y el tratamiento y manejo de la conducta suicida, así como sobre el estigma y la discriminación que generalmente se asocia $(167,168)$.

Estos programas de formación se pueden realizar mediante conferencias, role-playing y discusión de casos (167, 169-176).

Los programas formativos se relacionan con un aumento de la confianza de los profesionales sanitarios, mejora de sus actitudes y habilidades en la detección y manejo de la depresión, aunque no existe evidencia

RS de distintos tipos de estudios 3

Estudio casocontrol 2+ Estudio cuasiexperimental $2+$

Estudio casocontrol 2+ Estudio cuasiexperimental $2+$ 
concluyente sobre su efecto en la conducta suicida (167, 177-180).

No se ha demostrado que los programas formativos dirigidos a profesionales de atención primaria disminuyan las tasas de suicidio, aunque mejoran los conocimientos adquiridos y provocan cambios en la actitud y en la confianza de los participantes en el programa que se mantienen durante 6 meses (167-171).

Estudios sobre formación de profesionales de salud mental en la prevención de la conducta suicida muestran resultados positivos en la adquisición de conocimientos, cambios de actitud $(168,172)$ y en la habilidad para manejar estos pacientes, aunque su influencia sobre las tasas de suicidio no ha sido evaluada (172).

Los programas de formación sobre prevención del suicidio en los servicios de urgencias aumentan los conocimientos de los profesionales y la percepción de autoeficacia frente al manejo del paciente con riesgo de suicidio $(168,179,181-183)$.

Los programas específicamente desarrollados para profesionales de enfermería y médicos internos residentes, muestran una mayor confianza, actitud y competencia en el manejo de pacientes con conducta suicida (173-176), aunque en el caso de los médicos internos residentes la mejora fue temporal, lo que plantea la necesidad de refuerzo de los programas de forma periódica (173).

Para la puesta en marcha de programas preventivoeducativos en profesionales de la salud se ha propuesto: conocer las necesidades del área, mejorar la capacidad de identificación de personas con riesgo suicida, facilitar herramientas de ayuda diagnóstica y realizar una evaluación interna y externa del programa, entre otros aspectos (141).

Para la implementación de un programa de formación sobre prevención de la conducta suicida es necesario (179):

- Contar con un líder o coordinador de apoyo en la organización

Estudio casocontrol 2+

Estudio cuasiexperimental $2+$

RS de estudios $2+$

Estudio cuasiexperimental $2+$ Serie de casos 3

Estudio cuasiexperimental $2+$ Serie de casos 3

Opinión de expertos 4

Estudio cuasiexperimental $2+$ 
- Favorecer una mayor demanda de formación

- Tener un adecuado soporte financiero para su desarrollo.

\section{Recomendaciones}

\begin{tabular}{|c|l|}
\hline C & $\begin{array}{l}\text { De forma general, se recomienda que los programas destinados a } \\
\text { la formación del personal sanitario sobre conducta suicida inclu- } \\
\text { yan información sobre factores de riesgo y de protección, evalua- } \\
\text { ción y estrategias de intervención en crisis. El formato podrá ser } \\
\text { presencial, online o mixto, y basarse en conferencias, discusión de } \\
\text { casos o role-playing. }\end{array}$ \\
\hline C & $\begin{array}{l}\text { Se recomienda que los programas de formación incluyan sesiones } \\
\text { de refuerzo de forma periódica (al menos cada dos años). }\end{array}$ \\
\hline $\boldsymbol{J}$ & $\begin{array}{l}\text { Se recomienda la evaluación de los programas de formación tras } \\
\text { su implementación, sobre todo de su influencia sobre la práctica } \\
\text { asistencial. }\end{array}$ \\
\hline C & $\begin{array}{l}\text { Se recomienda que los programas de formación en atención pri- } \\
\text { maria incluyan, además de contenidos específicos sobre el suicidio, } \\
\text { otros referidos a la detección y tratamiento de la depresión. }\end{array}$ \\
\hline C & $\begin{array}{l}\text { Se recomienda que los programas de formación en los servicios de } \\
\text { urgencias aborden aspectos generales de suicidio y potencien el } \\
\text { desarrollo de competencias en la entrevista clínica para la detec- } \\
\text { ción de patología psiquiátrica comórbida, factores y grupos de } \\
\text { riesgo de suicidio. }\end{array}$ \\
\hline C & $\begin{array}{l}\text { Se recomienda que los programas de formación en los servicios } \\
\text { de salud mental aborden, además de los aspectos generales sobre } \\
\text { suicidio, la adquisición de habilidades en el manejo y prevención } \\
\text { de la conducta suicida. }\end{array}$ \\
\hline
\end{tabular}

\subsubsection{Profesionales no sanitarios}

\section{Preguntas para responder:}

- ¿Desde el punto de vista formativo, qué medidas de prevención de la conducta suicida podrían realizarse en profesionales no sanitarios? 


\section{Resumen de la evidencia}

Los programas desarrollados para prevención de la conducta suicida en escuelas, universidades o centros de menores mejoran significativamente el nivel de confianza, la percepción de habilidades y el conocimiento sobre el suicidio y se mantienen a los 3-6 meses de su finalización (incluso a los 18 meses, con sesiones de refuerzo de la formación inicial) (184-189).

Para la puesta en marcha de un programa de prevención de la conducta suicida en un centro educativo es recomendable el apoyo del director del centro, ofrecerlo al inicio del curso, ser de corta duración y estar destinado a todo el personal de la institución (188).

En los centros penitenciarios, los programas de prevención del suicidio tienen como objetivo principal capacitar al personal para la identificación y manejo de reclusos con riesgo de suicidio (130).

Los programas de formación destinados a policías, bomberos y socorristas se pueden desarrollar mediante estudios de casos y situaciones reales y tratan de capacitar a estos profesionales en gestión de crisis (133).

Los programas de formación y sensibilización sobre el suicidio para figuras clave (gatekeeper) o voluntariado se pueden realizar empleando material didáctico junto con visitas a domicilio y role-playing. Sus resultados muestran una mejoría en los conocimientos y la gestión de crisis, sobre todo en la búsqueda de ayuda de profesionales (190-192).

\section{Recomendaciones}

Opinión de expertos 4

Opinión de expertos 4

Estudio cuasiexperimental $2+$

Se recomienda que los programas destinados a la formación de personal no sanitario (profesorado, educadores, bomberos, poli-

C cías...) aborden fundamentalmente factores de riesgo de conducta suicida, aspectos preventivos, intervención en crisis e información sobre la búsqueda de ayuda profesional. 


\section{El cribado del riesgo de suicidio}

A pesar de la prevalencia de la ideación y la conducta suicidas y del conocimiento de sus factores de riesgo, alrededor del $83 \%$ de las personas con conducta suicida no han sido identificadas previamente por su médico, incluso siendo evaluadas en los meses previos al intento (193). Esta situación ha llevado a plantear la pregunta de si la administración de un test de cribado (bien en atención primaria, en los servicios de urgencias o en el ámbito de la salud mental), podría detectar de forma fiable el riesgo de suicidio de los pacientes.

\section{Preguntas para responder:}

- ¿El cribado de riesgo de suicidio podría detectar la conducta suicida futura y disminuir la mortalidad por esta causa? ¿Son eficaces los instrumentos de cribado para identificar el riesgo de suicidio?

\subsection{Cribado de riesgo de suicidio en adultos}

\section{Resumen de la evidencia}

Los estudios que abordan el cribado del riesgo de suicidio en adultos son muy escasos y ninguno de ellos contesta a la pregunta de si su realización en el ámbito de la atención primaria disminuye la morbimortalidad en pacientes cuyo riesgo no hubiera sido identificado previamente (194).

Un programa de cribado de ideación y conducta suicida realizado atención primaria observó una prevalencia de intentos de suicidio del $2,9 \%$ de los que el $9 \%$ tuvo pensamientos, gestos o intentos suicidas en el mes previo. Además, un $60 \%$ de los pacientes con ideación o conducta suicidas tuvieron un episodio depresivo previo, frente al 6,8\% de los no suicidas (195).

Entre las herramientas de cribado de riesgo de suicidio en adultos, el Symptom-Driven Diagnostic System for Primary Care ha mostrado una alta sensibilidad y especificidad, asociándose de forma indepen-
RS de estudios de pruebas diagnósticas $2+$

Serie de casos 3

RS de distintos tipos de estudios $2+$ 
diente con la ideación suicida, la depresión mayor y el abuso de drogas o dependencia de éstas (194).

El cuestionario Primary Care Evaluation of Mental Disorders, complementado con preguntas sobre conducta suicida, es también un buen método para los RS de estudios de pruebas diagnósticas $2+$ médicos de atención primaria a la hora de valorar el riesgo suicida y reconocer los trastornos mentales más frecuentes (195).

\section{Recomendaciones}

D mendar, ni a favor ni en contra, el cribado de riesgo de suicidio en adultos.

\subsection{Cribado de riesgo de suicidio en la infancia y la adolescencia}

\section{Resumen de la evidencia}

La evidencia acerca de herramientas o programas de cribado de suicidio en centros educativos muestra resultados poco concluyentes ya que no se determinó su efecRS de distintos tipos de estudios tividad ni su posible impacto sobre la conducta suicida futura (196).

Uno de estos programas de cribado es el TeenScreen Program que tiene como objetivo identificar, de forma temprana y voluntaria, trastornos mentales como la depresión o el riesgo de suicidio en jóvenes antes de que abandonen la escuela secundaria (197).

El cribado estandarizado del riesgo de suicidio en adolescentes en el ámbito de la atención primaria permite identificar jóvenes en riesgo de suicidio que necesiten una derivación a un servicio especializado (198).

Diferentes factores, como la falta de tiempo, de herramientas de detección y de protocolos consensuados

Estudio cualitativo Q 
hace que el cribado de riesgo de suicidio se realice en pocas ocasiones en los servicios de urgencias (199).

En niños y adolescentes, la presencia de factores estresantes, síntomas clínicos y utilización de servicios sanitarios predijeron un continuum de riesgo de suicidio desde la ideación a intentos repetidos. Algunos factores de estrés específicos asociados con un incremento del riesgo de suicidio fueron las rupturas de pareja, la exposición a casos de suicidios o intentos de suicidio cercanos y el embarazo no deseado (200).

En los servicios de urgencias, el cribado de riesgo de suicidio en adolescentes tiene potencial para identificar pacientes con alto riesgo de suicidio que acuden por otros motivos médicos y a pacientes con presencia de depresión, consumo de alcohol e impulsividad (201).

Se ha observado que la utilización de sistemas informáticos de cribado en un servicio de urgencias hospitalario incrementa significativamente la identificación de adolescentes con problemas psiquiátricos (202).

Se han encontrado diferentes herramientas de cribado validadas psicométricamente para detectar riesgo de suicidio en adolescentes: Columbia Suicide Screen (CSS), Diagnostic Predictive Scales (DPS), Suicidal Ideation Questionnaire (SIQ), Suicidal Ideation Questionnaire JR (SIQ-JR), Risk of Suicide Questionnaire (RSQ), Suicide Risk Screen (SRS) y la Suicide Probability Scale (SPS), oscilando su sensibilidad entre 1,00 y 0,48 (196).
Estudio de pruebas diagnósticas $2+$

Estudio de pruebas diagnósticas $2+$

Estudio de pruebas diagnósticas $2+$

Estudio observacional 3

\section{Recomendaciones}

\begin{tabular}{l|l|} 
C & $\begin{array}{l}\text { En centros educativos, la evidencia existente sobre la efectividad y } \\
\text { el posible impacto en la conducta suicida no permite recomendar } \\
\text { la implantación de programas de cribado. }\end{array}$
\end{tabular}




\begin{tabular}{|c|l|}
\hline C & $\begin{array}{l}\text { En atención primaria, se sugiere implementar programas de cri- } \\
\text { bado del riesgo de suicidio en adolescentes con presencia de facto- } \\
\text { res riesgo de suicidio que puedan necesitar ser derivados a un ser- } \\
\text { vicio especializado. Como herramienta de cribado puede utilizarse } \\
\text { el Risk of Suicide Questionnaire (RSQ), por ser el único validado } \\
\text { en castellano. }\end{array}$ \\
\hline $\mathbf{C}$ & $\begin{array}{l}\text { En los servicios de urgencias, se recomienda llevar a cabo un cri- } \\
\text { bado del riesgo de suicidio en aquellos adolescentes con presencia } \\
\text { de factores de riesgo (trastornos depresivos, consumo de alcohol, } \\
\text { impulsividad...) o que presenten factores de estrés asociados (rup- } \\
\text { tura de relación, embarazo no deseado, exposición a casos de suici- } \\
\text { dios o intentos, etc...), que acudan incluso por otros motivos. }\end{array}$ \\
\hline
\end{tabular}

\subsection{Cribado de riesgo de suicidio en personas mayores}

\section{Resumen de la evidencia}

La implementación de programas comunitarios de cribado de la depresión y de seguimiento y educación para la salud en mayores de 60 años se asocia con una reducción del riesgo de suicidio, siendo mayor esta reducción cuando el seguimiento lo realiza un psiquiatra que cuando lo realiza un médico de atención primaria. La reducción del riesgo de suicidio se ha observado en mayor medida en varones asociado especialmente a la impulsividad $(203,204)$.

En el ámbito de la atención primaria podrían utilizarse como instrumentos de cribado en personas mayores, la 15-item Geriatric Depression Scale (GDS) y la 5-item GDS subscale (GDS-SI). Dichas escalas identifican adecuadamente aquellos pacientes con ideación suicida (205).
RS de estudios cuasiexperimentales $2+$

Estudio de pruebas diagnósticas $2+$ 


\section{Recomendaciones}

\begin{tabular}{|l|l|}
\hline \multirow{6}{*}{ C } & $\begin{array}{l}\text { En personas mayores se recomienda la implementación del cri- } \\
\text { bado de depresión, asociado a un adecuado seguimiento y a pro- } \\
\text { gramas de educación para la salud ya que esta medida disminuye } \\
\text { el riesgo de suicidio. Como instrumentos de cribado podrían utili- } \\
\text { zarse la 15-item Geriatric Depression Scale (GDS) y la 5-item GDS } \\
\text { subscale (GDS-SI). }\end{array}$ \\
\hline
\end{tabular}

\subsection{Cribado de riesgo de suicidio en centros penitenciarios}

\section{Resumen de la evidencia}

Respecto a la prevención del suicidio en centros penitenciarios, la OMS recomienda realizar un cribado de riesgo de suicidio en el momento del ingreso, preferiblemente por parte de personal sanitario cualificado, y realizar una observación post-ingreso y un adecuado seguimiento (206).

Una revisión sistemática en la que se evaluó la validez y fiabilidad de escalas de cribado y de medición del riesgo suicida en adultos sometidos a privación de libertad mostró que ninguna de ellas (Suicide Concerns

Opinión de expertos 4

RS de estudios de pruebas diagnósticas $2+$ for Offenders in Prision Environment (SCOPE), Suicide Checklist (SCL), Suicide Probability Scale y Suicide Potential Scale) tenía valor predictivo para detectar conductas suicidas futuras (207).

\section{Recomendaciones}

En centros penitenciarios se recomienda el cribado de riesgo de

D suicidio de los reclusos a su ingreso, con posterior observación y seguimiento. No se ha encontrado evidencia para recomendar ninguna escala de cribado en esta población. 


\subsection{Posibles efectos adversos del cribado}

\section{Preguntas para responder:}

- ¿Preguntar sobre el suicidio puede incrementar la conducta suicida en la población estudiada?

\section{Resumen de la evidencia}

Un ensayo controlado y aleatorizado no encontró ECA $1+$ evidencia de que los programas de cribado de suicidio tuviesen un efecto iatrogénico sobre las personas, como aumentar el malestar emocional o generar ideación suicida (208).

No se encontraron estudios que evaluasen los posibles daños sobre la salud de los programas de cribado rutinario de trastornos depresivos mayores en niños y adolescentes (de 7 a 18 años) (209).

Un estudio posterior realizado con preadolescentes y jóvenes de 12-20 años tampoco observó influencia de los ítems de ideación suicida sobre el estado de ánimo (210).

RS distintos tipos de estudios $2+, 3$

Estudio de pruebas diagnósticas $2+$ 


\section{La conducta suicida en grupos de riesgo}

\subsection{La conducta suicida en la infancia y la adolescencia}

Uno de los datos más llamativos a nivel internacional es el incremento de las tasas de suicidio entre jóvenes de 15-24 años, convirtiéndose en una de las tres causas más frecuentes de muerte en esta franja de edad. Por debajo de los 15 años el suicidio es relativamente poco frecuente (211), aunque cuando se produce tiene un gran impacto familiar y social.

España se sitúa entre los países de Europa con las tasas más bajas de suicidio en la infancia y adolescencia (211) y el número de casos ha permanecido estable en los últimos años (29). A pesar de esto, se ha observado una evolución ascendente global de las tasas de suicidio en jóvenes durante el periodo 1986-2001, mientras que la tendencia en la mayoría de los países es hacia el descenso o estabilización de las tasas (212).

\subsubsection{Factores de riesgo y protectores}

\section{Preguntas para responder:}

- ¿Cuáles son los factores de riesgo y protectores asociados con la conducta suicida en la infancia y la adolescencia?

\section{Resumen de la evidencia}

Los factores de riesgo que más se han asociado a la conducta suicida en la infancia y adolescencia son:

- Edad adolescente (144)

- Sexo masculino $(144,213,214)$

- Depresión (144, 215-217), abuso de sustancias y otros trastornos mentales $(144,218-224)$

- Factores psicológicos: variables cognitivas, impulsividad, inhibición emocional, dificultad en solución de problemas y patrón de apego inseguro en la infancia $(144,225-228)$
RS de distintos tipos de estudios $2++, 2+, 3$

Estudio de cohortes $2+$ 
- Intento de suicidio previo (144)

- Factores genéticos y biológicos $(144,229)$

- Factores familiares y contextuales: psicopatología de los padres (144), conflictos familiares o violencia doméstica $(144,230)$, acontecimientos vitales estresantes (144), bullying (144, 231-233) y ciberbullying $(231,234)$, exposición a casos de suicidio cercanos $(144,215)$, malas relaciones con el grupo de iguales $(215,235)$

- Orientación sexual: homosexualidad $(215,236)$, bisexualidad (237)

- Maltrato físico y abuso sexual (144, 238, 239).

Algunos factores de riesgo que pueden anteceder a

RS de distintos la conducta suicida en este grupo de edad y actuar como factores precipitantes son: tipos de estudios

- Acontecimientos vitales estresantes $(144,240)$

- Crisis con los padres/conflictos familiares (144, 240)

- Factores psicológicos/personales (240)

- Problemas con el grupo de iguales o de pares (144)

- Dificultades escolares (144).

Los factores protectores asociados a una reducción del riesgo de suicidio en la infancia y adolescencia son:

- Alta cohesión familiar y bajo nivel de conflictos $(144,146,241)$

$2++, 2+$

RS de distintos tipos de estudios $2++, 2+$

Estudio

- Habilidades de solución de problemas y estratecaso-control $2+$ gias de afrontamiento $(144,241)$

- Actitudes y valores positivos, en particular frente al suicidio $(144,241)$

- Sexo femenino $(78,241)$

- Creencias religiosas o espirituales (144)

- Habilidades para estructurar razones para vivir (241)

- Nivel educativo medio-alto (144) 
- Locus de control interno, alta autoestima, buen nivel de inteligencia y adecuados sistemas de apoyo y recursos (78).

\section{Recomendaciones}

\begin{tabular}{|l|l|}
\hline $\mathbf{D}^{\mathbf{G P C}}$ & $\begin{array}{l}\text { En niños y adolescentes con presencia de factores de riesgo de } \\
\text { conducta suicida se recomienda realizar una amplia evaluación } \\
\text { psicopatológica y social. La evaluación deberá seguir los mismos } \\
\text { principios que en los adultos aunque considerando los aspectos } \\
\text { psicopatológicos propios de la infancia y adolescencia y prestando } \\
\text { especial atención a la familia y su situación social. }\end{array}$ \\
\hline
\end{tabular}

8.1.2. Detección y valoración del riesgo suicida

\section{Preguntas para responder:}

- ¿Cómo se realiza la detección y la valoración del riesgo suicida en la infancia y la adolescencia?

\section{Resumen de la evidencia}

La evaluación del riesgo suicida en la infancia y la adolescencia requiere una amplia evaluación psicopatológica y social (144).

RS de distintos tipos de estudios 3

Esta evaluación debe ampliarse a las personas cercanas (padres o profesores), debido a la necesidad de contextualizar y a que la información aportada por los menores en ocasiones no coincide con la de los adultos (144).

No existe evidencia de que la evaluación de la presencia de ideación o conducta suicida aumente el riesgo de suicidio o produzca malestar en adolescentes. Al contrario, ayuda a mejorar los niveles de ansiedad y a que el adolescente se sienta mejor comprendido $(208,210)$.

La evaluación psicopatológica y social acompañada de una intervención cognitiva incrementó de forma significativa el compromiso con el tratamiento a los tres meses, en comparación con la evaluación habitual (242).

ECA $1+$

Serie de casos 3

ECA $1+$ 


\section{Recomendaciones}

\begin{tabular}{|c|l|}
\hline $\mathbf{C}$ & $\begin{array}{l}\text { En la evaluación del riesgo de suicidio en el niño o adolescente se } \\
\text { recomienda preguntar directamente sobre la presencia de ideación } \\
\text { suicida o planificación, conducta suicida pasada y otros factores de } \\
\text { riesgo, así como ampliar la evaluación a personas cercanas (padres } \\
\text { o profesores). }\end{array}$ \\
\hline
\end{tabular}

8.1.3. Instrumentos psicométricos

\section{Preguntas para responder:}

- ¿Existe algún instrumento psicométrico adecuado para la valoración del riesgo de suicidio en la infancia y en la adolescencia?

\section{Resumen de la evidencia}

Las escalas que han demostrado propiedades psicométricas aceptables para la valoración del riesgo de suicidio

Estudio caso-control $2+$ en la infancia y adolescencia son:

- Cuestionario de riesgo de suicidio (Risk of Suicide Questionaire, RSQ) (243)

- Escala de desesperanza de Beck (Beck Hopelessness Scale, BHS) $(49,244)$

- Escala de intencionalidad suicida (Suicidal Intent Scale, SIS) (245)

- Inventario de depresión de Beck (Beck Depression Inventory, BDI) (52)

- Kiddie Schedule for Affective Disorders and Schizophrenia for School-Age Children (K-SADS) (246)

-Children Depression Rating Scale, Revised (CDRS-R) (247). 


\section{Recomendaciones}

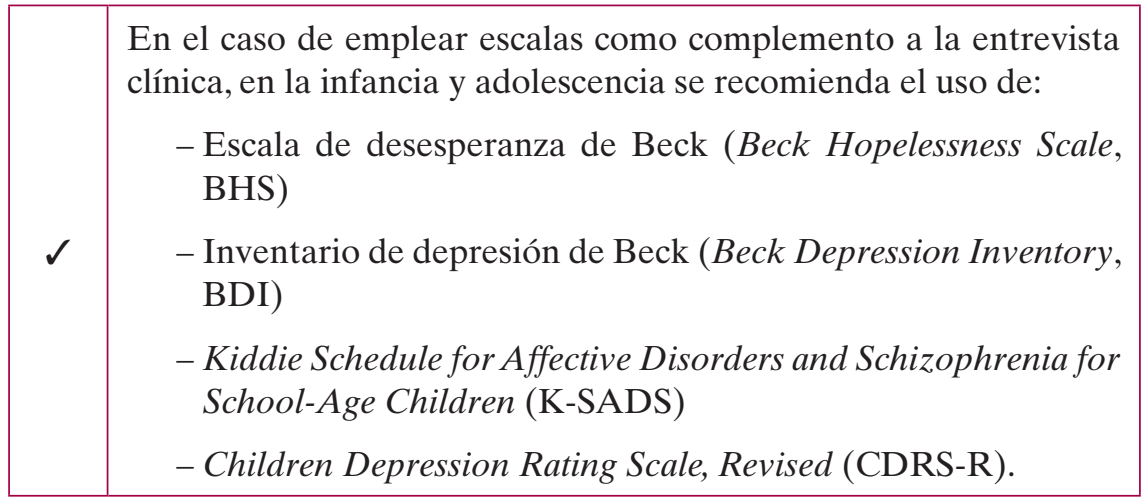

8.1.4. Intervenciones preventivas

\section{Preguntas para responder:}

- ¿Existe alguna intervención preventiva que reduzca el riesgo de suicidio en la infancia y en la adolescencia?

Intervenciones en el ámbito escolar

\section{Resumen de la evidencia}

En el ámbito escolar, los programas curriculares de ECA $1+$ prevención universal (3-5 días de clases) se asocian con aumentos significativos del nivel de conocimiento sobre el suicidio, mejores actitudes hacia el mismo y aprendizaje de conductas de autoayuda. El programa Signs of Suicide (SOS) se ha asociado con una disminución significativa de los intentos de suicidio. En él, los estudiantes recibieron información sobre la depresión y los signos de alarma de suicidio y sobre como reaccionar ante una persona con estos signos, y se les realizó un cribado de depresión (248).

El programa Personal Growth Class comparó la efectividad de tres intervenciones (un semestre de actiECA $1+$ vidades grupales, de valoración del estado de ánimo, comunicación, mejora de la autoestima y toma de decisiones y autocontrol; otro grupo que incluyó además un 
semestre de aplicación de las habilidades aprendidas; y un tercer grupo donde solo se realizó la evaluación). En los tres grupos se encontró una disminución significativa de conductas de riesgo de suicidio, depresión, desesperanza, estrés, agresividad y un aumento de la autoestima y la red social (249).

El programa Counselors Care comparó una intervención basada en 12 sesiones de entrenamiento de habilidades frente a un grupo de tratamiento habitual. No se encontraron diferencias entre los grupos en disminución de la conducta suicida, agresividad o estrés familiar. En el grupo de entrenamiento de habilidades se encontró un aumento significativo del control personal, habilidades de solución de problemas y apoyo familiar percibido (250).

En pacientes de alto riesgo de suicidio, la terapia interpersonal (10/12 sesiones) fue más efectiva que el tratamiento habitual (apoyo y psicoeducación) en la disminución de los niveles de depresión, ideación suicida, ansiedad y desesperanza (95).

En la actualidad no existe evidencia sobre la efectividad del cribado en el ámbito escolar que cuenta, además, con una baja aceptabilidad entre los profesionales ya que suele percibirse como una técnica invasiva $(196,251)$.

Los estudios de programas de figuras clave en el ámbito escolar han puesto de manifiesto un incremento en los conocimientos y actitudes hacia el suicidio y de las habilidades en la identificación de alumnos con riesgo de suicidio (251).

Los programas dirigidos a compañeros (peer helpers) tampoco han sido evaluados de manera adecuada, por lo que no existe evidencia suficiente de su efectividad ni de sus posibles efectos adversos (251).
ECA 1+

ECA $1+$

RS de distintos tipos de estudios $2++, 3$

RS de distintos tipos de estudios $1+, 3$ 


\section{Recomendaciones}

\begin{tabular}{|c|l|}
\hline C & $\begin{array}{l}\text { Dentro de la formación escolar se recomienda la implementación } \\
\text { de programas de prevención universal del suicidio, como por ejem- } \\
\text { plo el programa Signs of Suicide, una vez adaptado y contextuali- } \\
\text { zado al entorno sociocultural. }\end{array}$ \\
\hline C & $\begin{array}{l}\text { Se recomienda la implementación de programas de prevención } \\
\text { selectiva dirigidos a adolescentes con riesgo de suicidio, como el } \\
\text { Personal Growth Class o el Counselors Care, una vez adaptados y } \\
\text { contextualizados. }\end{array}$ \\
\hline C & $\begin{array}{l}\text { No existen datos suficientes que nos permitan recomendar el uso } \\
\text { de herramientas o programas de cribado de suicidio en el ámbito } \\
\text { escolar. }\end{array}$ \\
\hline D & $\begin{array}{l}\text { Se recomienda la implementación de programas de entrenamiento de } \\
\text { figuras clave (gatekeeper) para el personal de los centros educativos, } \\
\text { orientados a la identificación de alumnos con riesgo de suicidio. }\end{array}$ \\
\hline
\end{tabular}

Prevención en niños y adolescentes con trastornos mentales

\section{Resumen de la evidencia}

Algunas áreas de mejora en el manejo del suicidio en la infancia y la adolescencia son (251):

- Realizar una evaluación rigurosa del riesgo de RS de distintos tipos de estudios 3 suicidio de cara a valorar la estrategia de tratamiento más beneficiosa

- Prestar especial atención a la presencia de trastornos comórbidos

- Revisión regular de los síntomas de depresión, ideación suicida y presencia de posibles eventos vitales estresantes, ya que el riesgo de suicidio puede cambiar a lo largo del tratamiento

- Coordinación entre los diferentes niveles asistenciales y profesionales, de cara a realizar un adecuado seguimiento. 


\section{Recomendaciones}

\begin{tabular}{|l|l|}
\hline \multirow{1}{*}{ D } & $\begin{array}{c}\text { De cara a la prevención de la conducta suicida en niños y adoles- } \\
\text { centes con trastornos mentales se recomienda: } \\
\text { - Realizar una evaluación rigurosa del riesgo de suicidio de cara } \\
\text { a valorar la estrategia de tratamiento más beneficiosa en cada } \\
\text { caso } \\
\text { - Prestar especial atención a la presencia de trastornos comór- } \\
\text { bidos } \\
\text { - Valorar de forma periódica los síntomas de depresión, idea- } \\
\text { ción suicida y la presencia de posibles eventos vitales estre- } \\
\text { santes } \\
\text { - Favorecer la coordinación entre los diferentes profesionales y } \\
\text { niveles asistenciales, para realizar un adecuado seguimiento. }\end{array}$ \\
$\checkmark$ & $\begin{array}{l}\text { Se recomienda valorar como opciones de tratamiento para la con- } \\
\text { ducta suicida en la infancia y la adolescencia el tratamiento psico- } \\
\text { terapéutico, farmacológico, el tratamiento combinado y en ocasio- } \\
\text { nes excepcionales, la terapia electroconvulsiva. }\end{array}$ \\
\hline
\end{tabular}

Otras estrategias de prevención de la conducta suicida

\section{Resumen de la evidencia}

No existe evidencia de eficacia de las líneas telefónicas de ayuda en la prevención del suicidio en la infancia y la adolescencia $(251,252)$.

La mayoría de estudios sobre el control de acceso a métodos de suicidio se ha realizado en EE.UU, en donde la restricción del acceso a armas ha disminuido las tasas de suicidio, sobre todo en adolescentes y en adultos jóvenes $(251,253)$.

El impacto de los medios de comunicación sobre la conducta suicida parece aumentar en la adolescencia, y depende del tratamiento que se le de a la información sobre los suicidios $(161,254)$.

Existe evidencia de una relación entre las visitas a sitios web y chats donde se aporta información detallada sobre métodos de suicidio y el aumento de suicidios en personas jóvenes $(161,254)$.
RS de distintos tipos de estudios 3

RS de distintos tipos de estudios $2+, 3$

Serie de casos 3

Serie de casos 3 
Las estrategias de prevención del suicidio pasan Serie de casos 3 necesariamente por la regulación de los servicios proveedores de Internet y el uso de programas de filtro por parte de los padres $(161,254)$.

Es importante disponer en Internet de información Opinión de basada en la evidencia científica sobre la prevención del suicidio, específicamente dirigida a los adolescentes y sus familiares (255).

\section{Recomendaciones}

\begin{tabular}{|c|l|}
\hline$\checkmark$ & $\begin{array}{l}\text { Se recomienda dar pautas a los padres y/o cuidadores sobre el con- } \\
\text { trol del acceso directo por parte de niños y adolescentes a fárma- } \\
\text { cos, armas de fuego u otros medios potencialmente letales. }\end{array}$ \\
\hline C & $\begin{array}{l}\text { En la evaluación del riesgo de suicidio se recomienda que los clíni- } \\
\text { cos tengan en cuenta el uso patológico de Internet o su uso inade- } \\
\text { cuado, especialmente en adolescentes y adultos jóvenes. }\end{array}$ \\
\hline D & $\begin{array}{l}\text { Se recomienda ofrecer en Internet información de fácil acceso } \\
\text { sobre la conducta suicida y su prevención elaborada específica- } \\
\text { mente para adolescentes y sus familiares. }\end{array}$ \\
\hline
\end{tabular}

\subsection{La conducta suicida en personas mayores}

La prevención del suicidio en los mayores de 65 años es una prioridad a nivel internacional $(2,60,256)$ ya que, al igual que los adolescentes y adultos jóvenes, representan un grupo de especial riesgo de suicidio. En la mayoría de los países las tasas aumentan progresivamente con la edad, tanto en hombres como en mujeres, aunque existen algunos países con patrones diferentes (257).

España presenta unas tasas de suicidio que se incrementan con la edad a partir de los 65 años, sobre todo en los hombres, llegando a los 49,18/100 000 en el grupo de 90 a 94 años. En mujeres, las tasas más altas se encontraron en el grupo de 85-89 años, donde fueron de 7,29/100 000 (INE, 2009) (258). 


\subsubsection{Factores de riesgo y protectores}

\section{Preguntas para responder:}

- ¿Cuáles son los factores de riesgo y protectores asociados con la conducta suicida en personas mayores?

\section{Resumen de la evidencia}

Los factores de riesgo que más se asocian a la conducta suicida en mayores son:

- Intentos de suicidio previos e ideación suicida (47, 259-262)

- Presencia de trastorno mental (sobre todo depresión) y adicciones $(47,60,145,256,259-266)$

- Presencia de trastornos y rasgos de la personalidad específicos (especialmente del grupo A y B) $(47,261)$

- Enfermedad física crónica (47, 60, 256, 259, 261-263, 267-271)

- Aislamiento social y eventos vitales estresantes $(47,60,256,259,261-263,267,272)$

- Déficit funcional (47).

Los factores protectores asociados a la reducción del riesgo de suicidio en mayores son (47):

- Hábitos de vida saludables

- Contacto con la familia y amigos

- No consumo excesivo de alcohol

- Mantenerse activo

- Prácticas religiosas y sentimiento de tener un propósito en la vida

- Rasgos de la personalidad como extraversión, apertura a la experiencia y responsabilidad.

Los factores protectores que se asocian con una disminución de la ideación suicida son (145):
$\mathrm{RS}$ de distintos tipos de estudios $2++, 2+$

Estudio caso-control 2+ Serie de casos 3

$\mathrm{RS}$ de distintos tipos de estudios $2++$

Serie de casos 3 
- Locus de control interno

- Percepción de autoeficacia

- Satisfacción con la vida.

Otros factores protectores que podrían actuar de

Serie de casos 3 forma indirecta, aumentando el bienestar psicológico son (47):

- Percepción del significado de la vida y satisfacción con la misma

- Habilidades de afrontamiento

- Orientación al futuro y espiritualidad.

8.2.2. Detección y valoración del riesgo suicida

\section{Preguntas para responder:}

- ¿Cómo se realiza la detección y valoración del riesgo suicida en mayores?

\section{Resumen de la evidencia}

La evaluación del riesgo de suicidio en personas mayores RS de distintos requiere especial atención de las circunstancias y del entorno de la persona, sus expectativas, calidad de vida y tipos de estudios presencia de trastorno mental o enfermedad somática (47).

\section{Recomendaciones}

\begin{tabular}{l|l} 
D & $\begin{array}{l}\text { En la evaluación del riesgo de suicidio en mayores se recomienda } \\
\text { valorar especialmente la presencia de depresión, otras enfermeda- } \\
\text { des, abuso de alcohol o de alguna medicación. }\end{array}$
\end{tabular} 


\begin{tabular}{|c|c|}
\hline \multirow{4}{*}{ D } & $\begin{array}{l}\text { Se recomienda también valorar el entorno, la calidad de vida y las } \\
\text { expectativas de la persona: }\end{array}$ \\
\hline & $\begin{array}{l}\text { - Con quién vive, presencia de apoyo y relaciones sociofami- } \\
\text { liares }\end{array}$ \\
\hline & $\begin{array}{l}\text { - Capacidad de autocuidado y desarrollo de actividades de la } \\
\text { vida diaria }\end{array}$ \\
\hline & $\begin{array}{l}\text { - Presencia de desesperanza, actitud del paciente hacia la vida } \\
\text { y la muerte. }\end{array}$ \\
\hline
\end{tabular}

\subsubsection{Instrumentos psicométricos}

\section{Preguntas para responder:}

- ¿Existe algún instrumento psicométrico adecuado para la valoración del riesgo de suicidio en personas mayores?

\section{Resumen de la evidencia}

Las escalas con mejores propiedades psicométricas para RS de distintos la valoración del riesgo de suicidio en personas mayores son:

- Escala de ideación suicida de Beck (Scale for tipos de estudios $2++$ Suicide Ideation, SIS) (50)

- Escala de depresión geriátrica (Geriatric Depression Scale, GDS) (273)

- Geriatric Hopelessness Scale (GHS) (274)

- Inventario de razones para vivir para mayores (Reasons for Living Scale-Older Adult Version, RFL-OA) (275)

- Índice breve de bienestar de la OMS (Who-Five Well-Being Index, WHO-5-J) (276)

- Brief Symptom Rating Scale (BSRS-5) (277). 


\section{Recomendaciones}

\begin{tabular}{|c|l|}
\hline C & $\begin{array}{l}\text { En el caso de emplear escalas como complemento a la entrevista } \\
\text { clínica en la persona mayor, se recomienda la utilización de esca- } \\
\text { las validadas, como la Escala de depresión geriátrica (Geriatric } \\
\text { Depression Scale, GDS). }\end{array}$ \\
\hline
\end{tabular}

\subsubsection{Intervenciones preventivas}

\section{Preguntas para responder:}

- ¿Existe alguna intervención preventiva que reduzca el riesgo de suicidio en personas mayores?

\section{Resumen de la evidencia}

Medidas de prevención universal

Formación de los profesionales y medidas educativas

La formación de los profesionales implicados en el manejo de personas mayores es esencial. Algunas áreas son (47):

- Identificación de los factores de riesgo y de protección específicos del suicidio

- Evaluación y manejo de instrumentos psicométricos de valoración del riesgo de suicidio en personas mayores

- Aptitudes para la intervención en situaciones de riesgo de suicidio

- Manejo del riesgo de suicidio y su seguimiento.

El contacto con los profesionales sanitarios puede comunicación de ideación o intencionalidad suicidas y posibilitar el establecimiento de las medidas oportunas (278).

Con la finalidad de aumentar la concienciación y reducir el estigma del suicidio, es importante orientar la educación a las personas mayores, así como a sus cuida-
Estudio cualitativo Q

RS de distintos tipos de estudios 3

RS de distintos tipos de estudios 3 
dores y a la población general, incluidos los medios de comunicación (47).

\section{Restricción del acceso a medios}

Uno de los métodos de intento de suicidio más frecuente en mayores es la intoxicación medicamentosa. Otros métodos de suicidio utilizados son el ahorcamiento, la precipitación y el ahogamiento (279-281).

El control del acceso a los medios potencialmente letales es fundamental en la prevención del suicidio. Los médicos podrían limitar el riesgo de sobredosis prescribiendo envases de pequeñas cantidades de fármacos y haciendo un seguimiento de su uso (147).

\section{Prevención selectiva}

Lineas telefónicas de apoyo

El mantenimiento de contacto telefónico dos veces por semana y el servicio telefónico de urgencias las 24 horas se asoció con una disminución significativa de la tasa de suicidios en mujeres, no así en en hombres (282).

\section{Intervenciones comunitarias}

Una intervención comunitaria basada en actividades grupales, psicoeducación y evaluación de la depresión obtuvo, tras su implementación, una reducción significativa del $76 \%$, respecto de un área de referencia, en las tasas de suicidio de mujeres mayores de 65 años (283).

\section{Promoción de la resiliencia}

La TIP adaptada a pacientes mayores (16 sesiones de frecuencia semanal) consiguió una disminución significativa de las ideas de muerte, de ideación suicida y de la gravedad de los síntomas de depresión (152).

\section{Prevención indicada}

\section{Cribado de depresión y seguimiento}

Las intervenciones comunitarias de cribado de la depresión (evaluación + seguimiento por parte de psiquiatra o médico de atención primaria) redujeron las tasas de suicidio de forma significativa. El seguimiento realizado
Serie de casos 3

RS de distintos tipos de estudios 3

Estudio caso-control 2+

Estudio caso-control 2+

Serie de casos 3

Metanálisis 2++ Estudio de cohortes 2++ 
por el psiquiatra obtuvo mejores resultados en la reducción del riesgo de suicidio, sobre todo en hombres $(203,204)$.

\section{Cuidados compartidos (Collaborative Care)}

Un estudio realizó una intervención de cuidados compartidos en mayores con depresión o distimia basada en la incorporación de profesionales de enfermería y psicólogos quienes realizaron su evaluación y psicoeducación. Las opciones de tratamiento fueron antidepresivos o terapia de resolución de problemas (4-8 sesiones), además de un seguimiento cercano (contacto telefónico o entrevista personal). En comparación con el tratamiento habitual (antidepresivos, counselling y derivación a salud mental), se obtuvo una reducción significativa de la ideación suicida a los 6, 12, 18 y 24 meses $(84,284)$.

Un estudio realizado en mayores con depresión e ideación suicida comparó la prescripción de ISRS (citalopram) y/o TIP con tratamiento habitual, logrando una reducción significativa de la ideación suicida a los 12 meses $(94,285)$.

\section{Programas clínicos de prevención}

Un programa de prevención basado en el tratamiento combinado de la depresión, entrenamiento de figuras clave en la detección del riesgo (gatekeeper) y seguimiento tras el intento de suicidio con un modelo psiquiátrico orientado a la comunidad, obtuvo una reducción significativa de la tasa de suicidios a los dos años, aunque la reducción de los reintentos en el mismo plazo de tiempo no fue significativa (286).
ECA 1+

Serie de casos 3

\section{Recomendaciones}

\begin{tabular}{|c|l|}
\hline D & $\begin{array}{l}\text { Se recomienda orientar la educación sobre el suicidio a los propios } \\
\text { mayores, así como a sus cuidadores y a la población general, inclui- } \\
\text { dos los medios de comunicación, con la finalidad de aumentar la } \\
\text { concienciación y reducir el estigma. }\end{array}$ \\
\hline D & $\begin{array}{l}\text { En pacientes con factores de riesgo de suicidio se recomienda la } \\
\text { prescripción de fármacos en el envase de menor cantidad y hacer } \\
\text { un seguimiento de su uso por parte del médico. }\end{array}$ \\
\hline
\end{tabular}




\begin{tabular}{|c|l|}
\hline $\mathbf{C}$ & $\begin{array}{l}\text { En mayores con riesgo de suicidio se recomienda la realización de } \\
\text { intervenciones comunitarias de apoyo: líneas telefónicas, activida- } \\
\text { des grupales y psicoeducación. }\end{array}$ \\
\hline $\mathbf{D}^{\mathbf{G P C}}$ & $\begin{array}{l}\text { Para el manejo y tratamiento de la conducta suicida en mayores, } \\
\text { en líneas generales se seguirán las mismas recomendaciones que } \\
\text { para los adultos. }\end{array}$ \\
\hline
\end{tabular}

\subsection{Prevención de la conducta suicida en otros grupos de riesgo}

\subsubsection{Pacientes con gran dependencia o enfermedad somática grave}

\section{Preguntas para responder:}

- ¿Qué medidas de prevención se han mostrado efectivas para evitar la conducta suicida en pacientes con gran dependencia, enfermedad somática grave o discapacidad?

\section{Resumen de la evidencia}

Los estudios muestran una asociación entre la presencia de enfermedades crónicas con dolor y el riesgo de conducta suicida. La discapacidad física y el dolor pueden presentar asociación con ideación suicida sin trastorno depresivo asociado $(73,287,288)$.

La evidencia indica que los pacientes con dolor crónico presentan mayor prevalencia de suicidio que la población general. Los factores cuya presencia aumentan el riesgo son su localización, el tipo y la duración del dolor y/o la presencia de insomnio comórbido (289).

Se han encontrado distintos estudios sobre la relación existente entre las personas con discapacidad física y la presencia de conducta suicida, que es mayor cuando presentan síntomas depresivos comórbidos (290-292).

Los estudios muestran la necesidad de un seguimiento y evaluación por parte del médico de las personas que padecen una enfermedad crónica (293-295), dolor (289, 296-298), discapacidad física (290, 299-303), o que presentan un mal pronóstico $(288,304)$.
RS de distintos tipos de estudios $2++$

Serie de casos 3

RS de distintos tipos de estudios $2+$

Serie de casos 3 Opinión de expertos 4

Serie de casos 3 
En pacientes con enfermedades graves, existe un mayor riesgo de conducta suicida en el momento del diagnóstico, en el primer año de la enfermedad y cuando está en estado avanzado o tiene un mal pronóstico $(305,306)$.

Serie de casos 3

Opinión de

expertos 4

\section{Recomendaciones}

\begin{tabular}{|c|c|}
\hline$\checkmark$ & $\begin{array}{l}\text { En personas con enfermedad crónica y dolor o discapacidad física } \\
\text { grave se recomienda la realización de programas preventivos y de } \\
\text { evaluaciones específicas de riesgo de suicidio. }\end{array}$ \\
\hline$\checkmark$ & $\begin{array}{l}\text { Se recomienda realizar un seguimiento especial de aquellos pacien- } \\
\text { tes con presencia de factores de riesgo de suicidio, en el momento de } \\
\text { ser diagnosticados de una enfermedad grave, cuando existe un mal } \\
\text { pronóstico de la misma o cuando el estadio evolutivo es avanzado. }\end{array}$ \\
\hline \multirow{12}{*}{$\checkmark$} & $\begin{array}{l}\text { Las estrategias generales para el manejo de pacientes con } \\
\text { enfermedad crónica, discapacidad física o dolor crónico se deben } \\
\text { llevar a cabo en tres niveles diferentes: }\end{array}$ \\
\hline & - Universal: \\
\hline & - Evaluar la desesperanza y la ideación suicida \\
\hline & $\begin{array}{l}\text { - Monitorizar los signos de advertencia que pueden } \\
\text { aumentar el nivel de riesgo como presencia de síntomas } \\
\text { depresivos, abuso de sustancias, antecedentes de conducta } \\
\text { suicida... }\end{array}$ \\
\hline & $\begin{array}{l}\text { - Reconocer que las personas pueden estar en riesgo sin } \\
\text { importar el tiempo después de la lesión }\end{array}$ \\
\hline & $\begin{array}{l}\text { - Facilitar a los pacientes la disponibilidad de apoyo a largo } \\
\text { plazo. }\end{array}$ \\
\hline & - Selectivo: \\
\hline & $\begin{array}{l}\text { - Realizar seguimiento de las personas con patologías } \\
\text { psiquiátricas comórbidas. }\end{array}$ \\
\hline & - Indicado (presencia de ideación y/o conducta suicida): \\
\hline & $\begin{array}{l}\text { - Reducir el acceso a métodos potencialmente letales, } \\
\text { contemplando la posibilidad de más de un método }\end{array}$ \\
\hline & $\begin{array}{l}\text { - Proporcionar tratamiento, apoyo y seguimiento, por lo } \\
\text { menos de } 12 \text { meses después de un intento de suicidio }\end{array}$ \\
\hline & $\begin{array}{l}\text { - Favorecer la participación de amigos y familiares en la } \\
\text { planificación y desarrollo del tratamiento. }\end{array}$ \\
\hline
\end{tabular}




\subsubsection{Cuidadores no profesionales de enfermos}

\section{Preguntas para responder:}

- ¿Qué medidas de prevención del suicidio deberían llevarse a cabo en cuidadores no profesionales de enfermos con gran dependencia, enfermedad somática grave o discapacidad?

\section{Resumen de la evidencia}

La enfermedad crónica y la dependencia no solo afectan Opinión de al propio paciente sino que también repercuten en la expertos 4 familia y en especial en la persona que asume el rol de cuidador (307).

Existe evidencia sobre distintas intervenciones RS de distintos dirigidas a disminuir la sintomatología negativa del cuidador: la participación activa basada en TCC fue más eficaz que la basada solo en adquisición de conocimientos (308); otra intervención eficaz fue en formato grupal con técnicas de resolución de problemas y relajación (309).

Se ha encontrado poca información y de escasa evidencia sobre los factores de riesgo para el homicidiosuicidio en cuidadores; sin embargo, parecen tener peso tipos de estudios $2+$

Estudio casocontrol 2+ los sentimientos de impotencia, desesperanza y agotamiento, unido a la imposibilidad de mejorar la situación $(33,310)$.

\section{Recomendaciones}

\begin{tabular}{|c|l|}
\hline D & $\begin{array}{l}\text { Se recomienda una valoración del riesgo de suicidio en cuidadores } \\
\text { con síntomas de depresión. }\end{array}$ \\
\hline C & $\begin{array}{l}\text { En cuidadores con ansiedad, depresión y sobrecarga se recomienda } \\
\text { la realización de intervenciones de corte cognitivo-conductual con } \\
\text { el fin de disminuir el riesgo de suicidio. }\end{array}$ \\
\hline
\end{tabular}


8.3.3. En situaciones laborales consideradas de riesgo

\section{Preguntas para responder:}

- ¿Qué medidas de prevención del suicidio deberían adoptarse en diferentes situaciones laborales consideradas de riesgo?

\section{Resumen de la evidencia}

Varios estudios abordan la relación entre el tipo de trabajo y el suicidio, aunque existen profesiones más estudiadas que otras. Los profesionales con fácil acceso a métodos letales, estrés, exceso de horas de trabajo o rechazo a pedir ayuda, presentan mayor riesgo de suicidio (311-322).

Los programas de prevención del suicidio en centros de trabajo deben integrar aspectos sobre educación y formación a los trabajadores, servicios de apoyo, cooperación entre distintos estamentos, programas de mejora de gestión de personal y evaluación de los programas $(319,321)$.

Existe evidencia sobre la relación entre el desempleo (323), las dificultades financieras $(324,325)$ o el aislamiento social y el aumento de riesgo de suicidio $(33,324)$.

Son también estrategias de prevención de la conducta suicida, determinar la situación laboral de las personas como parte del proceso de valoración, proporcionar apoyo social a los desempleados y aumentar el grado de integración social $(311,324)$.

Parece existir una asociación entre ideación suicida y acoso psicológico en el trabajo (mobbing). Además, los trabajadores que sufren mobbing suelen presentar somatizaciones, como dolores de cabeza, taquicardias, trastornos del sueño o gastrointestinales (326-328). El mobbing puede también causar conflictos en la vida cotidiana fuera del trabajo (329-331).
RS de estudios

$2+$

Estudio caso-control $2+$

Serie de casos 3

RS de estudios $2+$

Estudio cuasiexperimental $2+$

$\mathrm{RS}$ de estudios 2+

Estudio caso-control 2+

Opinión de expertos 4

Serie de casos 3

Estudio trasversal 3 
El acoso sexual en el trabajo se ha asociado con Serie de casos 3 cambios de comportamiento, enfermedad física, abuso de sustancias, abandono del trabajo, síntomas depresivos, de ansiedad y conducta suicida $(332,333)$.

Opinión de

expertos 4

\section{Recomendaciones}

\begin{tabular}{|c|l|}
\hline C & $\begin{array}{l}\text { En el ámbito laboral se recomienda realizar programas de promo- } \\
\text { ción de la salud que ofrezcan apoyo y asesoramiento a los trabaja- } \\
\text { dores, así como aumentar el grado de integración y la accesibilidad } \\
\text { a los servicios de prevención. }\end{array}$ \\
\hline D & $\begin{array}{l}\text { Se recomienda evaluar la situación laboral en personas en riesgo de } \\
\text { suicidio. }\end{array}$ \\
\hline
\end{tabular}

\subsubsection{Personas que sufren violencia doméstica}

\section{Preguntas para responder:}

- ¿Qué medidas de prevención podrían recomendarse para evitar la conducta suicida en personas que sufren violencia doméstica?

\section{Resumen de la evidencia}

Existe poca información y de baja calidad sobre la asociación de ideación y conducta suicidas en personas que sufren violencia doméstica. Sin embargo, las tasas de ideación e intentos de suicidio son 4-8 veces mayores que en población general $(33,60)$.

Los estudios encontrados se centran en su mayoría en mujeres $(334,335)$ y adolescentes $(336)$. Las personas que sufren este tipo de violencia pueden presentar ideación suicida dentro de un contexto de estrés postraumático o depresión. La asociación encontrada entre violencia doméstica y conducta suicida hace necesario elaborar programas de prevención y de especial seguimiento de todas las víctimas.
RS de distintos tipos de estudios 3

Metanálisis 2++ Estudio casocontrol $2+$ Serie de casos 3 


\section{Recomendaciones}

\begin{tabular}{|c|l|}
\hline C & $\begin{array}{l}\text { Se recomienda realizar programas preventivos de suicidio que } \\
\text { conlleven una especial atención a personas víctimas de la violencia } \\
\text { doméstica. }\end{array}$ \\
\hline
\end{tabular}

\subsubsection{Población penitenciaria}

\section{Preguntas para responder:}

- ¿Qué medidas de prevención de la conducta suicida se pueden recomendar en la población penitenciaria?

\section{Resumen de la evidencia}

Las personas en prisión presentan entre 6 y 7 veces mayor riesgo de suicidio que la población general. Opinión de expertos 4 Este aumento se debe, entre otros factores, a un mayor porcentaje en la población penitenciaria de personas con trastornos mentales, abuso de sustancias o aislamiento social (130).

El riesgo de suicidio en la población reclusa aumenta justo después del ingreso, en jóvenes tras su primer delito, en personas con abuso de sustancias y cuando existen problemas legales o familiares $(33,130,256)$.

Los programas preventivos pueden disminuir de forma significativa el número de suicidios en la prisión. Todos los programas presentan los siguientes puntos en común: formación del personal, identifica-

Opinión de expertos 4

Serie de casos 3

Opinión de expertos 4

\section{Recomendaciones}

\begin{tabular}{|l|l|} 
D & $\begin{array}{l}\text { Se recomienda realizar programas preventivos de suicidio en } \\
\text { centros penitenciarios que incluya tanto a funcionarios como a } \\
\text { reclusos. }\end{array}$ \\
\hline
\end{tabular}




\section{Intervenciones en familiares, allegados y profesionales después de un suicidio}

El término superviviente de un suicidio se emplea para referirse a los allegados de una persona que ha realizado un suicidio y, aunque tradicionalmente el concepto se ha reservado para la familia, en la actualidad se ha extendido también a los allegados no familiares (pareja, amigos, compañeros de trabajo o de clase y vecinos) (339).

El fallecimiento a causa de un suicidio supone una situación de gran impacto vital en sus familiares y allegados quienes, en comparación con la población general, además de un mayor riesgo de trastornos como la depresión o el trastorno por estrés postraumático (340) presentan un incremento de entre dos y diez veces del riesgo de suicidio (341).

\subsection{Necesidades y expectativas de la familia y allegados tras un suicidio}

Existen algunas diferencias entre el duelo tras un suicidio y el duelo tras otro tipo de fallecimiento, que pueden complicar el proceso o prolongarlo en el tiempo y que sitúan a los allegados en situación de riesgo. Entre los factores subyacentes que podrían explicar esta diferencia destacan el estigma y las implicaciones emocionales que el suicidio provoca en las personas cercanas, como los sentimientos de culpa y la búsqueda de una explicación al suicidio (340, 342).

\section{Preguntas para responder:}

- ¿Cuáles son las necesidades y expectativas de los allegados tras un suicidio?

\section{Resumen de la evidencia}

Los allegados de las personas fallecidas a causa de un RS de distintos suicidio demandan mayor número de intervenciones de apoyo basadas en figuras clave, apoyo social y ayuda tipos de estudios profesional. En cuanto a la ayuda profesional, se consi- 
dera crucial contar con la información necesaria en estas circunstancias, poder elegir entre diferentes modalidades de ayuda, tratamientos específicos en la infancia y adolescencia y seguimiento a largo plazo (339).

Los padres en situación de duelo por un hijo fallecido a causa de un suicidio presentan un conflicto entre la necesidad de hablar del suicidio libremente y el estigma social percibido (343).

Para los adolescentes que han superado el suicidio de una persona cercana, una buena atención sanitaria incluiría: atención automática tras el suicidio, adaptada a sus necesidades y prolongada en el tiempo. También es esencial que la atención sea flexible, empática y con la posiblidad de participar en sesiones individuales (344).

Los aspectos clave a considerar de cara al desarrollo de programas de intervención tras un suicidio son: atender a las diferentes realidades culturales, tener en cuenta el efecto del estigma y considerar las necesidades y expectativas de los allegados (339).

Estudio cualitativo Q

Estudio cualitativo Q

Opinión de expertos 4

\section{Recomendaciones}

\begin{tabular}{|c|l|}
\hline \multirow{5}{*}{ D } & $\begin{array}{l}\text { A la hora de poner en marcha cualquier intervención tras un suici- } \\
\text { dio dirigida a los familiares y allegados se recomienda: } \\
\text { - Contextualizar la estrategia de intervención }\end{array}$ \\
& $\begin{array}{l}\text { - Tener en cuenta el efecto del estigma en los allegados } \\
\text { - Considerar las necesidades y expectativas de las personas } \\
\text { implicadas. }\end{array}$ \\
\hline$\checkmark$ & $\begin{array}{l}\text { Tan pronto como sea posible después de un suicidio, se recomienda } \\
\text { ofrecer una atención flexible y adaptada a las necesidades de cada } \\
\text { persona. }\end{array}$ \\
\hline
\end{tabular}




\subsection{Intervenciones preventivas en familiares y allegados}

La posvención o intervenciones tras un suicidio, son aquellas actividades desarrolladas con los allegados con la finalidad de prevenir posibles efectos negativos, incluyendo el mismo suicidio (345). Son intervenciones muy importantes debido a que, por un lado, se proporciona el apoyo necesario en una situación de duelo que puede devenir patológica (por la presencia de factores como el estigma asociado, el riesgo de depresión o trastorno de estrés postraumático, sentimientos de abandono y búsqueda de una respuesta al suicidio) y, por otro, son una intervención de prevención del suicidio en sí misma (341).

\section{Preguntas para responder:}

- Tras el suicidio de una persona, ¿existe alguna intervención preventiva que reduzca el impacto en sus familiares y allegados?

\section{Resumen de la evidencia}

Intervenciones en la familia

La posvención se debe realizar desde las fases tempranas Opinión de del duelo, y el trabajo psicoterapéutico con los familiares debe incluir los siguientes aspectos (141):

- Confrontar con la realidad la culpabilidad hacia uno mismo y hacia los otros, y el sentimiento de abandono

- Ayudar a corregir las negaciones y distorsiones

- Explorar las fantasías de los familiares respecto a cómo les afectará la muerte en el futuro

- Trabajar el enfado y la rabia que este tipo de muerte genera

Las intervenciones familiares en formato grupal obtuvieron mejorías significativas en diferentes variables como: síntomas de depresión, ansiedad, factores psicológicos, reducción en distrés a corto plazo, evolución del duelo y satisfacción con la participación en la terapia (346).

RS de distintos tipos de estudios $1+, 2+, 3$ 
Las intervenciones que se realizaron de forma inmediata tras un suicidio se relacionaron con un aumento significativo de conductas de búsqueda de autoayuda en los allegados y mayor participación en terapias de apoyo (346).

En un ECA en el que se comparó la TCC familiar (4 sesiones realizadas en los 3-6 meses tras el suicidio) con el tratamiento habitual, no se encontraron diferencias significativas entre los grupos en las reacciones complicadas de duelo, ni en la presencia de ideación suicida o depresión. Sin embargo, el grupo que recibió la TCC mostró menos reacciones desadaptativas y menor percepción de culpabilidad por la conducta suicida de su familiar. También se encontró que las personas con ideación suicida se beneficiaron más del tratamiento y que la TCC redujo el riesgo de duelo patológico en estas personas (347).

\section{Recomendaciones}

RS de distintos tipos de estudios $2+$

\section{ECA 1+}

\begin{tabular}{|c|l|}
\hline D & $\begin{array}{l}\text { Tras un suicidio, se recomienda que los profesionales sanitarios } \\
\text { ofrezcan apoyo a los allegados y les aporten toda la información } \\
\text { necesaria sobre los recursos de ayuda disponibles, incluyendo tra- } \\
\text { tamientos específicos y la posibilidad de realizar un seguimiento a } \\
\text { largo plazo. }\end{array}$ \\
\hline B & $\begin{array}{l}\text { Tras un suicidio se recomienda la terapia cognitivo-conductual en } \\
\text { aquellos familiares y allegados con presencia de ideación suicida, } \\
\text { ya que reduce el riesgo de duelo patológico en estas personas. }\end{array}$ \\
\hline
\end{tabular}

Intervenciones en el ámbito escolar tras un suicidio

No existe evidencia concluyente sobre las intervenciones tras un suicidio dirigidas a alumnos en el ámbito escolar $(346,347)$.

Los programas de entrenamiento de profesionales en el ámbito escolar (gatekeeper e intervención en crisis) se asociaron con un aumento significativo en el nivel de conocimientos sobre el suicidio y con altos niveles de satisfacción y utilidad (346).
RS de distintos tipos de estudios $1+, 2+, 3$

$\mathrm{RS}$ de distintos tipos de estudios 3 


\section{Recomendaciones}

\begin{tabular}{|l|l|}
\hline D & $\begin{array}{l}\text { Se recomienda la implementación de programas de entrenamiento } \\
\text { de figuras clave (gatekeeper) en el ámbito escolar, de cara a aumen- } \\
\text { tar los conocimientos de los profesionales de los centros educati- } \\
\text { vos sobre la conducta suicida y el impacto del suicidio en las per- } \\
\text { sonas allegadas. }\end{array}$ \\
\hline
\end{tabular}

\subsection{Intervenciones comunitarias}

\section{Preguntas para responder:}

- ¿Existe alguna intervención comunitaria para la prevención tras un suicidio?

Se han llevado a cabo diversas iniciativas para prevenir el suicidio a nivel comunitario, aunque la mayoría no han sido evaluadas.

\section{Resumen de la evidencia}

No existe evidencia concluyente sobre la efectividad $\mathrm{RS}$ de distintos de los programas de intervención comunitaria tras un suicidio (346).

tipos de estudios 3

\subsection{Intervenciones en profesionales de la salud tras el suicidio de un paciente}

\section{Preguntas para responder:}

- ¿Existe alguna intervención tras el suicidio de un paciente que reduzca el impacto en los profesionales implicados en su manejo?

Los profesionales de la salud se relacionan con frecuencia con pacientes que presentan conducta suicida, tanto en el ámbito de la atención primaria como de la especializada. El suicidio de un paciente es siempre un hecho de gran impacto, fundamentalmente cuando ha existido una importante relación terapéutica, llegando a generar distrés grave en tres de cada diez profesionales (348). Sin embargo, la investigación sobre la trascendencia y las necesidades de los profesionales ante estas situaciones es muy limitada. 


\section{Resumen de la evidencia}

Las diferentes fases que suelen presentarse en un profesional tras el suicidio de un paciente son (349):

Opinión de expertos 4

- Fase 1 (inmediata): de shock

- Fase 2 (intermedia): de sensación y sentimientos de presión, desasosiego o desazón

- Fase 3 (postraumática): de hacerse preguntas y de dudas de uno mismo

- Fase 4 (recuperación): de renovación de la confianza.

En diferentes estudios se ha puesto de manifiesto que después del suicidio de un paciente puede presentarse: trastorno por estrés postraumático, agresividad, sentimientos de duelo, culpa, aislamiento y humillación, así como baja autoestima y preocupación por la reacción de los compañeros $(216,340)$.

Entre los factores que se han relacionado con la aparición de distrés en los profesionales destacan cuestiones referidas al plan terapéutico, posibles reacciones negativas de los compañeros o directivos y la posibilidad de implicaciones legales del caso, fundamentalmente si el paciente no estaba hospitalizado (350).

Algunas estrategias útiles tras el suicidio de un paciente son: buscar apoyo en los compañeros y la revisión del caso (351-353).

Se considera muy importante recibir formación específica sobre el manejo del suicidio y las posibles implicaciones emocionales en los profesionales (353-355).

En el caso de un suicidio en un paciente hospitalizado puede ser conveniente realizar una reunión de todo el personal de la unidad para informar del suicidio y desarrollar una estrategia de apoyo a los restantes pacientes de cara a la prevención de la imitación de la conducta suicida (354).

RS de distintos tipos de estudios 3

Serie de casos 3

Serie de casos 3

Serie de casos 3

Opinión de expertos 4 


\section{Recomendaciones}

\begin{tabular}{|c|l|}
\hline C & $\begin{array}{l}\text { Se recomienda que todos los profesionales reciban formación } \\
\text { específica sobre las posibles implicaciones emocionales del suicidio } \\
\text { de un paciente y las estrategias de afrontamiento necesarias. }\end{array}$ \\
\hline D & $\begin{array}{l}\text { Tras el suicidio de un paciente se recomienda garantizar el apoyo } \\
\text { necesario a los profesionales directamente implicados y la realiza- } \\
\text { ción de una revisión del caso y de los factores subyacentes. }\end{array}$ \\
\hline
\end{tabular}




\section{Programas clínicos de intervención sobre la conducta suicida en España}

En este apartado se describen una serie de programas clínicos de prevención terciaria de la conducta suicida desarrollados en España. Estos se basan en la puesta en marcha de dispositivos en los que se garantiza una asistencia inmediata y un seguimiento adecuado a los pacientes que han llevado a cabo un episodio de conducta suicida. Aunque hablamos de prevención terciaria, estos programas abordan también la prevención secundaria ya que otro de sus objetivos es la sensibilización, formación y educación sanitaria, para incrementar el diagnóstico de pacientes en riesgo de conducta suicida.

\section{Preguntas para responder:}

- ¿Son efectivos los programas clínicos de intervención llevados a cabo en España en la reducción de episodios futuros de conducta suicida?

\section{Resumen de la evidencia}

Programa de Intervención Intensiva en Conducta Suicida del Área Sanitaria de Ourense $(356,357)$

El programa se llevó a cabo en dos fases. En la primera, desde noviembre de 2008 a enero de 2009, se realizaron 19 cursos de formación de hora y media en los principales servicios de atención primaria del Area sanitaria de Ourense, dirigidos a médicos y profesionales de enfermería. Incluían un entrenamiento en la detección de pacientes en riesgo, técnicas de manejo inicial y criterios de derivación. La segunda fase o de asistencia a pacientes en riesgo de suicidio se inició en abril de 2009 y se mantiene hasta la actualidad. Este programa atiende pacientes que hayan realizado un intento de suicidio o que tengan ideas graves de suicidio, siendo derivados desde atención primaria, servicios de urgencias o unidades de agudos. A los pacientes se les realiza valoración y tratamiento farmacológico por parte de un psiquiatra, psicoterapia de corte cognitivo conductual específica y reglada por parte de un psicólogo clínico y un plan de cuidados específico por parte de un DUE especialista en salud mental con apoyo telefónico. 
Los pacientes que siguieron el programa de interEstudio de vención recayeron un $10 \%$ frente a un $20,6 \%$ en los que cohortes $2+$ recibieron asistencia habitual $(\mathrm{p}=0,047)$. El riesgo de recaída de los pacientes del programa en relación al grupo control fue del 0,49, lo que quiere decir que el programa reduce el riesgo de recaída en un $51 \%$. De cada 100 personas tratadas en el programa se evitaron 10 casos de recaída y se necesitaron tratar a 9,5 pacientes con el programa para evitar un caso de recaída.

Estar en el programa supuso un riesgo seis veces menor de recaer en un nuevo intento de suicidio que no estar en él, siendo independiente del sexo, la edad, el número de intentos previos y de la necesidad de ingreso tras el intento. El único factor predictor de protección asociado fue haber estado en el programa.

Programa de Prevención de la Conducta Suicida (PPCS) desarrollado en el distrito de la Dreta de l'Eixample de Barcelona (358)

El programa se desarrolló en cuatro fases entre septiembre de 2005 y diciembre de 2008. Fue coordinado por el Servicio de Psiquiatría del Hospital de la Santa Creu i Sant Pau y el Centre de Salut Mental d'Adults de la Dreta de l'Eixample. Se compara los pacientes que realizan el programa en el sector de estudio con otros pacientes que han consultado por el mismo motivo y que residen en sectores diferentes, fuera del área de influencia del PPCS.

El programa tuvo varias fases:

Primera fase (septiembre 2005 - abril 2006): creación de un equipo multidisciplinar y diseño de los circuitos asistenciales para los pacientes.

Segunda fase: elaboración de un programa de información, educación y sensibilización dirigido a los profesionales sanitarios y trabajadores sociales a través de sesiones informativas; elaboración de materiales audiovisuales; creación de un sitio web y formación sobre el riesgo suicida a diferentes sectores de la población general.

Tercera fase (abril 2006 - diciembre 2007): asistencia de los pacientes con ideación o conducta suicida. Los pacientes acudían al PPCS derivados de los servicios de urgencias de psiquiatría, de los médicos de familia del sector y de la interconsulta hospitalaria. El programa consistió en una atención preferente en un máximo de 48 horas, evaluación por un psiquiatra, plan terapéutico individualizado (psiquiatra de referencia encargado de coordinar la asistencia durante los 3-6 meses en que el paciente era atendido 
en el PPCS, psicoterapia individual o grupal con psicólogo clínico y enfermería y consultas a asistente social si precisaban), posterior integración del paciente en el circuito asistencial de salud mental y organización de grupos de psicoterapia cognitivo conductual y de intervención en crisis, así como de ayuda a los supervivientes.

Cuarta fase (durante el año 2008): fase de seguimiento en la que se evaluó a los pacientes a través de entrevistas protocolizadas presenciales o telefónicas a los 6 y 12 meses, realizadas por el psiquiatra o la enfermera.

Las conclusiones más importantes fueron:

- Confirmación de la efectividad del PPCS mediante la significativa reducción de la recidiva de la conducta suicida (11\% grupo PPCS y $32 \%$ grupo control; $\mathrm{p}<0,001)$ y de las hospitalizaciones $(9,5 \%$ grupo PPCS y $18 \%$ grupo control; $\mathrm{p}=0,03)$.

- La información sanitaria realizada a través de medios audiovisuales, divulgando los recursos de atención inmediata para las personas en riesgo, no provocó un efecto contagio ni una sobredemanda asistencial.

- Entre los pacientes del sector Dreta de l'Eixample hubo un porcentaje mucho mayor de ideas autolíticas que en el grupo control, debido posiblemente a que la fase del programa dirigida a la psicoeducación determinó la detección de dichas ideas en una fase más temprana, ya sea por la intervención de asistencia primaria o por la iniciativa de los pacientes o su familia.

- Los resultados fueron indicativos de que la información razonada sobre el riesgo suicida facilita la petición de ayuda.

- Se encontró dificultad para delimitar cuál de las fases del programa tenía mayor eficacia respecto a las otras (educación sanitaria, asistencia individualizada o coordinación de los recursos).

- La mortalidad por suicidio no pudo ser evaluada por la ausencia de datos estadísticos en cada sector de población.
Estudio de cohortes $2+$ 
Programa de intervención multinivel para la prevención de la depresión y el suicidio (Corporació Sanitària i Universitària Parc Taulí de Sabadell (Barcelona) (359).

El Programa se basa en intervenciones comunitarias desarrolladas en cuatro niveles: 1) cooperación con los médicos de atención primaria y pediatras;2) actividades de relaciones públicas, cooperación con los medios de comunicación local e implementación de programas escolares, folletos de información y sesiones formativas para profesores; 3 ) sesiones de formación de figuras clave; 4) intervenciones específicas en salud para grupos de alto riesgo.

Se elaboró un programa de gestión telefónica apliEstudio de cado a 991 pacientes atendidos por tentativa de suicidio cohortes $2+$ en el Servicio de Urgencias de la Corporació Sanitària i Universitària Parc Taulí de Sabadell (Barcelona). El programa consistió en un seguimiento telefónico regular durante un año (a la semana y a los 1, 3, 6, 9 y 12 meses). Los resultados se compararon con una población control (Hospital de Terrassa) que recibió el tratamiento habitual.

- Los pacientes que siguieron el programa de gestión telefónica tardaron más tiempo en cometer el siguiente reintento de suicidio en relación al año anterior $(\mathrm{p}<0,0005)$ o a la población control en el mismo periodo ( $\mathrm{p}<0,0005)$.

- En el grupo de intervención se redujo la tasa de pacientes con reintentos de suicidio en un $8 \%$ con respecto al año anterior y a la población control.

Programa de intervención en personas que han realizado intentos de suicidio. Áreas de Salud de Valladolid Este y Oeste (360)

Los participantes fueron personas entre 12 y 70 años del Área de salud de Valladolid Este y Oeste hospitalizadas por tener ideas de suicidio o haber realizado una tentativa, ingresadas en las unidades de hospitalización psiquiátrica en un período de 6 meses. Se realizó un seguimiento longitudinal para determinar la efectividad del programa mediante un diseño de comparación interna de tipo pre-postest.

Principales resultados

- El 90\% de los pacientes derivados al programa aceptaron participar y el 10\% restante padecía Estudio de comorbilidad psicótica u obsesiva grave. Abandocohortes $2+$ 
naron el programa el 17,9\% de los participantes, de los que el $25 \%$ eran transeúntes y carecían de residencia fija, por lo que su seguimiento era muy difícil.

- El $80 \%$ de los pacientes no tuvieron recaídas durante el período de seguimiento. El 23\% fueron puestos en contacto en tratamiento estable con otros dispositivos del área. De ellos, la tercera parte acudió a un hospital de día, el 8,7\% a una unidad de convalecencia y el $57,4 \%$ se puso en contacto con asociaciones de autoayuda.

\section{Recomendaciones}

\begin{tabular}{|c|l|}
\hline C & $\begin{array}{l}\text { Se recomienda la implementación en los servicios de salud de pro- } \\
\text { gramas clínicos de prevención de la conducta suicida basados en } \\
\text { educación sanitaria y en la puesta en marcha de dispositivos que } \\
\text { garanticen una asistencia inmediata y un seguimiento adecuado. }\end{array}$ \\
\hline
\end{tabular}




\section{Aspectos legales del suicidio en España}

\section{Preguntas para responder:}

- ¿Cuáles son los aspectos legales más importantes a la hora de abordar la conducta suicida en España?

\section{Resumen de aspectos legales}

Código Penal y suicidio: el suicidio en España no está penado. Sí se recoge en el Código Penal, la inducción y la cooperación al suicidio y la imprudencia profesional (361).

Internamiento involuntario en caso de riesgo suicida es una de las excepciones de la Ley de Autonomía del paciente (362) y sólo sería posible si existe un riesgo inmediato grave para la integridad física o psíquica del paciente y no es posible conseguir su autorización. Requerirá autorización judicial. Ésta será previa al internamiento, salvo que por razones de urgencia se hiciese necesaria la inmediata adopción de la medida, de la que se dará cuenta cuanto antes al Juez y, en todo caso dentro del plazo de 24 horas.

Cualquier persona puede pedir un internamiento involuntario poniendo en conocimiento del ministerio fiscal o del juez la existencia de un individuo que por riesgo a sí mismo o hacia terceros precise esta medida. Precisa de informe realizado por cualquier facultativo en la que conste la necesidad de ingreso.

La conducta suicida es la causa más frecuente de demandas judiciales al psiquiatra por mala práctica (363).

La responsabilidad profesional puede ser por (364):

- Conducta imprudente (asumiendo riesgos innecesarios)

- Negligente (dejadez o descuido)

- Impericia (carencia de conocimientos y experiencia)

Los casos más frecuentes de mala praxis son $(364,365)$ :

- Negligencia al no ingresar o dar de alta a un paciente que a continuación se suicida o lesiona; 
- Diagnóstico incorrecto del que deriva un ingreso o detención improcedente, fracaso en la protección o control de un paciente suicida.

El profesional sanitario tendrá responsabilidad penal cuando la conducta sea claramente previsible y humanamente evitable y la actitud del profesional manifiestamente descuidada u osada. El profesional deberá probar que tomó las medidas adecuadas.

Formas de actuación preventiva sobre la conducta suicida:

- Valorar siempre personalmente al paciente con ideas de suicidio

- Realizar una historia clínica completa y correcta

- Informar a la familia de manera clara y adecuada, dar pautas de acompañamiento y control del tratamiento farmacológico

- Informar del posible potencial suicida del tratamiento tanto al paciente como a su familia

- Adoptar otras medidas de control si se precisa: internamiento con un mayor o menor grado de vigilancia

- Si no se dispone de medios/herramientas terapéuticas remitir al paciente para tratamiento por otros profesionales o centros donde pueda ser tratado de forma adecuada.

Secreto profesional: toda persona tiene derecho a que se respete el carácter confidencial de los datos eferentes a su salud, y a que nadie pueda acceder a ellos sin previa autorización amparada por la ley $(361,362)$.

Excepciones al secreto profesional:

- Conocimiento de la existencia de un delito

- Presencia de enfermedad infecto-contagiosa y riesgo grave para terceras personas o para la salud pública

- Riesgo inmediato grave para la integridad física o psíquica del enfermo y no es posible conseguir su autorización (estado de necesidad)

- Declaración como imputado, denunciado o acusado

- Informes a otro compañero, incluida inspección médica (secreto compartido). 


\section{Estrategias diagnósticas y terapéuticas}

Se presentan los algoritmos de manejo de la ideación y conductas suicidas en atención primaria y en los servicios de urgencias. En las notas del algoritmo se detallan algunos aspectos de los mismos.

\section{Algoritmo 1. Manejo de la conducta suicida en atención primaria}

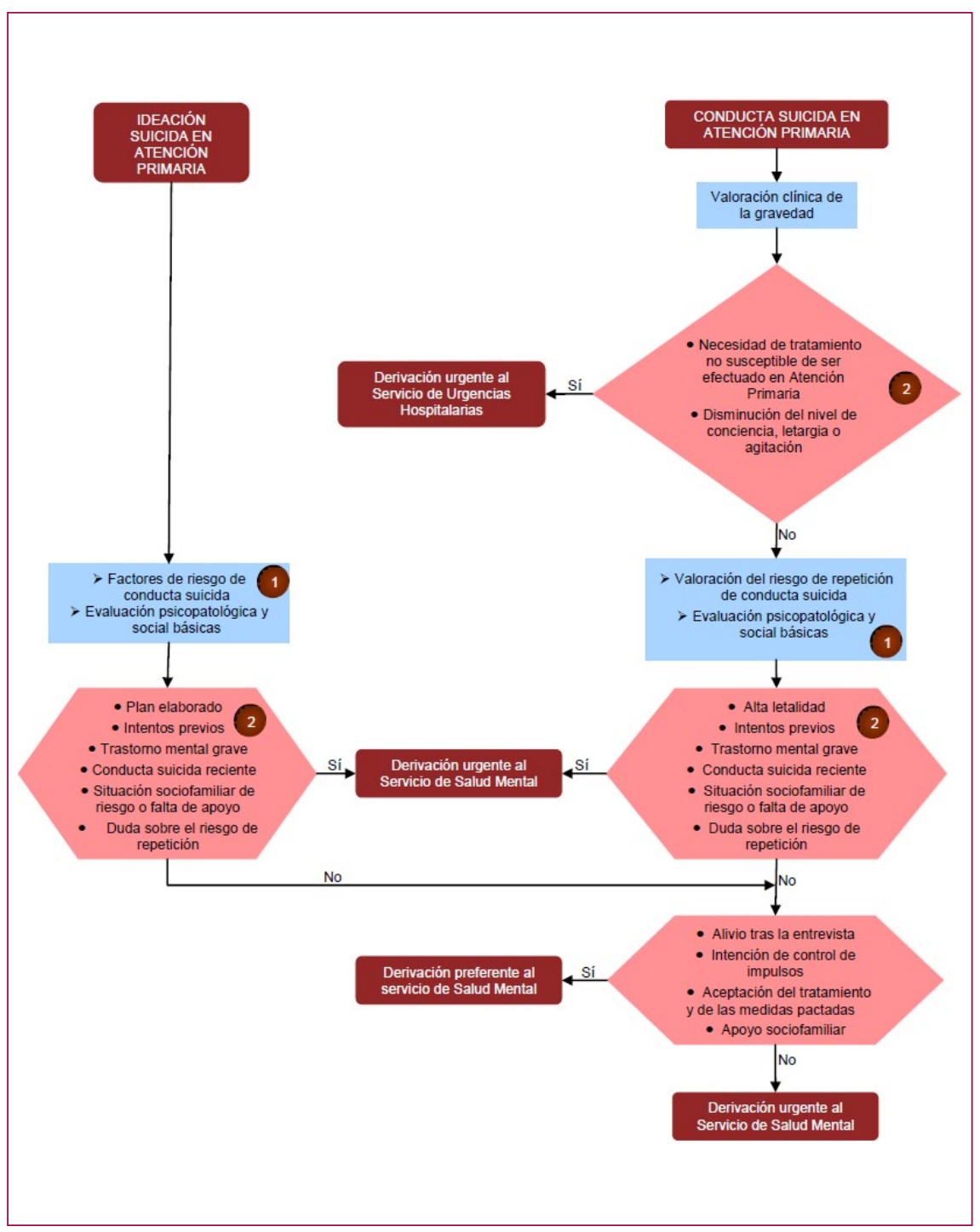


Algoritmo 2. Manejo de la conducta suicida en el servicio de urgencias hospitalarias

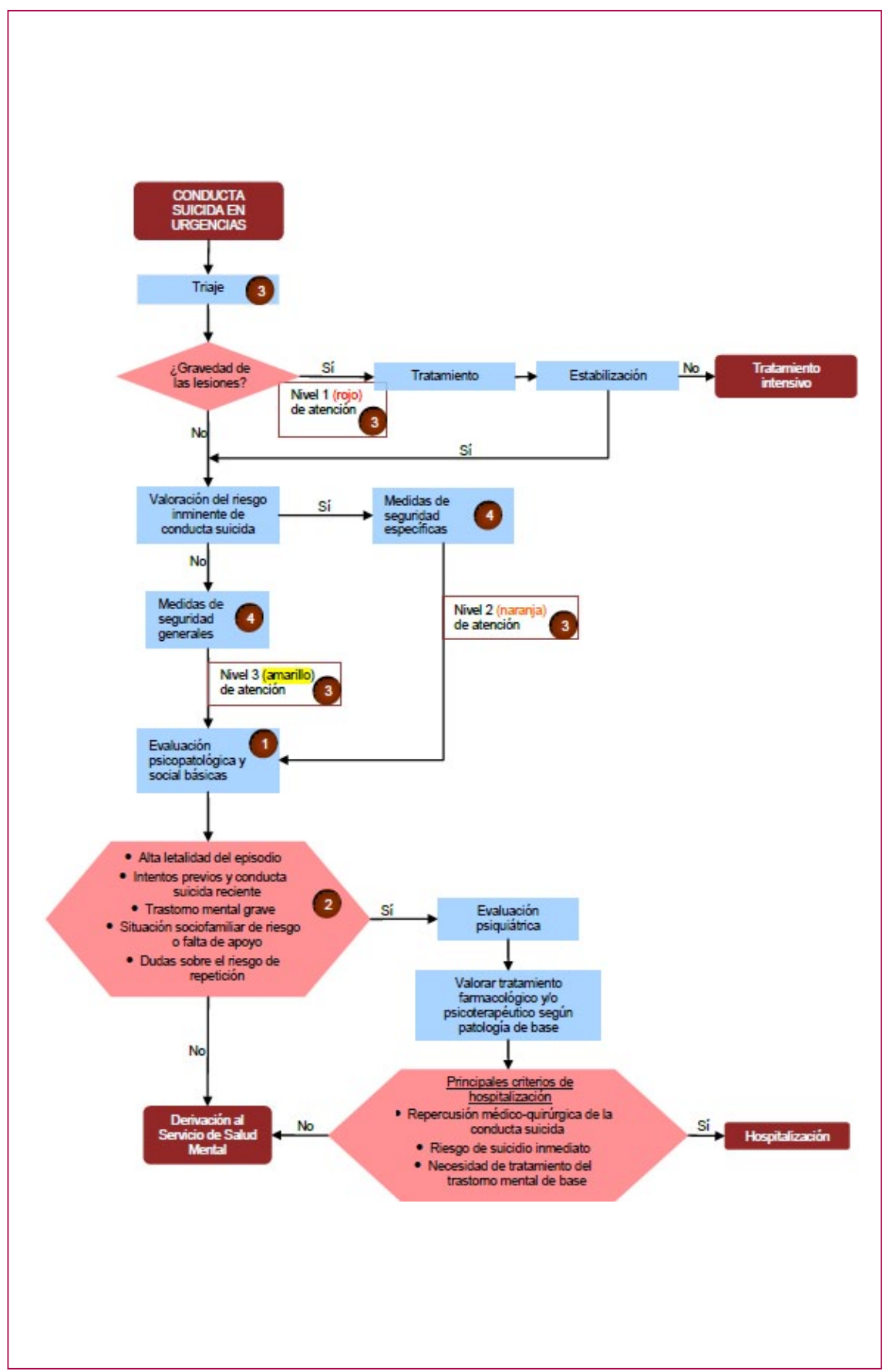




\section{NOTAS DEL ALGORITMO}

\section{Generales}

El manejo de la ideación y la conducta suicidas deberá incluir siempre:

- Psicoeducación

- Apoyo individual y familiar

- Coordinación entre profesionales de diferentes niveles asistenciales

- Atención a la posible patología de base y a las comorbilidades

- Hacer partícipe a la familia y allegados en el proceso de evaluación y tratamiento

- Garantizar un ambiente de privacidad, confidencialidad y respeto.

\section{Evaluación psicopatológica y social básicas}

Tras un episodio de ideación o conducta suicidas se debe realizar una evaluación psicopatológica y del medio social básicas, tanto en atención primaria como en el servicio de urgencias hospitalarias. Deberá incluir la evaluación de los factores psicológicos y contextuales y una valoración de los factores de riesgo. Esta evaluación será preliminar y se completará posteriormente por el servicio de salud mental. Podrá ser necesario contar con la valoración e intervención de los servicios sociales.

La derivación al psiquiatra deberá realizarse cuando el paciente esté plenamente consciente y pueda llevarse a cabo una adecuada valoración psicopatológica.

\section{Criterios de derivación}

La decisión final sobre la derivación a otro dispositivo y el carácter de dicha derivación (urgente o preferente) se realizará mediante una valoración global de estos criterios. De forma general, se considera que al menos uno de los criterios debe ser positivo para decidir la derivación urgente. Los motivos de dicha derivación deberán ser registrados convenientemente en la historia clínica.

En algunos casos, y como medida de seguridad, será necesario hacer el traslado desde atención primaria en ambulancia.

\section{Triaje}

Todos los pacientes que acudan a un servicio de urgencias hospitalarias debido a una conducta suicida deberían ser catalogados de forma que se asegurase su atención al menos dentro de la primera hora desde su llegada. Utilizando el sistema de triaje de Manchester, los niveles de atención serían los siguientes:

\begin{tabular}{|c|c|c|c|}
\hline Nivel & Nombre & Color & Tiempo de atención \\
\hline 1 & Emergencia & Rojo & $0 \mathrm{~min}$. \\
\hline 2 & Muy urgente & Naranja & $10 \mathrm{~min}$. \\
\hline 3 & Urgente & Amarillo & $60 \mathrm{~min}$. \\
\hline
\end{tabular}


El Cuestionario de riesgo de suicidio de Horowitz podría ayudar en el triaje a conocer el grado de necesidad de atención inmediata (en personas en las que no existe afectación física grave). Las preguntas del cuestionario serían las siguientes:

- ¿Acude usted porque ha tratado de lesionarse a sí mismo?

- ¿En la semana pasada ha tenido ideas relacionadas con suicidarse?

- ¿Ha tratado de lesionarse a sí mismo en el pasado?

- ¿Le ha sucedido algo muy estresante en las últimas semanas?

\section{Medidas de seguridad}

Deberán adoptarse todas aquellas medidas de seguridad que impidan la fuga y la auto o heteroagresividad. De forma general, a los pacientes se les debe pedir que entreguen todo objeto potencialmente dañino y no debe haber medicamentos a su alcance. En algunos casos será necesario avisar al servicio de seguridad y/o la policía. Debería existir un protocolo específico de cómo registrar y retirar estos objetos potencialmente dañinos.

Cuando existe un riesgo inminente de conducta suicida, además de las medidas anteriores, deberá valorarse la necesidad de contención mecánica, no dejar a la persona sola y/o asegurar la supervisión y contacto regular con algún profesional del servicio de urgencias hospitalarias. 


\section{Anexos}

\section{Anexo 1. Aspectos a recoger en urgencias hospitalarias ante una conducta suicida}

\begin{tabular}{|c|c|}
\hline $\begin{array}{l}\text { DATOS } \\
\text { PERSONALES }\end{array}$ & $\begin{array}{l}\text { Sexo: } \square \text { Hombre } \square \text { Mujer } \quad \text { Edad: } \\
\text { Estado civil: } \square \text { Soltero } \quad \square \text { Casado/en pareja } \\
\\
\square \text { Separado/divorciado } \quad \square \text { Viudedad } \\
\text { Ocupación: } \square \text { Trabaja/estudia } \square \text { Paro } \square \text { Jubilado } \square \text { Otros }\end{array}$ \\
\hline $\begin{array}{l}\text { FACTORES DE } \\
\text { RIESGO }\end{array}$ & $\begin{array}{l}\text { Antecedentes de trastornos mentales: } \\
\begin{array}{l}\square \text { Depresión mayor } \\
\square \text { Trastornos psicóticos }\end{array} \text { Trastorno bipolar } \\
\square \text { Trastorno conducta alimentaria } \quad \square \text { Ansiedad } \\
\square \text { Trastorno de personalidad, impulsividad y agresión alcohol/drogas } \\
\text { Intentos previos suicidio: } \\
\text { Presencia reciente de ideación suicida: } \square \text { sí } \square \text { No } \square \text { No } \\
\text { Enfermedad física, dolor, discapacidad o cronicidad: } \square \\
\text { Historia familiar previa de suicidio: } \\
\text { Presencia de eventos vitales estresantes: } \\
\text { Factores sociales y ambientales: } \\
\square \text { Falta de apoyo social/familiar } \\
\square \text { Historia de acoso }\end{array}$ \\
\hline $\begin{array}{l}\text { CARACTERÍSTICAS } \\
\text { DEL INTENTO DE } \\
\text { SUICIDIO }\end{array}$ & 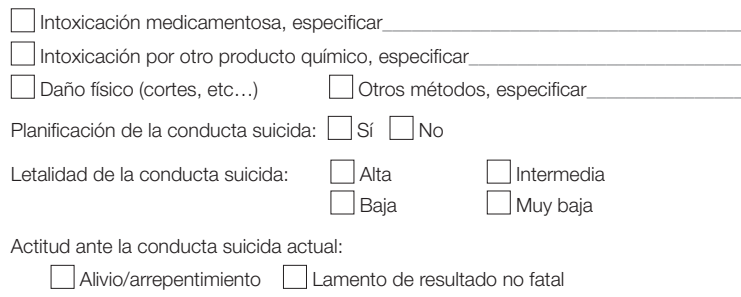 \\
\hline $\begin{array}{l}\text { EVALUACIÓN } \\
\text { CLÍNICA }\end{array}$ & 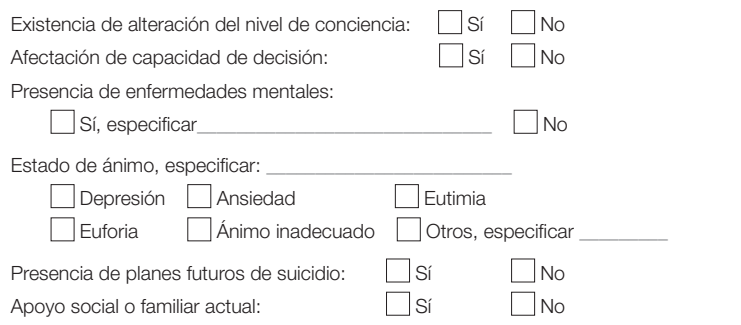 \\
\hline CONCLUSIONES & $\begin{array}{l}\text { Riesgo de suicidio inmediato: } \square \text { sí } \quad \square \text { No } \\
\text { Capacidad de decisión: } \quad \square \text { sí } \quad \square \text { No } \\
\text { Necesidad de evaluación psiquiátrica durante el episodio: } \square \text { sí } \square \text { No } \\
\square \text { Inmediata } \quad \square \text { En } 24 \text { horas } \\
\square \text { En una semana } \quad \square \text { Otro periodo, especificar: }\end{array}$ \\
\hline
\end{tabular}




\section{Anexo 2. Objetivos de las intervenciones preventivas de suicidio}

Figura 1. Modelo propuesto por Mann et al. (135) para la prevención del suicidio basado en los factores de riesgo.

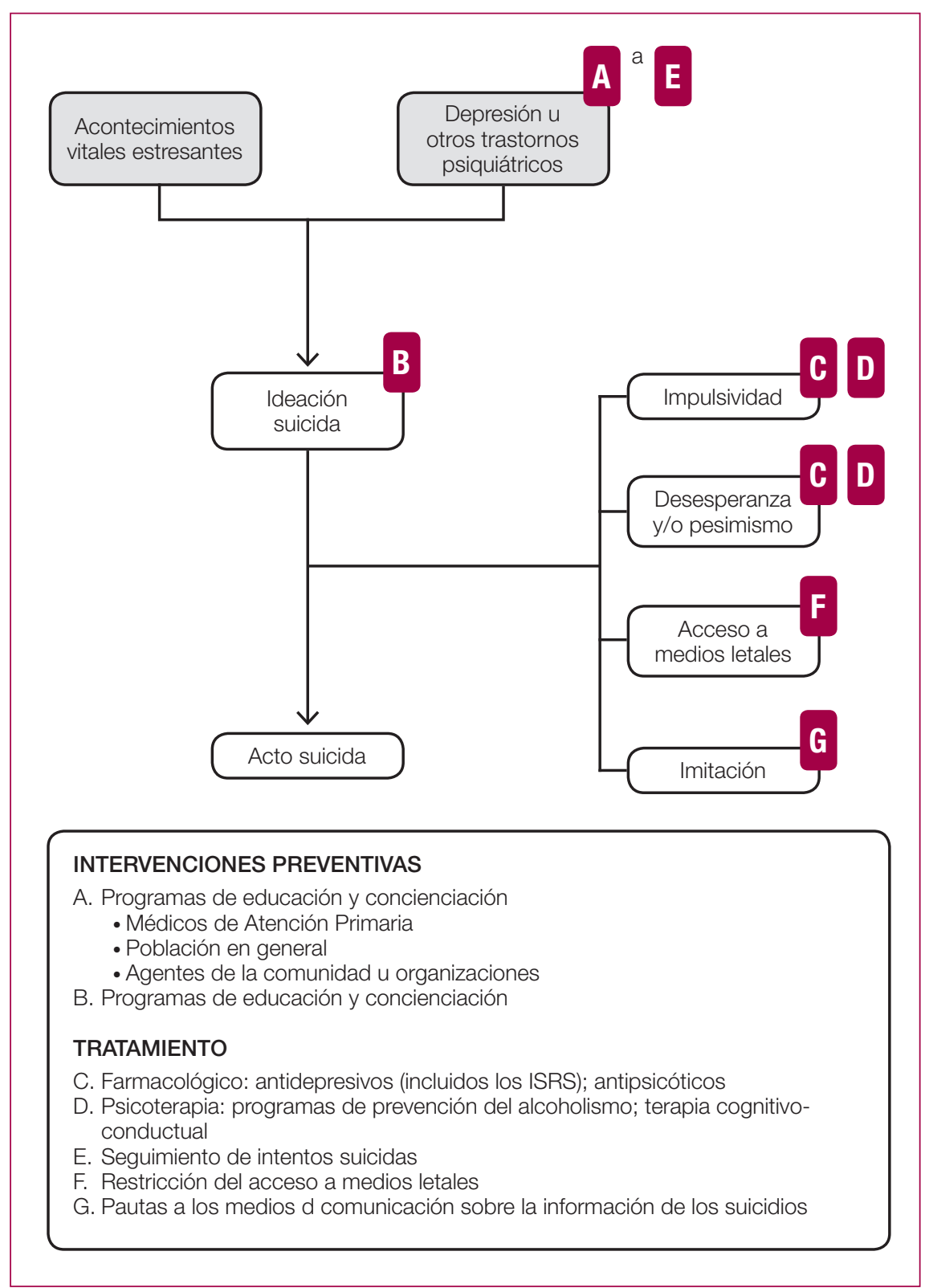


Anexo 3. Información para pacientes y familiares sobre la ideación y conducta suicidas

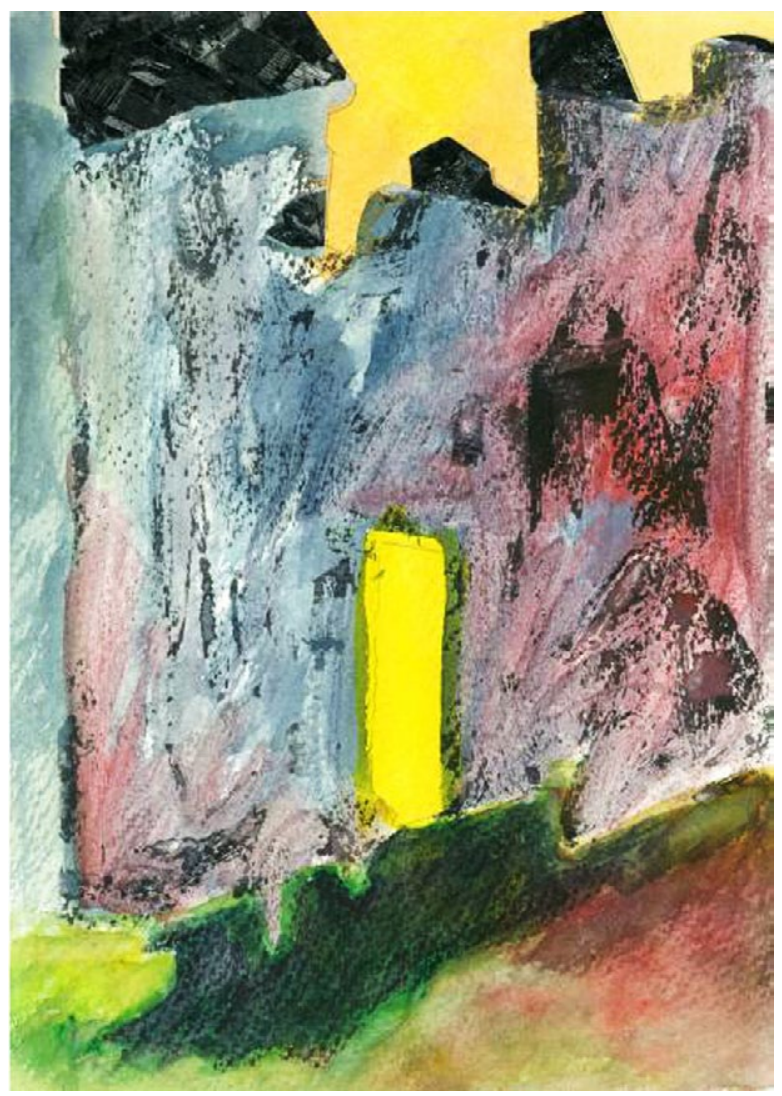

\section{LA CONDUCTA SUICIDA}

Información para pacientes, familiares y allegados 


\section{CONTENIDO}

\section{Información General}

1.1. Algunas preguntas sobre el suicidio

1.2. ¿Cuáles son los mitos e ideas erróneas sobre el suicidio?

1.3. ¿Cuáles pueden ser algunas de las señales de alerta en el suicidio?

1.4. ¿Qué sucesos o circunstancias podrían precipitar la conducta suicida?

\section{Folletos específicos}

2.1. INFORMACIÓN PARA PACIENTES que presentan ideas suicidas

2.2. INFORMACIÓN PARA FAMILIARES Y ALLEGADOS

2.2.1. ¿QUÉ PODEMOS HACER cuando vemos señales de alerta y/o de ideación suicida en un familiar o allegado?

2.2.2. ¿QUÉ HACER Y QUÉ NO HACER ante la posible conducta suicida de un familiar o allegado?

Esta información ha sido elaborada a partir del conocimiento basado en la literatura científica disponible en el momento de la publicación.

\section{Agradecimientos}

El grupo elaborador de la Guía de Práctica Clínica desea dar las gracias a José Luis Iglesias Diz y a Luis Iglesias Fernández, autores de las ilustraciones y de forma especial a todos los pacientes y familiares que han colaborado en la elaboración de este material. 


\section{Introducción}

El documento que tiene en sus manos busca proporcionarle información sobre uno de los problemas más graves de salud de los últimos años: el suicidio.

En el año 2010 se publicaron datos donde se puso de manifiesto que en 2008, el suicidio en España fue la primera causa de muerte violenta, superando a los accidentes de tráfico. Desde entonces el suicidio sigue siendo la primera causa de muerte violenta. Pero a diferencia de lo que ocurre con los accidentes, no se percibe una reacción por parte de la sociedad hacia el suicidio, posiblemente debido a que el conocimiento no se ha divulgado convenientemente y de forma objetiva, siguiendo vigentes muchos mitos o creencias erróneas sobre el mismo.

Tratar el tema del suicidio no es fácil, ya que en él intervienen muchos factores. Además, es relativamente sencillo caer en estereotipos sobre el suicidio, en mitos o en argumentos morales que poco ayudan a la persona o familiares. Pero no debemos quedarnos indiferentes ante la magnitud de este problema, y las siguientes páginas tienen precisamente ese objetivo y el de poder influir en el suicidio de modo positivo.

La información que le facilitamos se ha escrito pensando en las personas que sufren, en quienes les rodean (y quieren) y en los profesionales. Aquí no encontrará opiniones particulares, sino los resultados y conclusiones extraídos de estudios científicos seleccionados por su calidad y neutralidad.

Esperamos que le resulte de ayuda y que cumpla el objetivo de apoyar a quienes lo lean y lo apliquen en sí mismos o en los demás. 


\section{Información General}

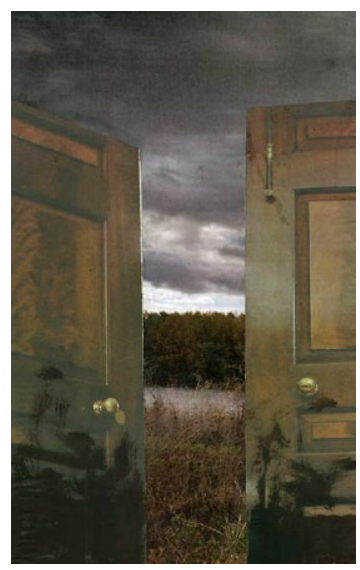

\subsection{Algunas preguntas sobre el suicidio}

¿Qué personas podrían tener un mayor riesgo de suicidio?

Existen varios factores que podrían influir a la hora de intentar o consumar un suicidio, aunque el hecho de que estén presentes no quiere decir que vaya a ocurrir. Los más frecuentes son:

- Haber tenido un intento de

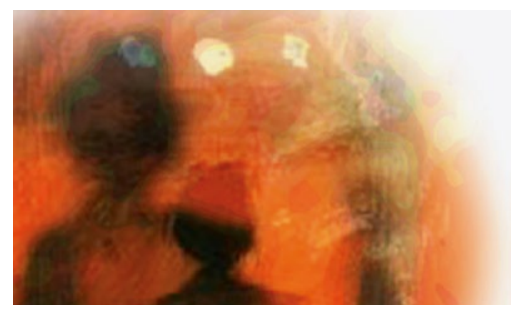
suicidio previo

- Antecedentes de depresión o de otro trastorno mental

- Abuso de drogas o alcohol

- Antecedentes familiares de suicidio o violencia

- Padecer una enfermedad física o tener desesperanza ${ }^{4}$

- Antecedentes de abuso sexual en la infancia

- Tendencias impulsivas o agresivas

4 Aunque es una palabra difícil de definir, podríamos decir que una persona con desesperanza tiene la convicción o la seguridad de que su problema o carencia actual no se resolverá en el futuro inmediato. 
¿Qué comportamiento presenta una persona que quiere suicidarse?

La persona que quiere suicidarse suele presentar cambios en las emociones, en los pensamientos, en los hábitos y en el comportamiento habitual.

Entre estos cambios podemos encontrar:

- Tristeza

- Ideas de suicidio

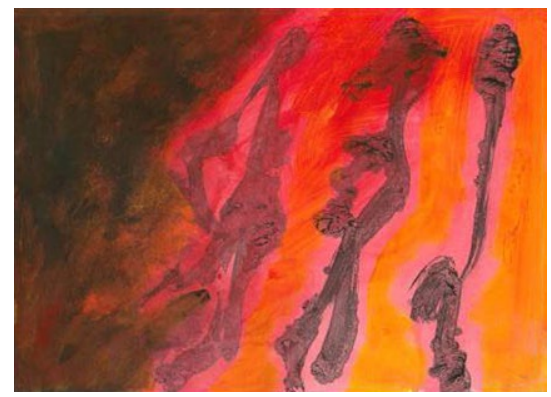

- Escribir notas de despedida

- Entrega de posesiones valiosas

- Aislamiento

- Incremento de consumo de alcohol, drogas u otras sustancias adictivas

- Presencia de trastornos del sueño y del apetito.

¿Puede heredarse el riesgo de suicidio?

Los factores genéticos y familiares podrían contribuir a aumentar el riesgo de suicidio. Así, entre los factores familiares, la ausencia de apoyo, un bajo nivel socioeconómico y educativo de la familia o antecedentes de suicidios en ella parecen incrementar el riesgo de suicidio.

Sin embargo, esto no significa

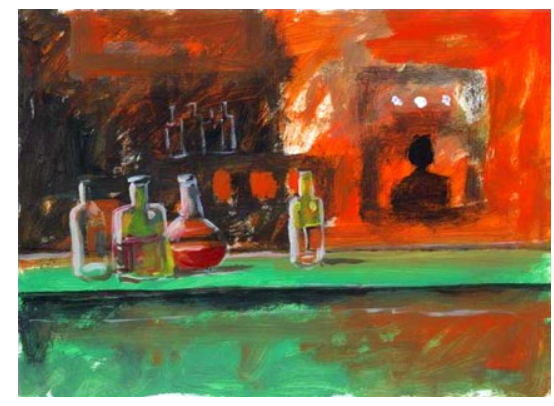
que la conducta suicida sea inevitable para personas con este historial genético o familiar; simplemente significa que pueden ser más vulnerables y deben tomar medidas para reducir su riesgo, tales como solicitar ayuda y tratamiento ante un primer signo de alarma.

¿La depresión aumenta el riesgo de suicidio?

Aunque la mayoría de las personas que tienen depresión no se suicidan, el padecer depresión aumenta el riesgo de suicidio, sobre todo si ésta es grave. Así, cerca del $60-90 \%$ de las personas que se suicidan tienen síntomas de depresión. 
¿Aumenta el uso de alcohol y otras drogas el riesgo de suicidio?

El abuso de alcohol o de otras drogas se asocia con mayor riesgo de suicidio. Este abuso suele ser común entre personas con tendencia a ser impulsivas, a tener mayor número de problemas sociales y econó-

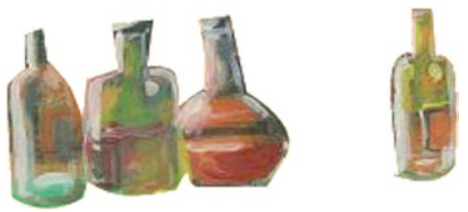
micos, y entre personas con conductas de alto riesgo que pueden resultar con frecuencia en lesiones.

\section{¿Qué significa "suicidio por contagio" o "imitación”?}

La imitación de la conducta suicida se puede producir cuando se informa a una persona de que alguien de su entorno (familiares, amigos, compañeros de trabajo...) se suicida o al menos lo intenta. Si esta persona se encuentra en una situación inestable o difícil, ese suceso puede facilitar, por imitación, que también se intente suicidar.

Por otro lado, la manera en que los medios de comunicación tratan el suicidio puede favorecer un "efecto contagio". Así la información sobre el suicidio con muchos detalles, dar la noticia de forma sensacionalista o cuando el suicidio se aborda con admiración (valentía, romanticismo etc.) puede favorecer la aparición de conductas de imitación, especialmente en adolescentes y adultos jóvenes. Esto, sin embargo, no ocurre cuando la información se enfoca a sensibilizar a la población y prevenir el suicidio.

¿Cómo puedo ayudar a una persona que ha intentado suicidarse pero parece que sólo lo hace para llamar la atención?

No se debe restar importancia a un acto suicida y creer que la persona lo realiza para llamar la atención. Todas las personas que hacen un intento de suicidio desean expresar que algo no va bien, que nos demos cuenta de que se sienten mal e incapaces de adaptarse a las exigencias que les pide la vida.

¿Cómo se puede ayudar al familiar o al amigo de una persona que se ha suicidado?

Lo primero que debemos hacer es permitirles expresar su pena y sus emociones. El duelo por una persona que se ha suicidado se ve acompañado con frecuencia de sentimientos de culpa, la búsqueda de por qué lo hizo, el vivirlo como una mancha en la familia y otras muchas emociones. Superar esta situación puede llevar dos años o más. 


\section{¿Es posible predecir el suicidio?}

Actualmente no hay una medida definitiva para predecir el suicidio. Aunque los investigadores han identificado algunos factores que hacen que un individuo tenga un alto riesgo de suicidio, realmente muy pocas personas con estos factores llegan a intentar suicidarse. El suicidio es relativamente infrecuente por lo que es difícil predecir qué personas con factores de riesgo finalmente se suicidarán.

¿Qué pueden hacer los medios de comunicación a la hora de informar sobre un suicidio?

Los medios de comunicación pueden minimizar el riesgo de contagio proporcionando una información concisa de los suicidios. Las noticias sobre suicidios no deben ser repetitivas, porque la exposición prolongada puede aumentar la posibilidad del contagio en personas vulnerables. El suicidio es el resultado de muchos factores, por lo que el reportaje no debe dar explicaciones simplistas, como por ejemplo que un evento negativo reciente en la vida de la persona ha

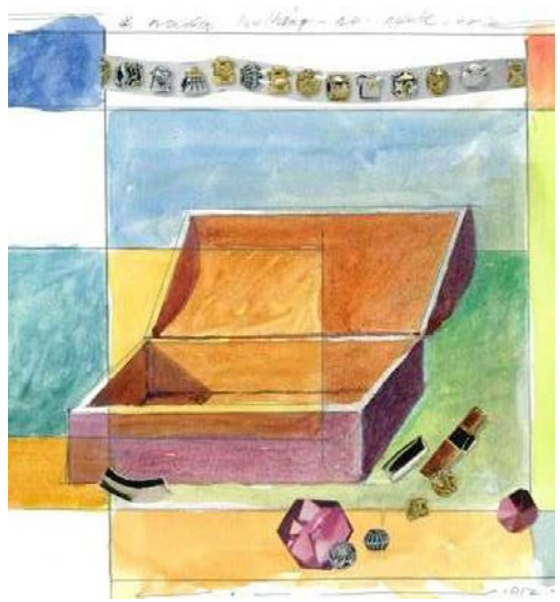
sido la causa del suicidio. Tampoco se debería divulgar una descripción detallada del método de suicidio utilizado, glorificar a la víctima ni señalar que el suicidio fue efectivo en lograr una meta personal.

Estas mismas recomendaciones deberían aplicarse a la información que se divulga a través de Internet, dado el uso masivo y cotidiano de esta fuente de información. 


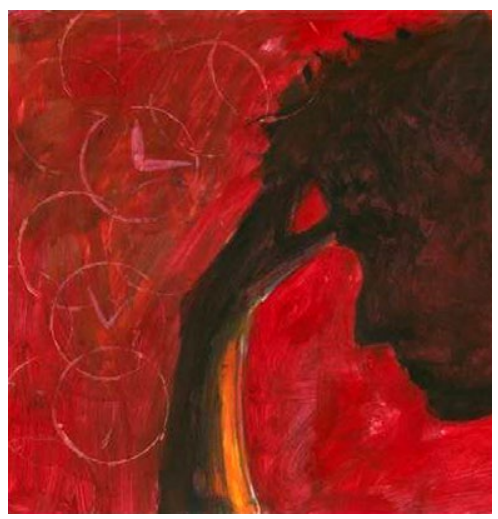

\section{2. ¿Cuáles son los mitos o ideas erróneas sobre el suicidio?}

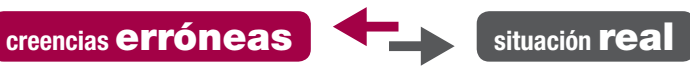

\begin{tabular}{|l|l|l|}
\hline EL QUE SE QUIERE & Conduce a no prestar atención a las personas \\
MATAR NO LO DICE & \\
que manifiestan sus ideas suicidas o amenazan \\
con suicidarse. \\
De cada diez personas que se suicidan, nueve \\
manifestaron claramente sus propósitos y la \\
otra dejó entrever sus intenciones de acabar \\
con su vida.
\end{tabular}




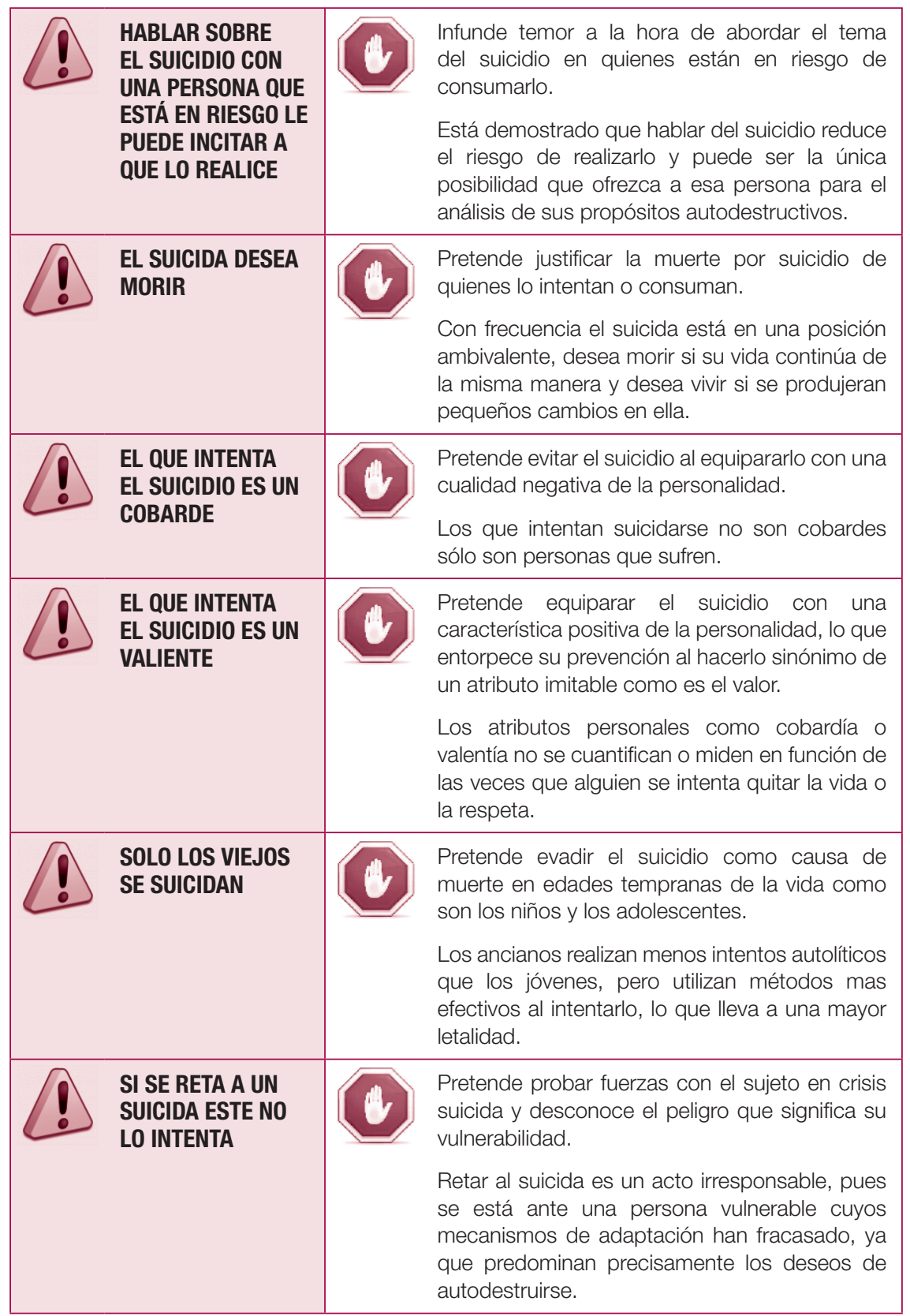




\begin{tabular}{|l|l|l|}
\hline $\begin{array}{l}\text { LOS MEDIOS DE } \\
\text { COMUNICACIÓN } \\
\text { NO PUEDEN } \\
\text { CONTRIBUIR A LA } \\
\text { PREVENCIÓN DEL } \\
\text { SUICIDIO }\end{array}$ & $\begin{array}{l}\text { Pretende continuar emitiendo noticias } \\
\text { sensacionalistas, con el objetivo primordial de } \\
\text { vender, sin tener en cuenta las consecuencias } \\
\text { del mensaje emitido. }\end{array}$ \\
& $\begin{array}{l}\text { Los medios de comunicación pueden } \\
\text { convertirse en un valioso aliado en la prevención } \\
\text { del suicidio si enfocan correctamente la noticia } \\
\text { sobre el tema y tienen en cuenta las sugerencias } \\
\text { de los expertos: publicar señales de alerta de } \\
\text { una crisis suicida, dispositivos de salud mental a } \\
\text { los que puede acudir, divulgar grupos de riesgo } \\
\text { y medidas sencillas que permitan a la población } \\
\text { saber qué hacer en caso de detectar a un sujeto } \\
\text { con riesgo de suicidio. }\end{array}$ \\
\hline
\end{tabular}

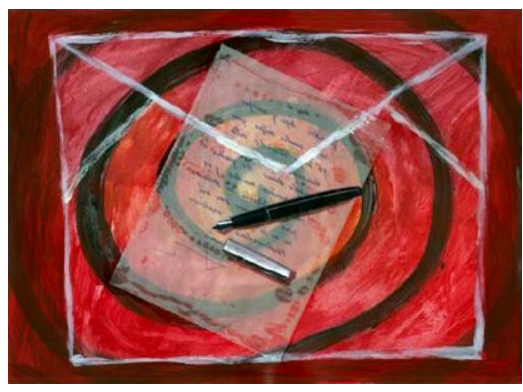

\section{3. ¿Cuáles pueden ser} algunas de las señales de alerta de un suicidio inmediato?

Una señal de alerta nos indica que una persona estaría teniendo serios pensamientos de quitarse la vida y que podría incluso estar planificando como realizarlo.

Las señales de alerta podrían ser también una petición de ayuda y nos proporcionan una oportunidad (tanto a la familia como a amigos, conocidos y profesionales de la salud) para intervenir y prevenir que esta persona se suicide.

Si usted se da cuenta de que alguien conocido está actuando de un modo extraño, que no tiene que ver con su carácter habitual, es importante que hable con él sobre lo que puede estar pasando.

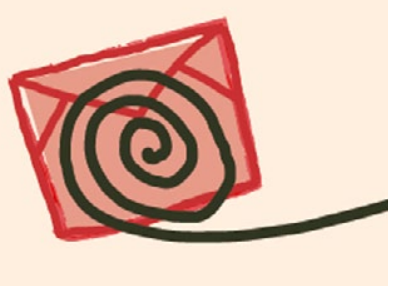


Las siguientes conductas son frecuentes entre personas que están considerando quitarse la vida:

- Amenazan con dañarse o matarse

- Buscan medios para suicidarse o hablan de un plan de suicidio

- Hablan o escriben sobre la muerte, el morirse o el suicidio (sobre todo cuando esto no era propio de la persona o era muy raro)

- Expresan sentimientos de desesperanza

- Expresan sentimientos de ira, rabia o venganza

- Se involucran en conductas que implican un riesgo innecesario o que son irresponsables

- Expresan sentimientos de estar atrapado, de no ver una salida

- Incrementan el uso de alcohol u otras drogas

- Se retiran o evitan el contacto con amigos, familias o su entorno

- Se muestran ansiosos o agitados

- Hay patrones anormales de sueño, como el no dormir o el dormir todo el tiempo

- Cambios dramáticos en el humor, tales como sentimientos de alegría tras un largo período de tristeza o depresión

- Se desprenden de sus posesiones o se despiden de su familia y amigos

- Pierden el interés en muchas actividades en las que antes participaban

- Dicen que no hay razones para vivir o que la vida es un despropósito.

En caso de identificarlos, es importante responder con rapidez, especialmente si la persona muestra varios al mismo tiempo, hablando con la persona y buscando la ayuda y el apoyo de otros.

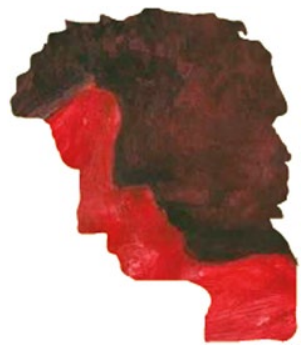




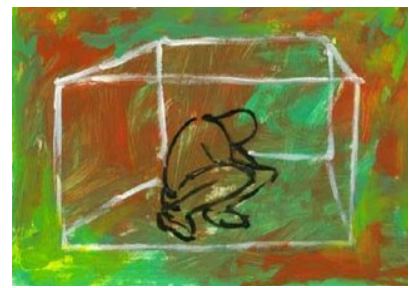

\section{4. ¿Qué circunstancias podrían precipitar la conducta suicida?}

Algunos acontecimientos o situaciones de la vida, a los que llamaremos precipitantes, pueden provocar un estrés intenso en un momento particular de una persona. Estos precipitantes pueden ser vistos como la gota de agua que rebosa el vaso y pueden llevar a alguien que estuvo pensando en quitarse la vida, a dar el paso de intentarlo.

Algunos ejemplos de sucesos y circunstancias que pueden actuar como precipitantes:

- Una discusión con una persona importante o con alguien amado

- La ruptura o pérdida de una relación afectiva

- El suicidio de un familiar, de un amigo o de un personaje público

- Abuso de alcohol o de otra sustancia

- Un reportaje sobre el suicidio o métodos de suicidio

- La aparición o el agravamiento de un trastorno mental o de una enfermedad física o accidente

- Cambios inesperados en las circunstancias de la vida

- Experimentar un acontecimiento vital traumático, como abuso, acoso o violencia

- Pérdida de estatus social, o episodio vivido como de pérdida del respeto por parte de los demás.

Más información

- ACUDA A SU CENTRO DE SALUD

- Teléfono de urgencias: 061 ○ 112.

- Confederación Española de Agrupaciones de Familiares y Personas con Enfermedad Mental (ofrecen información y apoyo y disponen de algunos recursos psicosociales). www.feafes.com.

- Teléfono de la Esperanza (tienen teléfono de crisis 24 horas en las principales poblaciones españolas). www.telefonodelaesperanza.org.

- www.suicidioprevencion.com

- www.redaipis.org 


\section{Información Específica}

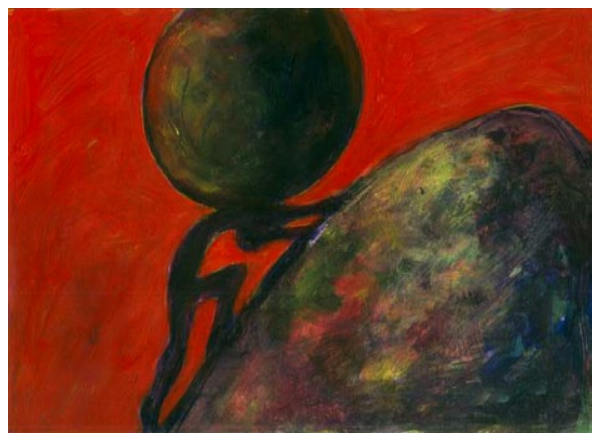

2.1. Información para pacientes que presentan ideas suicidas

¿Qué puede hacer usted si ha comenzado a pensar en el suicidio?

A continuación le exponemos una serie de recomendaciones importantes para una persona que tiene ideas de suicidio:

- Aunque no se le ocurra otra solución que el suicidio, no significa que no la haya, sino que usted no la puede ver en ese momento. Otra persona puede ayudarle a encontrar esa solución.

- Busque ayuda lo antes posible. Si cree que no puede más, hable con un amigo o con un familiar en quien confíe, vaya a ver a su médico o llame a un servicio de atención telefónica.

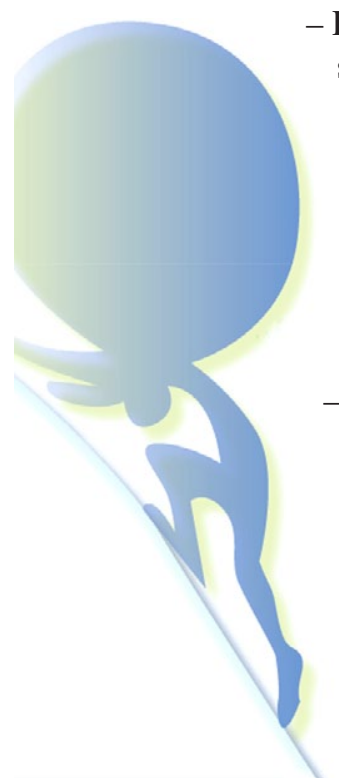

- Hable de sus pensamientos suicidas. No se guarde para sí mismo sus pensamientos suicidas.

- Posponga cualquier decisión acerca del suicidio: cuando la persona es capaz de posponer su decisión tan sólo 24 horas, las cosas mejoran y se sentirá más capaz de enfrentarse a sus problemas.

- Permanezca acompañado hasta que los pensamientos sobre el suicidio disminuyan.

- Las crisis son transitorias. Muchas personas han pensado en el suicidio en algún momento de su vida, pero deciden vivir porque se dan cuenta de que las crisis son transitorias, mientras que la muerte no lo es.

- Muchas personas que alguna vez han pensado en suicidarse, en realidad no querían morir sino acabar con su sufrimiento. Por eso están contentas de no haberlo hecho una vez que el sufrimiento ha pasado. 
- Piense en las cosas o personas importantes que le han ayudado a superar otros momentos difíciles. Esas son precisamente las cosas o personas por las que también ahora merece la pena vivir.

- No se aísle. Trate de salir o de recibir en su casa a familiares y amigos, aunque no disfrute de su compañía como antes. Es muy importante seguir manteniendo el contacto.

- Trate de centrarse en el día a día. Pensar más allá puede ser abrumador si siente que tiene muchos problemas y no se ve capaz de afrontarlos.

- Cuando esté desanimado, evite las drogas y el alcohol. Muchas sustancias aumentan su malestar. Además, no le ayudarán a resolver los problemas y pueden llevarle a hacer cosas que normalmente no haría.

- Manténgase sano, trate de hacer suficiente ejercicio y de comer bien. El ejercicio puede ayudarle a sentirse mejor mediante la liberación de ciertas substancias en su cerebro. Comer bien ayuda a notarse con más energía y a sentirse capaz de manejar los momentos difíciles de la vida.

- Vaya a ver a su médico o a su especialista para hablar del apoyo o el tratamiento. Hable de sus pensamientos y sentimientos sobre el suicidio con su médico. Converse sobre los modos con los que usted se mantiene a salvo y asegúrese de que recibe los mejores tratamientos y cuidados.

- Escriba un diario en el que pueda anotar las cosas realmente importantes para usted. Escriba sus sentimientos y léalos cuando los pensamientos suicidas le aparezcan.

Más información

- ACUDA A SU CENTRO DE SALUD

- Teléfono de urgencias: 061 o 112.

- Confederación Española de Agrupaciones de Familiares y Personas con Enfermedad Mental (ofrecen información y apoyo y disponen de algunos recursos psicosociales). www.feafes.com.

- Teléfono de la Esperanza (tienen teléfono de crisis 24 horas en las principales poblaciones españolas). www.telefonodelaesperanza.org.

- www.suicidioprevencion.com

- www.redaipis.org 


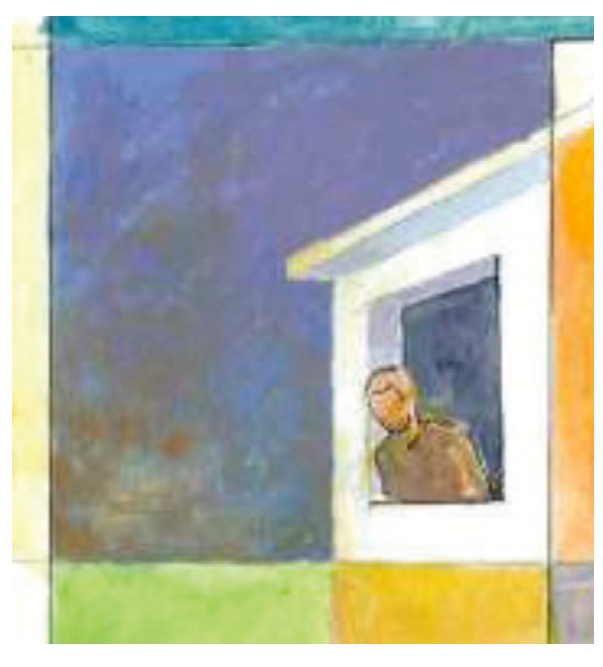

\subsection{Información para familiares y allegados}

¿QUÉ PODEMOS HACER cuando vemos señales de alerta y/o de ideación suicida en un familiar o allegado?

- Estar atento. Si alguien que usted conoce muestra algunos o todas las señales de alerta para el suicidio y/o ha experimentado algún factor precipitante, debería actuar inmediatamente para asegurar su seguridad.

- Conservar la calma. Si alguien que usted conoce muestra señales de alerta o ha alcanzado su tope, intente no reaccionar de modo exagerado.

- Hablar con esa persona. Mientras le muestra que usted entiende que se sienta desesperado o que en este preciso momento se encuentran en una posición difícil y frágil. Hágale saber que hay ayuda disponible, que no siempre se sentirá tan mal, y que con la ayuda correcta es posible que pueda manejar sus problemas y sentirse mejor en el futuro.

- Eliminar el acceso a cualquier método de suicidio y no dejar nunca sola a la persona. Si duda sobre el riesgo concreto, hable con ella y busque la ayuda de otras personas.

- Valorar el riesgo. Hable con la persona que podría estar en riesgo de suicidio y valore la situación. ¿Tiene un plan para matarse? ¿Tiene los medios para llevarlo a cabo? Si es así, la persona tiene un riesgo elevado de suicidio. Busque ayuda inmediatamente llamando al 061 o al 112 inmediatamente y ayúdele a mantenerse a salvo. 


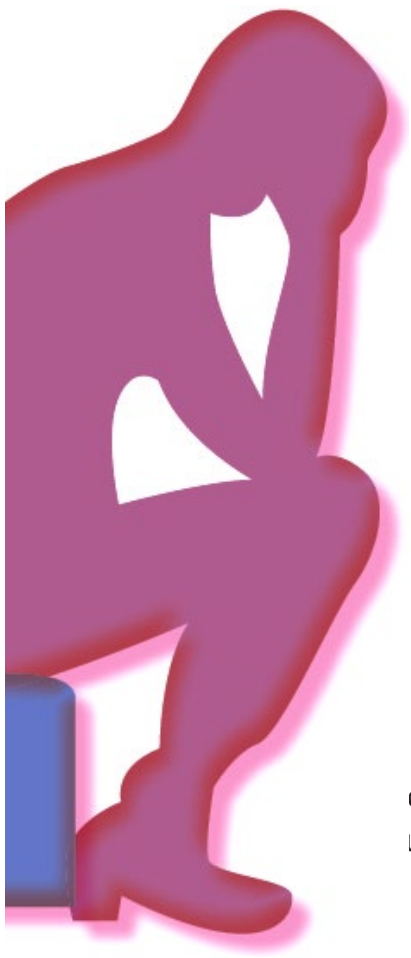

cicios. Proporcione ayuda práctica para que la persona en riesgo de suicidio tenga una atención adecuada a sus necesidades y situación. Tengan un plan de emergencia por si resulta que el servicio no está disponible o que tiene una larga lista de espera.

- Cuídese usted mismo. Ayudar a alguien a enfrentarse a los traumas y al estrés puede ser muy fatigoso y dejarnos agotados. Encuentre algún tiempo para las cosas con las que usted disfruta y busque a otras personas que puedan ayudarlo a apoyar a quien más lo necesita. 
¿QUÉ HACER Y QUÉ NO HACER ante la posible conducta suicida de un familiar o allegado?

\section{QUÉ HACER}

ante la posible conducta suicida de un familiar o allegado

\section{HAGA ALGO AHORA}

Tome las señales de alerta en serio y pregúntele a la persona si está pensando en el suicidio y si tiene algún plan. Busque urgentemente ayuda si la necesita llamando al 112 ó 061 o lleve a la persona al Servicio de Urgencias más próximo.

\section{HABLAR SOBRE EL SUICIDIO}

Hablar sobre el suicidio no va a meterle esa idea en la cabeza y, sin embargo, puede animarle a hablar sobre sus sentimientos. Un plan detallado indica mayor riesgo. No se comprometa a guardarlo como un secreto desde el momento en el que la seguridad física de la persona es su principal preocupación.

\section{ACEPTAR SU PROPIA REACCIÓN}

Usted puede sentir miedo o preferir ignorar la situación. Si le está costando dominarse, solicite la ayuda de alguien de confianza.

\section{ESTAR AHÍ POR ÉL O POR ELLA}

Pase algún tiempo con esa persona, anímele a hablar de cómo se está sintiendo, identifique a quien podría pedir apoyo, y anime a la persona para que acepte tener apoyo también más adelante.

\section{ACEPTAR LO QUE LE ESTÁ DICIENDO}

Mantenga una comunicación directa, abierta y honesta con esta persona. Permita que la persona exprese sus sentimientos y exprese su preocupación sin juzgarlo. Diga cosas como "Aquí estoy para ayudarte", "Hablemos" y "Estoy aquí por ti".

\section{ADOPTAR MEDIDAS DE SEGURIDAD}

Pregúntese hasta qué punto la persona está pensando en suicidarse. Si usted está claramente preocupado no deje sola a esa persona. Retire cualquier medio disponible para el suicidio, incluyendo armas, cuerdas, cinturones, medicinas, alcohol y otras drogas, incluyendo el acceso a cualquier vehículo.

\section{DECIDIR QUÉ HACER}

Comenten de modo conjunto qué decisión tomar. Usted podría necesitar contar con más ayuda (compañeros, padres, amigos cercanos u otras personas) para convencer a la persona para buscar ayuda profesional. Solo compartiendo esa información puede usted asegurarse que la persona tenga la ayuda y apoyo que necesita. 
ANIMAR A LA PERSONA A OBTENER APOYO

Médicos de atención primaria y urgencias

Servicio de salud mental

Servicios sociales

Orientadores escolares, educadores

Servicios religiosos

Servicios de ayuda tanto on line, como telefónica.

\section{PEDIR UN COMPROMISO}

Pídale a la persona que se comprometa a no callar su malestar y preocupación y a hablar con alguien si vuelven las ideas de suicidio. Esto facilitará que el busque ayuda.

\section{CUIDARSE A SÍ MISMO}

Es difícil y emocionalmente agotador apoyar a alguien que piensa en suicidarse, no lo haga usted solo. Encuentre a alguien con quien hablar, tal vez amigos, familiares o un profesional sanitario.

\section{MANTENERSE INVOLUCRADO}

Los pensamientos de suicidio no desaparecen fácilmente. La continua preocupación de la familia y amigos es muy importante para la recuperación de la persona. Manténgase atento o atenta a la evolución de la persona.

\section{QUÉ NO HACER}

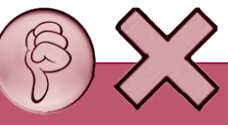

ante la posible conducta suicida de un familiar o allegado

\section{NO REHUIR LOS PROBLEMAS}

No deje a la persona sola si cree que su vida está en riesgo inmediato. 访

\section{NO BANALIZAR, NI DESAFIAR}

No trate con ligereza cualquier amenaza, sobre todo si la persona empieza a bromear con eso. NO minimice la situación o la intensidad de las emociones y del malestar. Retar a que lo haga no va a ayudarle. No le diga cosas como "A qué no eres capaz. Si lo haces, hazlo bien". \&

\section{NO UTILIZAR GRITOS O REPRIMENDAS}

No actúe de modo excesivo o lo culpe por estar mal. ¡No vaya a ser otra petición de ayuda! Muchas veces lo que necesitan es motivación y eso no se consigue con un buen grito. 


\section{NO TEMER PREGUNTAR}

No le de miedo preguntar a la persona por qué está tan triste y tan deprimida ni si se quiere hacer daño a sí misma.

\section{NO JUZGAR, NO COMPARAR}

No le diga que eso es de cobardes, o que es de valientes y que él o ella no lo es. No le diga cosas como "algo habrás hecho para estar así", responsabilizándola de toda la situación, o señalar que "está mucho mejor que otras personas". Esto suele incrementar los sentimientos de culpa y de malestar. \&3

\section{NO MANTENGA TODO EN SECRETO}

Entre la vida de su amigo y su confianza, escoja la vida. \&

\section{NO DÉ SOLUCIONES SIMPLISTAS}

Una solución obvia y simple puede ayudar a incrementar los sentimientos de incapacidad, vergüenza o soledad en la persona.

\section{NO INTENTE AYUDAR A LA PERSONA USTED MISMO SIN AYUDA DE NADIE}

No piense que usted es quien mejor la conoce, que nunca le va a faltar ni a cansarse y que los demás sobran, incluyendo los profesionales. \&

\section{Más información}

- ACUDA A SU CENTRO DE SALUD

- Teléfono de urgencias: 061 o 112.

- Confederación Española de Agrupaciones de Familiares y Personas con Enfermedad Mental (ofrecen información y apoyo y disponen de algunos recursos psicosociales). www.feafes.com.

- Teléfono de la Esperanza (tienen teléfono de crisis 24 horas en las principales poblaciones españolas). www.telefonodelaesperanza.org.

- www.suicidioprevencion.com

- www.redaipis.org 
Anexo 4. Información para familiares y allegados sobre el duelo tras un suicidio

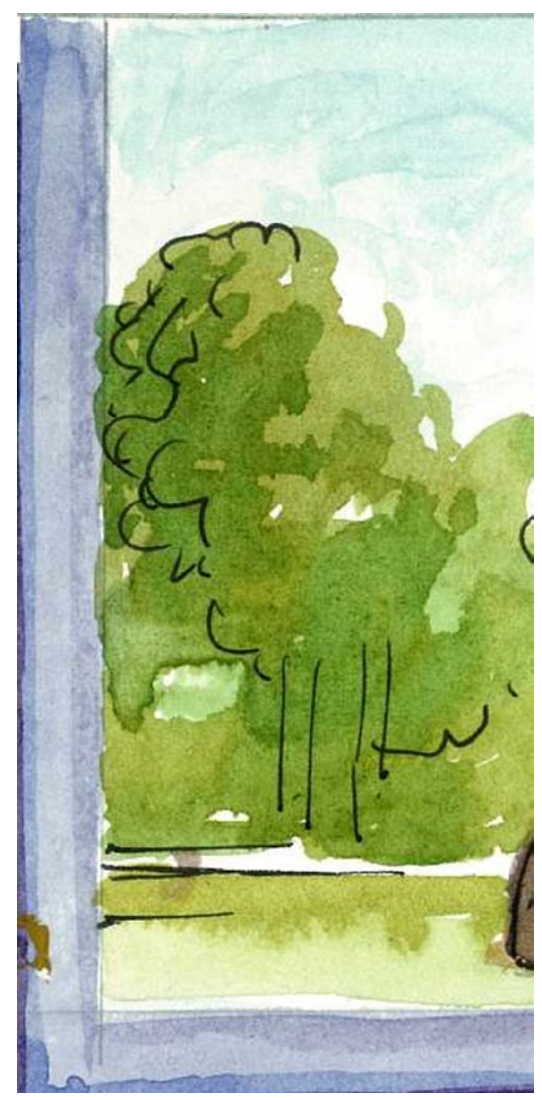

\section{EL DÍA DESPUÉS DEL SUICIDIO DE UN FAMILIAR O ALLEGADO}

Información para familiares y allegados 


\section{CONTENIDO}

\section{La experiencia de duelo}

1.1. ¿Qué es el duelo?

1.2 ¿Cuáles son los sentimientos y emociones más frecuentes asociados al duelo?

\section{El duelo tras un suicidio}

2.1. ¿Es el duelo de un fallecimiento por suicidio diferente a otras situaciones de duelo?

2.2. ¿Cómo puedo enfrentarme a esta situación?

\section{El duelo en la infancia y la adolescenciao}

3.1. ¿Cómo actuar ante un niño que vive el suicidio de alguien cercano?

3.2. ¿Cómo pueden ayudar los profesores?

\section{Ayudar a una persona que está pasando por una situación de duelo tras un suicidio}

4.1. ¿Qué hacer para ayudar a un familiar o amigo a enfrentarse a esta situación?

Esta información ha sido elaborada a partir del conocimiento basado en la literatura científica disponible en el momento de la publicación.

\footnotetext{
Agradecimientos

El grupo elaborador de la Guía de Práctica Clínica desea dar las gracias a José Luis Iglesias Diz y a Luis Iglesias Fernández, autores de las ilustraciones y de forma especial a todos los pacientes y familiares que han colaborado en la elaboración de este material.
} 


\section{Introducción}

La muerte de un familiar o allegado es una de las situaciones más estresantes por las que puede pasar una persona. Pero cuando esta muerte se produce a causa de un suicidio, suele hacerse todavía más complicada, causando un dolor intenso y prolongado que será diferente y único en cada persona que lo sufre.

Este documento es un intento de explicar cuáles son las reacciones más frecuentes cuando alguien pierde a un ser querido o alguien cercano a causa de un suicidio y pretende servir de ayuda para afrontar estas situaciones. Ha sido realizado por profesionales implicados en el tratamiento de personas con conducta suicida y por pacientes y familiares, participantes en la elaboración de la Guía de Práctica Clínica de prevención y tratamiento de la conducta suicida.

Toda la información que se recoge proviene de estudios realizados con personas que han vivido esta situación, de recomendaciones de guías nacionales e internacionales, libros de autoayuda y de la experiencia de los profesionales implicados.

Esperamos que esta información le sea de ayuda y que le sirva para aliviar su duelo. 


\section{La experiencia de duelo}

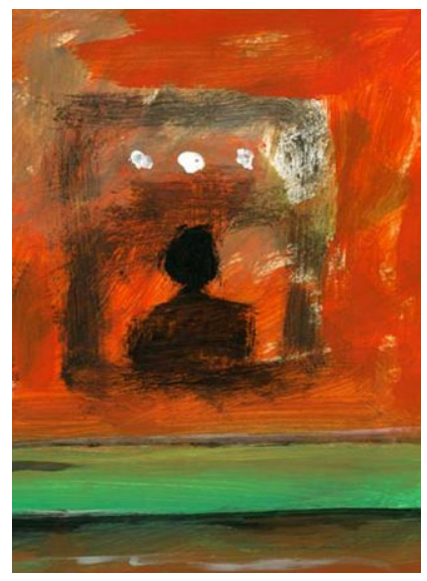

\section{1. ¿Que es el duelo?}

Llamamos duelo a la reacción emocional y física que se produce tras el fallecimiento de un ser querido. El duelo es una respuesta normal ante esta pérdida.

No hay una forma correcta de pasar el duelo y cada persona lo vive a su manera. Depende de diferentes aspectos, como la relación con la persona fallecida, la forma en la que se produjo la muerte, experiencias pasadas, el carácter y la existencia o no de apoyo familiar o social.

No existe una única manera de pasar el duelo. Aunque cada persona es diferente y tiene su propio ritmo, se han descrito tres etapas que suelen pasar las personas que pierden a un ser querido.

\section{Estas fases o etapas son:}

Etapa 1: es frecuente sentir rabia, confusión, angustia o aturdimiento, creer que lo que está pasando no es real y negar sentimientos. También puede aparecer la distancia emocional para protegerse o incluso sentir alivio.

Etapa 2: la persona se siente sola, triste y deprimida. También son frecuentes algunas emociones como desesperación, agresividad, culpa y sentir que la vida ha perdido su significado. También suelen aparecer problemas para comer y dormir.

Etapa 3: se produce una aceptación gradual de la pérdida, la persona comienza a sentirse mejor no piensa tanto en lo ocurrido y los sentimientos son menos intensos. Poco a poco se van desarrollando nuevas tareas que antes no se hacían y se establecen nuevas relaciones. 

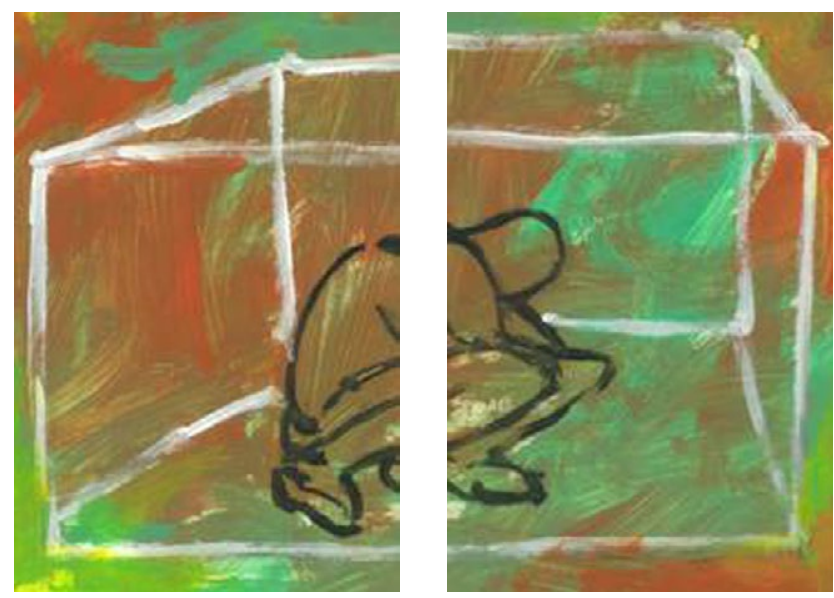

\section{2. ¿Cuáles son los sentimientos y emociones más frecuentes asociados al duelo?}

A continuación se describen las emociones más frecuentes que pueden sentir las personas que atraviesan por esta situación. Puede reconocer algunas de ellas o puede sentir otras diferentes, aunque las que aquí se describen suelen ser frecuentes.

\section{Shock}

La muerte de alguien cercano puede suponer una gran conmoción, sobre todo cuando es una muerte inesperada. En esta situación es frecuente sentirse tembloroso, adormecido o insensible, como fuera de la realidad. También es normal tener sensaciones físicas desagradables, como dificultad para respirar, boca seca, náuseas, opresión en la garganta y en el pecho, fatiga y un gran sentimiento de vacío. Esta sensación de shock puede durar desde días hasta semanas tras la muerte.

\section{Aturdimiento}

A veces en estas situaciones es muy frecuente sentir que todo es un sueño, o sentirse como fuera de la realidad. Muchas personas no son capaces de llorar en el funeral o expresar sus sentimientos y constantemente piensan que esa situación no puede estar pasando. Estos sentimientos son una reacción normal que puede proteger a las personas ante un dolor muy grande. 


\section{Confusión}

Es muy habitual sentirse confuso e incapaz de concentrarse tras la pérdida de un ser querido. Algunas personas también tienen la sensación de que han perdido el control de sus vidas y no se sienten capaces de tomar decisiones. Hay que darse tiempo para aceptar la muerte y que la persona no va a volver. Hablar de la situación con otras personas y la celebración o asistencia al funeral u otros rituales puede ayudar a aceptar lo ocurrido y a ir asumiéndolo poco a poco.

\section{Búsqueda}

Después del shock inicial y cuando la pérdida se va aceptando, es normal que muchas personas necesiten "buscar" a la persona fallecida, repitiendo su nombre o soñando con ella, teniendo la sensación de que la ve por la calle o que la persona fallecida le está llamando.

\section{Angustia y desesperación}

En ocasiones es normal sentir desesperación por no poder ver o no poder hablar con la persona fallecida. Puede pensar de forma incontrolable y repetida en lo que pasó y que tenga la necesidad de hablar del tema.

\section{Tristeza}

Tras la pérdida de un ser querido es una reacción normal sentirse muy triste. Es posible que prefiera estar solo y tenga la necesidad de llorar. Para muchas personas, llorar es muy positivo, porque ayuda a reducir el estrés y a desahogarse, así que no se sienta mal por hacerlo. Pero tampoco se sienta mal si tiene la sensación de no querer o no ser capaz de llorar, porque también es perfectamente normal.

\section{Enfado}

Ante la muerte de un familiar o allegado, muchas personas pueden sentir enfado o rabia. Es posible que se pregunte “¿cómo puede pasarme esto a mi?” y que al pensarlo sienta un gran sentimiento de rabia. Este enfado puede ser general o hacia personas que usted

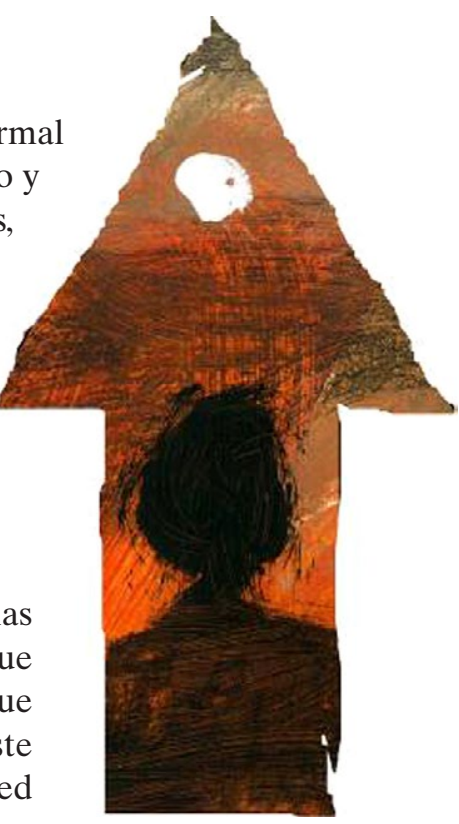


piensa que no hicieron nada por ayudar (familia, amigos, médicos...). También puede sentir enfado con la persona que se suicidó, porque se siente abandonado por ella. Otras personas también se sienten mal consigo mismas porque tienen la sensación de no haber hecho nada por evitarlo. Todas estas sensaciones son normales, debe intentar controlar el enfado y pensar que muchas veces es muy difícil evitar la muerte.

\section{Culpa}

Pensar qu e no hicimos nada por prevenir la muerte de un familiar es muy doloroso. Sentir culpa es algo muy frecuente en los familiares, y es una de las partes más difíciles de superar. Algunas personas además de sentirse culpables, sienten que no tienen derecho a vivir o a ser felices después de algo así.

\section{Alivio}

Si la persona llevaba mucho tiempo enferma o sufriendo y no podía ser feliz, a veces la familia siente un alivio que es perfectamente normal.

\section{Miedo}

Es posible sentir miedo y pérdida del control en nuestra vida y en las de los seres queridos. Además, este miedo suele acompañarse de síntomas físicos, como dificultad al respirar, o notar que el corazón se acelera. Estas sensaciones irán disminuyendo con el tiempo.

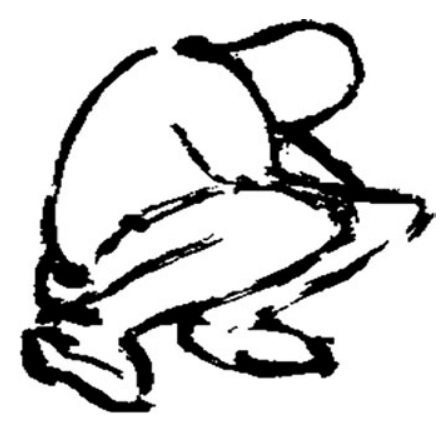


Es necesario que entienda que para superar el duelo hay que llevar a cabo cuatro "tareas" importantes:

\section{QUÉ HACER}

para superar el duelo

\section{ACEPTAR LA PÉRDIDA}

Es importante que intente aceptar que la persona no va a volver. Hable con los demás de cómo se está sintiendo.

\section{TRABAJAR CON EL DOLOR Y LAS EMOCIONES}

Tiene que darse tiempo para entender y aceptar emociones y sentimientos. Intentar evitar estos sentimientos hace que la situación no termine de superarse.

\section{APRENDER A VIVIR SIN LA PERSONA QUERIDA}

Puede significar aceptar nuevas tareas que antes no se hacían o aprender nuevas habilidades. Debe intentar reconstruir su vida o hacer que su día a día vuelva a la normalidad, volviendo al trabajo y haciendo poco a poco las actividades de antes.

\section{SEGUIR ADELANTE}

Debe pensar en el futuro sin la persona fallecida y adaptar los planes de futuro a la nueva situación.

Lo más frecuente es que el malestar intenso vaya mejorando con el tiempo, a medida que se va restableciendo su vida. Sin embargo, a veces el duelo se complica y es necesario ir al médico para que se realice una evaluación y se valore la necesidad de recibir tratamiento.

Debe acudir al médico cuando el malestar es intenso, se prolonga mucho en el tiempo y cuando están presentes:

1. Incapacidad para aceptar la muerte del familiar o allegado

2. Ideas persistentes de muerte

3. Sentimientos de culpa

4. Preocupación excesiva sobre la muerte del ser querido

5. Incapacidad para hacer las actividades de su vida diaria

6. Recuerdos recurrentes de la muerte del ser querido 
7. Ansiedad, irritabilidad, agresividad

8. Dificultad para dormir y concentrarse

9. Aumento del consumo de fármacos, alcohol, $\mathrm{u}$ otras drogas

10. Incapacidad para relacionarse con otras personas.

\section{Más información}

- ACUDA A SU CENTRO DE SALUD

- Teléfono de urgencias: 061 ○ 112.

- Confederación Española de Agrupaciones de Familiares y Personas con Enfermedad Mental (ofrecen información y apoyo y disponen de algunos recursos psicosociales). www.feafes.com.

- Teléfono de la Esperanza (tienen teléfono de crisis 24 horas en las principales poblaciones españolas). www.telefonodelaesperanza.org.

- www.suicidioprevencion.com

- www.redaipis.org 


\section{El duelo tras un suicidio}

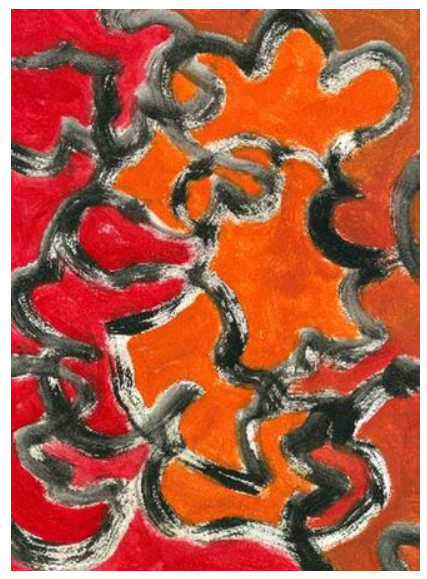

\section{1. ¿Es el duelo de un fallecimiento por suicidio diferente a otras situaciones de duelo?}

Nadie está preparado para recibir la noticia de que un ser querido se ha quitado la vida.

El duelo de alguien cercano es duro, independientemente de la causa de la muerte. Pero cuando la causa de la muerte es un suicidio, es más duro todavía de superar para las personas cercanas.

Algunas veces, el duelo que sufren las personas que pasan por el suicidio de un ser querido es diferente a otros duelos por muertes naturales o a causa de un accidente. En ocasiones puede ser más prolongado, y el shock, el aislamiento y la culpa pueden ser mayores que tras otro tipo de muertes. El proceso se suele caracterizar por cuestionarse aspectos relacionados con la persona fallecida y por la búsqueda de una explicación. Todas estas reacciones emocionales no son más que reacciones normales de expresión del sufrimiento.

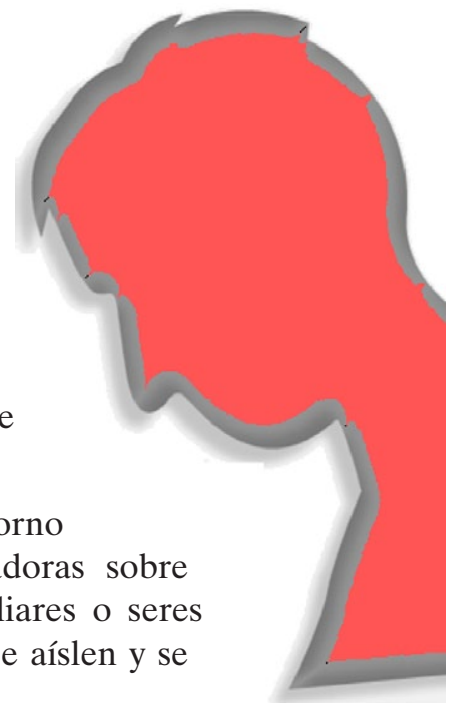

Otras veces, las personas del entorno presentan actitudes negativas o culpabilizadoras sobre el suicidio, que contribuyen a que los familiares o seres queridos de la persona que se ha suicidado se aíslen y se sientan estigmatizados. 
Es frecuente que las personas allegadas se formulen estas preguntas y experimenten algunas de estas situaciones:

- Preguntarse por qué: una de las primeras ideas que tendrá en la cabeza es preguntarse el motivo del suicidio. Normalmente la familia

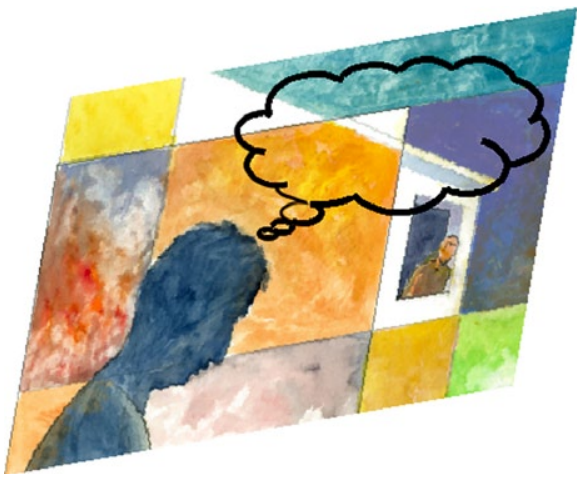
intenta buscar una explicación o significado al fallecimiento de la persona, por lo que es posible que surjan muchas dudas y que puedan darse situaciones tensas en la familia. Para muchas personas es muy difícil aceptar la idea de que nunca sabrán el verdadero motivo de la muerte de su familiar.

- Imágenes que se repiten de la persona fallecida: una de las cosas más frecuentes entre las personas allegadas es tener todo el tiempo imágenes de la persona que se ha suicidado y suele ser peor para las personas que encuentran el cuerpo. Normalmente estas imágenes dejan de ser tan recurrentes con el tiempo y a medida que la persona va aceptando la situación.

- ¿Podríamos haber hecho algo?: es algo normal entre los familiares pensar que podían haber hecho algo para prevenir el suicidio de un ser querido o que algo que hicieron o dijeron podría haber tenido algo que ver. Debes pensar que aunque hay algunas señales que nos pueden estar alertando del riesgo de suicidio, incluso para los profesionales es difícil de prevenir.

- ¿Qué le digo a la gente de la causa de la muerte?: para muchas personas es difícil hablar abiertamente sobre el suicidio, pero tratar de esconderlo puede ser peor a largo plazo. Tampoco debe dar explicaciones si no le apetece, pero no es bueno que tenga la sensación de tener que esconderlo. Es una decisión que debe tomar usted mismo.

- Sentimientos de rechazo y abandono: es normal sentirse abandonado o rechazado por

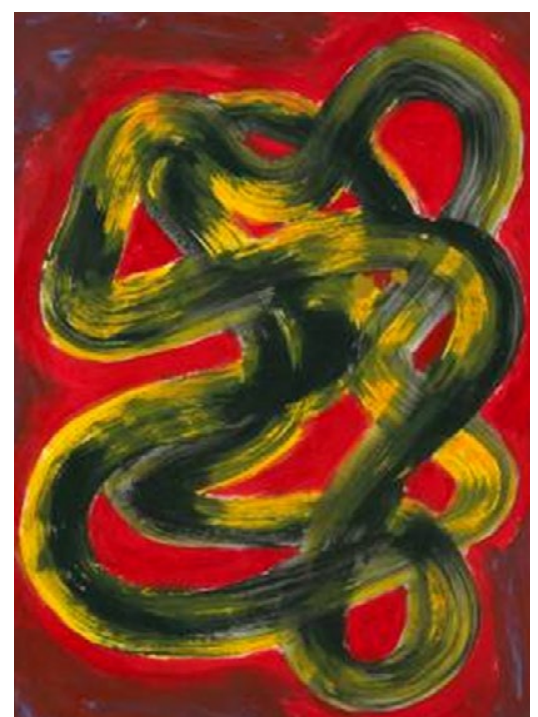


la persona fallecida y que le parezca una conducta egoísta. Piense que normalmente las personas que se suicidan están tan preocupadas por sus propios problemas que no son capaces de pensar en los demás

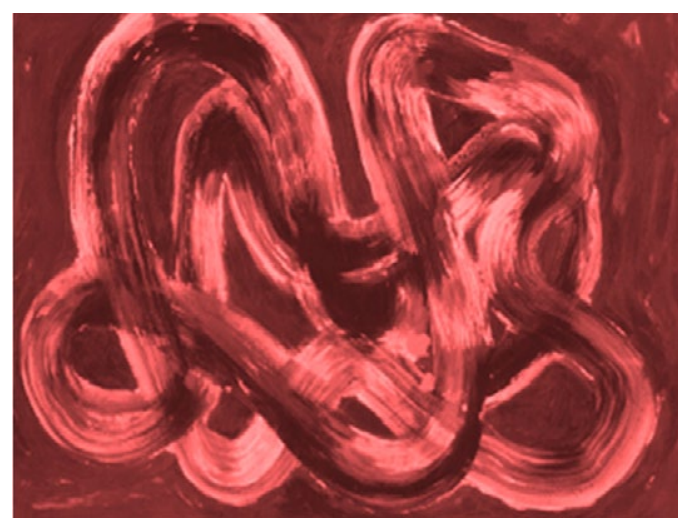

- Preocupación por su propio suicidio: muchas personas tienen miedo de estar en riesgo de suicidio, e incluso pueden pensar en él. Es importante que no tenga miedo a hablarlo con sus amigos o familia y a comentárselo a su médico.

- Estigma: aunque las actitudes hacia el suicidio están cambiando, existe mucho desconocimiento y a veces intolerancia. Muchas personas desconocen que la conducta suicida es un grave problema de salud pública y una de las primeras causas de muerte en todo el mundo. El silencio de los otros acerca del suicidio o la forma de actuar de los demás pueden hacerle sentir culpable y que no tenga ganas de estar con los demás. Pero debe pensar que la mayoría de las veces, muchas personas no saben qué decir o cómo actuar.

- Aislamiento: es posible que piense que nadie le entiende y que necesita estar solo. Aunque los momentos de soledad son necesarios, es importante relacionarse con los demás y no encerrarse en uno mismo. La actividad social le irá ayudando a volver a la normalidad.

Si usted siente que no es capaz de enfrentarse solo a la situación o que estos sentimientos no van mejorando con el tiempo, acuda a su centro de salud o busque ayuda. 


\section{2. ¿Cómo puedo enfrentarme a esta situación?}

QUÉ HACER

ante un duelo por suicidio

\section{RESÉRVESE UN TIEMPO CADA DÍA}

Es importante reservar un tiempo cada día, si es posible a la misma hora y en el mismo sitio, de modo que pueda llorar, recordar a la persona muerta, rezar o meditar.

\section{ESCRIBA}

Lleve un diario para registrar sus sentimientos, pensamientos y recuerdos. Esto puede ayudarle a ganar un cierto control sobre emociones intensas.

\section{HAGA UN POCO DE EJERCICIO}

Ande todos los días por lo menos 20 minutos. Generalmente le ayudará a sentirse mejor y mejorará su sueño.

\section{REDUZCA EL ESTRÉS}

La meditación, las técnicas de relajación, el masaje o escuchar música pueden ayudarle a reducir el estrés emocional y físico por la pérdida.

\section{CUÍDESE}

Trate de descansar lo suficiente y comer bien. Piense en cómo pasar cada día, no más allá. Cuando sea capaz, empiece a dedicar tiempo a las cosas que le hacían disfrutar. Esto no es desleal y le ayudará a enfrentarse mejor con el dolor.

\section{EXPRESE SUS SENTIMIENTOS}

A algunas personas les ayuda hacer actividades creativas, como la poesía o la pintura, para expresar sus sentimientos. Otras actividades, como la costura, cocina, jardinería o carpintería, pueden también ser de ayuda.

\section{COMPARTA SU EXPERIENCIA}

La participación en grupos de apoyo o la lectura de libros de autoayuda sobre experiencias similares son muchas veces la única forma de compartir lo más profundo de su pena con otros que han pasado por los mismos sentimientos.

\section{COMUNIQUE LO QUE NECESITA}

Pídale a su familia o allegados lo que necesite (por ejemplo estar solo). Así será más fácil que puedan ayudar.

\section{NO TOME DECISIONES IMPORTANTES}

Trate de evitar tomar decisiones importantes, como cambiar de casa o librarse de sus posesiones personales, inmediatamente después de la muerte. Es posible que no esté pensando claramente y puede hacer cosas de las que luego se arrepienta. 


\section{DESE TIEMPO}

Recuperarse de una muerte por suicidio necesita tiempo para curar, igual que una herida profunda.

\section{RESPETE LA ELECCIÓN DE SU FAMILIAR O ALLEGADO}

Aunque no esté de acuerdo, se sienta perjudicado o no lo entienda. Usted no pudo elegir por él o por ella.

\section{NO SE SIENTA CULPABLE}

Incluso para un profesional es muy difícil prevenir un suicidio. No sienta que por lo que dijo o no hizo hubiese podido cambiar el desenlace.

\section{SU DOLOR NO ES UNA ENFERMEDAD}

No significa que esté enloqueciendo. Ese dolor tan profundo es una reacción normal de un ser humano sensible frente a la experiencia más difícil que una persona puede vivir.

\section{NO ABUSE DE FÁRMACOS O DE DROGAS}

Procure no recurrir al alcohol o las drogas como una forma de aliviar su tristeza. Si bien le pueden proporcionar alivio de sus sentimientos a corto plazo, impiden el duelo y pueden causar depresión u otros trastornos.

\section{SOLICITE AYUDA PROFESIONAL}

Si pasa el tiempo y usted se sigue sintiendo ansioso o deprimido (problemas con el sueño, falta de apetito, pérdida de energía e interés por las cosas, pensamientos suicidas), es importante buscar la ayuda de su médico.

\section{NO BUSQUE EXPLICACIONES}

La mayoría de las veces, por más que uno lo intenta, nunca consigue entender las razones que llevaron a un ser querido a quitarse la vida.

\section{Más información}

- ACUDA A SU CENTRO DE SALUD

- Teléfono de urgencias: 061 o 112.

- Confederación Española de Agrupaciones de Familiares y Personas con Enfermedad Mental (ofrecen información y apoyo y disponen de algunos recursos psicosociales). www.feafes.com.

- Teléfono de la Esperanza (tienen teléfono de crisis 24 horas en las principales poblaciones españolas). www.telefonodelaesperanza.org.

- www.suicidioprevencion.com

- www.redaipis.org 


\section{El duelo en la infancia y adolescencia}

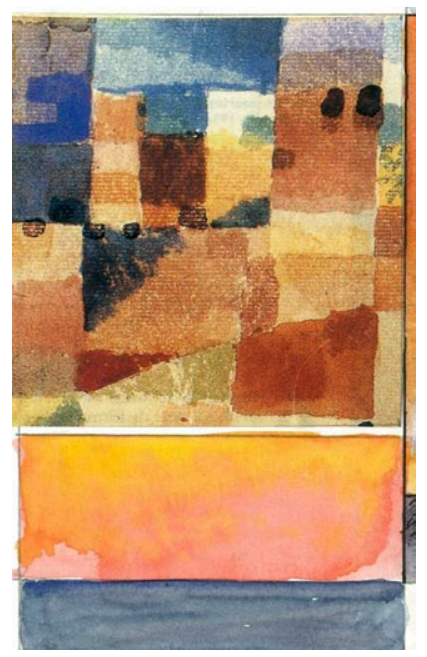

\section{1. ¿Cómo actuar ante un niño que vive el suicidio de alguien cercano?}

No todos los miembros de la familia experimentan el duelo de la misma manera, con las mismas etapas ni en el mismo tiempo. Cada persona necesita su espacio y su propio camino para pasar el duelo y, en el caso de los niños, puede ser difícil saber cómo ayudarlos a enfrentarse a la pérdida.

Los niños y adolescentes son especialmente vulnerables, puesto que tienen una forma diferente de expresar sus sentimientos, aunque no por esto debemos pensar que no sienten dolor. Además, lo que los niños pueden entender sobre la muerte depende en gran medida de su edad, sus experiencias vitales y su personalidad.

Algunos consejos sobre cómo manejar la situación son:

- Dependiendo de las circunstancias y de la madurez del niño, es recomendable ser honesto y hablar sinceramente de lo ocurrido, aunque no es necesario dar muchos detalles.

- Es mejor evitar frases como "se ha ido a dormir" o "está en un sitio mejor", porque estas frases pueden confundir a los niños.

- A los más pequeños les costará entender lo que significa la muerte. Será necesario explicar una y otra vez el significado de algo definitivo e irreversible con un lenguaje adecuado a su edad.

- No caer en la tentación de apartarle de la realidad que está viviendo con el pretexto de ahorrarle sufrimiento. 
- Se debe facilitar que el niño hable de sus sentimientos y que no los guarde para él. Leer historias o cuentos pueden ayudar a que el niño comunique sus emociones.

- Hay que entender que los niños pueden actuar de forma muy diferente a los adultos y pueden expresar sus sentimientos de muchas formas: irritabilidad, pesadillas, travesuras y a veces, síntomas somáticos: vómitos, dolores, disminución de apetito o con la aparición de comportamientos regresivos: hacerse pis, hablar mal.

- Es frecuente que sientan culpa y abandono: es importante que el niño no se sienta culpable, que se sienta arropado y que no tenga la sensación de que se va a quedar solo o de que

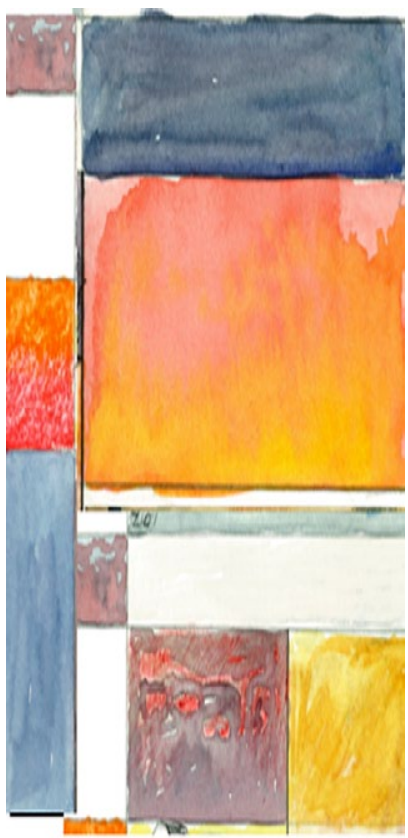
la gente a la que quiere se morirá de forma repentina.

- Algunos niños pueden creer que la muerte es "contagiosa".Es imprescindible darle seguridad, la certeza de permanecer a su lado y fortalecer el contacto físico: acercarse, sentarlo a nuestro lado, abrazarlo y escucharlo.

- El adolescente expresa con dificultad lo que siente. Por ello es necesario vigilar la aparición de cambios de hábitos: en el estudio (fracaso escolar), aislamiento de sus amigos y familia, abuso de alcohol $\mathrm{u}$ otras drogas, promiscuidad, peleas o práctica de deportes de riesgo que pueden indicar la necesidad de búsqueda de ayuda especializada.

- Si la situación es muy difícil para usted, deje que los demás le ayuden. Hable con el médico y con los profesores, ellos podrán orientarle sobre cómo enfrentarse a la situación y pueden ser de gran ayuda.

\section{2. ¿Cómo pueden ayudar los profesores?}

Las reacciones más habituales en la infancia cuando se vive un suicidio cercano, pueden adoptar la forma de alteraciones en el comportamiento, alteraciones emocionales y disminución del rendimiento académico. Su evolución dependerá en parte de cómo transcurra la situación en su entorno 
más próximo, de modo que a medio plazo, una adecuada estabilización del entorno familiar y escolar favorecerá en gran medida su recuperación.

Los niños y adolescentes que viven el suicidio de alguien cercano pueden necesitar apoyo en la escuela. Si es usted profesor, puede ayudar de la siguiente manera:

- Intente mantener la normalidad

- Busque algún momento para hablar con el niño

- Hable a los demás compañeros de lo sucedido y cómo deben actuar y pueden ayudar, en un momento en

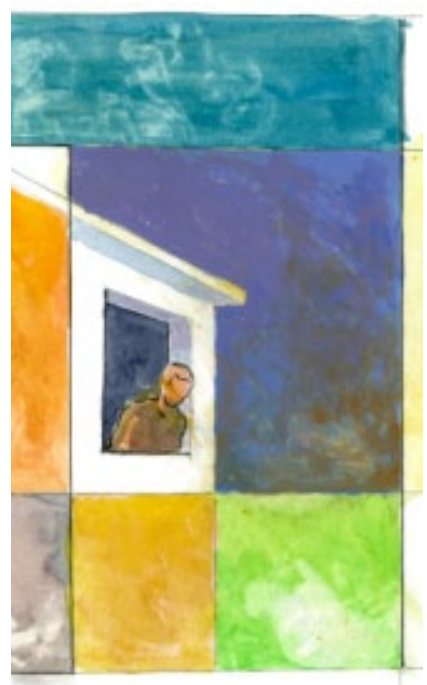
que el alumno implicado esté ausente

- Tenga especial atención en fechas especiales como las navidades, los cumpleaños o el aniversario

- Observe si se produce algún cambio de comportamiento que pueda estar indicando algún problema

- Esté atento a las señales de alarma que indican riesgo de suicidio

- Intentar hablar abiertamente de la muerte es más recomendable que evitar el tema.

En caso de que las dificultades que se presentan sean relevantes, será necesaria una valoración médica y psicológica específica.

\section{Más información}

- ACUDA A SU CENTRO DE SALUD

- Teléfono de urgencias: 061 o 112.

- Confederación Española de Agrupaciones de Familiares y Personas con Enfermedad Mental (ofrecen información y apoyo y disponen de algunos recursos psicosociales). www.feafes.com.

- Teléfono de la Esperanza (tienen teléfono de crisis 24 horas en las principales poblaciones españolas). www.telefonodelaesperanza.org.

- www.suicidioprevencion.com

- www.redaipis.org 


\section{Ayudar a una persona que esté pasando por una situación de duelo tras un suicidio}

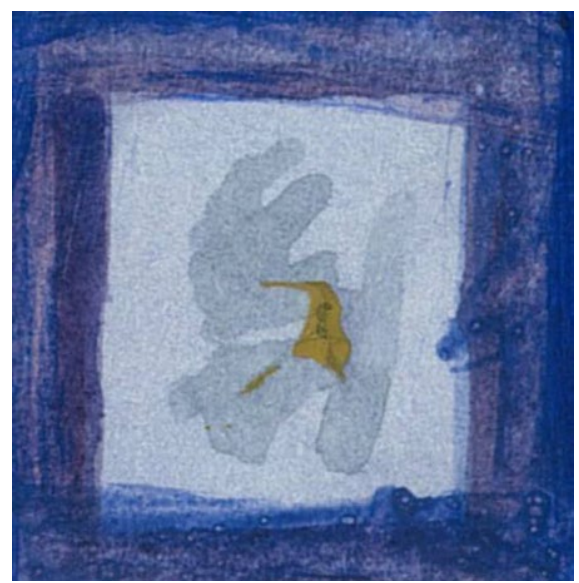

4.1. ¿Qué hacer para ayudar a un familiar o amigo a enfrentarse a esta situación?

Perder a un ser querido debido a un suicidio provoca un gran número de emociones y preocupaciones. Muchas veces esta situación sobrepasa a las personas que lo sufren y tienen la necesidad de llorar o gritar, pueden mostrarse agresivos, con mal humor e irritables, mientras que a la vez pueden querer estar solos y no hablar.

\section{Qué hacer}

- Tenga paciencia e intente entender que la situación que está pasando su familiar o amigo es muy difícil

- Es importante no buscar culpables de lo sucedido ni hacer juicios sobre nadie

- Trate a la persona como a cualquier otra que pierde a un ser querido

- Póngase en contacto tan pronto como pueda. Aunque hay personas que prefieren no recibir visitas, muestre sus sentimientos tan pronto como pueda, porque es importante que sepa que usted está preocupado y que se ofrece a ayudar en lo posible

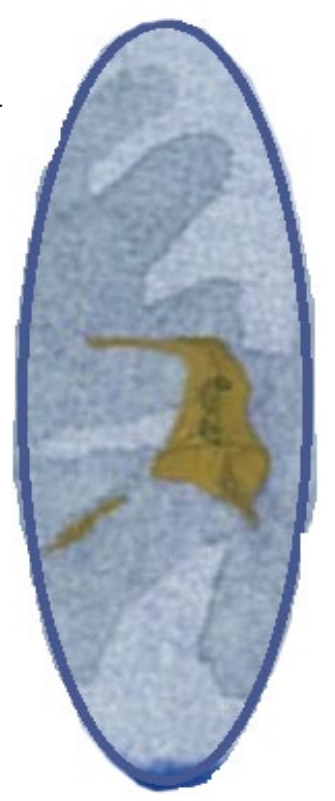


- Permita que la persona se exprese y que pueda desahogarse. Una de las cosas más importantes es escuchar

- Deje que hable cuando esté preparado para hacerlo

- A veces cosas sencillas, como un abrazo o acompañarle a dar un paseo, pueden ayudar mucho

- También puede ayudar ofreciéndose para echar una mano con las tareas del día a día, como hacer la comida, cuidar a los niños o ayudar con el papeleo

- La ayuda deberá prologarse en el tiempo, no solo en las primeras semanas. A veces también se necesita ayuda en fechas especiales, como el aniversario, los cumpleaños y otras fechas importantes en la vida de estas personas

- Si ve que necesita ayuda, acompáñele al médico o recomiéndele ir. El médico podrá orientarle sobre cuál es la mejor opción en su caso

- Si usted también está pasándolo mal por el suicidio de la persona querida, piense que usted puede necesitar apoyo y hablar con otros amigos, familia o con los profesionales sanitarios sobre cómo se encuentra.

\section{Qué decir}

- Es mejor que diga "no sé qué decir", que evitar hablar de lo sucedido

- Diga que lo siente tan pronto como sea posible

- Pregunte a la persona cómo se siente y qué necesita

- Ofrézcase para hablar o para ayudar en lo necesario

- Puede hablar de la persona fallecida y de lo importante que era para usted

- Evite preguntar detalles de la muerte

- Intente no juzgar la situación ni dar opiniones sobre la posible causa o buscar explicación al suicidio.

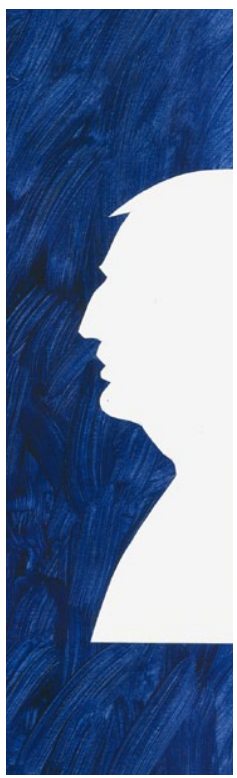




\section{Más información}

- ACUDA A SU CENTRO DE SALUD

- Teléfono de urgencias: 061 o 112.

- Confederación Española de Agrupaciones de Familiares y Personas con Enfermedad Mental (ofrecen información y apoyo y disponen de algunos recursos psicosociales). www.feafes.com.

- Teléfono de la Esperanza (tienen teléfono de crisis 24 horas en las principales poblaciones españolas). www.telefonodelaesperanza.org.

- www.suicidioprevencion.com

- www.redaipis.org 
Anexo 5. Abreviaturas

AIPIS Asociación de Investigación, Prevención e Intervención del Suicidio

AEN Asociación Española de Neuropsiquiatría

AEPCP Asociación Española de Psicología Clínica y Psicopatología

AMAFE Asociación Madrileña de Amigos y Familiares de personas con Esquizofrenia

ANESM Asociación Nacional de Enfermería de Salud Mental

BDI Beck Depression Inventory

BHS Beck Hopelesness Scale

BPRS-24 Brief Psychiatric Rating Scale-24

ECA Ensayo clínico aleatorio

EE.UU. Estados Unidos de América

ESEMeD European Study of the Epidemiology of Mental Disorders

FAECAP Federación de Asociaciones de Enfermería Comunitaria y Atención Primaria

FDA Food and Drug Administration

FEAFES Federación de Asociaciones de Familiares y Personas con Enfermedad Mental

GPC Guía de Práctica Clínica

HoNOSCA Health of the Nation Outcome Scales for Children and Adolescents

HRSD Hamilton Rating Scale for Depression

ISRS Inhibidores selectivos de la recaptación de serotonina

INE Instituto Nacional de Estadística

IS PATH WARM Ideation, Substance abuse, Purposelessness, Anger, Trapped, Hopelessness, Withdrawing, Anxiety, Recklessness, Mood

K-SADS-PL Kiddie-Schedule for Affective Disorders \& Schizophrenia, Present \& Lifetime Version

NICE National Institute for Health and Clinical Excellence

NIMH National Institute of Mental Health

OMS Organización Mundial de la Salud

PPCS Programa de Prevención de la Conducta Suicida

RD Real Decreto

RS Revisión Sistemática

RSQ Risk of Suicide Questionaire 
SAD PERSONS Sex, Age, Depression, Previous attempt, Ethanol abuse, Rational thinking loss, Social support lacking, Organized plan for suicide, No spouse, Sickness

SIGN Scottish Intercollegiate Guidelines Network

SEEP Sociedad Española de Epidemiología Psiquiátrica

SEMFYC Sociedad Española de Medicina de Familia y Comunitaria

SEMES Sociedad Española de Medicina de Urgencias y Emergencias

SEMERGEN Sociedad Española de Médicos de Atención Primaria

SEPG Sociedad Española de Psicogeriatría

SEP Sociedad Española de Psiquiatría

SEPB Sociedad Española de Psiquiatría Biológica

SEPL Sociedad Española de Psiquiatría Legal

SPS Suicide Probability Scale

SSI Scale for Suicide Ideation

SSI-W Scale for Suicide Ideation-Worst

SUPRE Suicide Prevention

TCC Terapia cognitivo-conductual

TDC Terapia dialéctico-conductual

TEC Terapia electroconvulsiva

TIP Terapia interpersonal

TRP Terapia de resolución de problemas

USM Unidad de Salud Mental 


\title{
Anexo 6. Glosario
}

\begin{abstract}
Alianza terapéutica: establecimiento de una relación interpersonal entre el paciente y el profesional caracterizada por la colaboración, el consenso y orientación a resultados. Es un componente esencial en el proceso terapéutico, puesto que favorece la comunicación, aumenta la confianza del paciente y la colaboración con el tratamiento.
\end{abstract}

Amenaza suicida: acto interpersonal, verbal o no verbal, que podría predecir una posible conducta suicida en el futuro cercano.

Autoayuda: aprendizaje o potenciación de repertorios de conducta o capacidades de afrontamiento de situaciones y estados emocionales negativos, sin intervención o con participación mínima del terapeuta. Tiene como objetivo dotar a los pacientes de conocimientos y habilidades que faciliten la superación o el manejo de sus problemas de salud.

Autolesión: conducta potencialmente lesiva autoinflingida para la que existe evidencia, implícita o explícita, de que la persona no tiene la intención de matarse. La persona desea utilizar la aparente intencionalidad de morir con alguna finalidad. Este tipo de conducta puede no provocar lesiones, provocar lesiones o provocar la muerte (muerte autoinflingida no intencionada). También se denomina gesto suicida.

Autopsia psicológica: método de recogida de datos tras un suicidio. Consiste en la entrevista a familiares y allegados con la finalidad de recabar información acerca de la existencia previa de ideación/ comunicación suicida y presencia de factores de riesgo.

Befriending: conjunto de técnicas similares a las empleadas en la terapia de apoyo.

Cluster B, trastornos de personalidad: incluye los trastornos antisocial, límite, histriónico y narcisita. Al igual que en otros clusters, existe cierto grado de superposición entre los trastornos que lo componen, sobre todo entre el antisocial y el límite de la personalidad.

Cochrane Library Plus: versión en castellano de la revista electrónica The Cochrane Library, el principal vehículo de información de la Colaboración Cochrane. Se consulta a través de Internet y se actualiza cada tres meses. Apareció en 2002 y es la única versión en lengua no inglesa de la Cochrane Library.

Comorbilidad: situación clínica en la que se produce la coexistencia de dos o más enfermedades o condiciones, como por ejemplo, depresión y ansiedad. 
Comunicación suicida: acto interpersonal en el que se transmiten pensamientos, deseos o intencionalidad de acabar con la propia vida, para los que existe evidencia implícita o explícita de que este acto de comunicación no supone por sí mismo una conducta suicida. Existen dos tipos de comunicación suicida: amenaza suicida y plan suicida.

Conducta suicida: conducta potencialmente lesiva y autoinflingida, en la que hay evidencia de que: a) la persona desea utilizar la aparente intencionalidad de morir con alguna finalidad, b) la persona presenta algún grado, determinado o no, de intencionalidad suicida.

Conducta suicida no determinada: conducta con grado indeterminado de intencionalidad suicida que puede resultar sin lesiones, con lesiones o causar la muerte (muerte autoinflingida con grado indeterminado de intencionalidad).

Consejo u orientación (counseling): pretende descubrir los factores emocionales en conflicto que condicionan problemas de personalidad. En consecuencia, tiene por fin ayudar a comprender los obstáculos que impiden el desarrollo normal de la personalidad y los medios de superarlos en orden a favorecer el funcionamiento de los procesos psicológicos constructivos. Es una terapia psicológica que ofrece información e intercambio de experiencias y se apoya en cuatro pilares: 1) habilidades de comunicación asertiva, 2) soporte emocional, 3) modelo de solución de problemas y 4) autocontrol.

Cuidados habituales: cuidados que reciben los pacientes según el área donde se lleven a cabo. La definición de cuidados habituales o tratamiento habitual empleada varía en los diferentes estudios, e incluye diferentes intervenciones psicoterapéuticas y/o farmacológicas.

Data Mining: conjunto de técnicas que se basan en algoritmos, más o menos sofisticados, que se aplican sobre un conjunto de datos para obtener unos resultados. Proporciona un nuevo sistema para el manejo de grandes bases de datos.

Derivación: envío de un paciente de un servicio asistencial a otro, ya sea para consulta o para atención, debido a que el servicio que deriva no está preparado o cualificado para proporcionarlas. La prioridad de la derivación es establecida por el médico prescriptor y dependerá del proceso que motiva la consulta, de la patología y/o de la situación personal del paciente.

Desesperanza: esquemas cognitivos que tienen en común expectativas negativas acerca del futuro, sea este el futuro inmediato o el más remoto. La medición del constructo desesperanza fue iniciada por Beck y sus colaboradores, con la elaboración de la Escala de Desesperanza de Beck (Beck Hopelessness Scale, BHS). 
Eficacia: grado en el que una determinada intervención en condiciones ideales produce un resultado beneficioso. Los ensayos clínicos aleatorizados son el patrón oro en la evaluación de la eficacia.

Efectividad: grado en el que una intervención produce un resultado beneficioso en circunstancias ordinarias.

Ensayo clínico aleatorizado: estudio experimental en el que los participantes son asignados de forma aleatoria (al azar) a recibir un tratamiento o intervención entre dos o más opciones posibles. Uno de los grupos suele recibir el tratamiento convencional (grupo control), que sirve como patrón de comparación, mientras que otro grupo recibe el tratamiento objeto de estudio (grupo experimental).

Escala autoaplicada: instrumento de evaluación diseñado para ser cumplimentado por el propio individuo o por un informante.

Escala heteroaplicada: instrumento de evaluación diseñado para ser cumplimentado por un examinador. Para su aplicación es necesario que el profesional cuente con diferentes niveles de capacitación profesional según el instrumento.

Estudio de cohortes: consiste en el seguimiento de una o más cohortes de individuos sanos que presentan diferentes grados de exposición a un factor de riesgo y en quienes se mide la aparición de la enfermedad o condición a estudio.

Estudio de casos-control: estudio observacional y analítico en el que los sujetos son seleccionados en función de que tengan (casos) o no tengan (control) una determinada enfermedad, o en general un determinado efecto. Una vez seleccionados, se investiga si estuvieron expuestos a una característica de interés y se compara la proporción de expuestos en el grupo de casos frente a la del grupo de controles.

Estudio observacional: conjunto de estudios epidemiológicos donde no hay intervención por parte del investigador, si no que éste se limita a medir las variables que define en el estudio.

Embase (Excerpta Medica data BASE): base de datos bibliográfica producida por la empresa Elsevier que está especializada en el campo de la biomedicina y la farmacología. Contiene más de 12 millones de registros y se puede consultar desde 1974.

Evaluación psicosocial: evaluación que incluye diferentes componentes, de los cuales los más importantes son la evaluación de los factores psicológicos y sociales que pueden explicar la conducta suicida. 
Grupos de apoyo: suelen ser convocados por un profesional y estar compuestos por personas que comparten algún tipo de problema que altera o modifica aspectos de su funcionamiento normal. En ocasiones, estos grupos pueden ser guiados por paraprofesionales entrenados o supervisados por profesionales.

Ideación suicida: pensamientos sobre el suicidio (cogniciones).

Intento de suicidio: conducta potencialmente lesiva autoinflingida y sin resultado fatal, para la que existe evidencia, implícita o explícita, de intencionalidad de provocarse la muerte. Dicha conducta puede provocar o no lesiones, independientemente de la letalidad del método.

LifeSpan: modelo de terapia breve individual con orientación cognitiva específicamente diseñada para jóvenes con trastornos mentales graves y riesgo inminente de suicidio. La terapia incluye de 8 a 10 sesiones individuales y 4 fases: inicial, de evaluación del riesgo de suicidio, módulos cognitivos y de cierre.

Lista de espera: término empleado en los ensayos clínicos para designar al grupo con el que se compara la intervención experimental. Se caracteriza porque las variables clínicas de los participantes asignados a este grupo se miden al final del periodo de espera, y posteriormente reciben el tratamiento.

Locus de control: es el grado en que un sujeto percibe el origen de eventos y de su propio comportamiento de manera interna o externa a él. El locus de control interno es la percepción de que los eventos ocurren principalmente como efecto de las propias acciones, mientras que el locus de control externo es la percepción de que los eventos ocurren como resultado del azar, el destino, la suerte o el poder y decisiones de otros.

Manejo de contingencias: variedad de técnicas skinnerianas $u$ operantes que comparten la meta común de controlar el comportamiento manipulando sus consecuencias.

Medline: base de datos bibliográfica producida por la National Library of Medicine de los Estados Unidos. Recoge las referencias bibliográficas de los artículos publicados en más de 4500 revistas médicas desde 1966. Cada registro de Medline contiene los datos básicos de la referencia bibliográfica para su posterior recuperación. PubMed es un sistema de recuperación de la información basado en tecnología world wide web, que permite buscar en bases de datos, entre ellas Medline.

Metanálisis: método estadístico en el que se combinan los resultados de diferentes estudios para evaluar la heterogeneidad y generar resultados globales. 
Método RAND/UCLA: técnica de consenso. Se basa en una modificación del método Delphi. Con este método se permite combinar las opiniones de una serie de expertos que se constituyen en un panel para discutir la utilización de un procedimiento médico.

Mindfulness: también denominada plenitud de la conciencia o atención plena, es la capacidad para prestar atención a la experiencia tal y como es en el momento presente, sin juzgar y sin evaluar.

NICE (National Institute for Health and Clinical Excellence): organización británica independiente que proporciona directrices de promoción de la salud y de prevención y tratamiento de enfermedades al National Health Service.

Plan suicida: propuesta de un método con el cual llevar a cabo una conducta suicida potencial.

Psicoeducación: programas en formato individual o grupal que establecen una interacción explícita y educativa entre el profesional, el paciente y sus cuidadores.

Recaída: empeoramiento de un episodio aparentemente controlado, hasta alcanzar de nuevo criterios de nivel diagnóstico, que ocurre durante la remisión y antes de la recuperación.

Recuperación: es la duración del período de remisión que se requiere para determinar que existe una recuperación completa del episodio depresivo. Según los criterios DSM-IV, este período sería de dos meses.

Recurrencia: desarrollo de un trastorno depresivo en una persona que previamente ha padecido depresión. Habitualmente se considera que el nuevo episodio depresivo ocurre después de seis meses.

Remisión: la remisión requiere que el paciente esté asintomático y que no sufra más allá de los síntomas residuales mínimos, y, además, debe producirse una restauración total de la función.

Respuesta: ausencia de síntomas o disminución significativa de la sintomatología de depresión durante al menos dos semanas. También se considera respuesta aquella mejoría al menos del $50 \%$ respecto a los valores iniciales en una escala de medición de la depresión.

Revisión sistemática: forma de investigación que proporciona un resumen de los estudios existentes sobre una pregunta específica, utilizando para ello métodos explícitos y sistemáticos de identificación, evaluación crítica y síntesis de la literatura científica.

Técnicas de solución de problemas: el entrenamiento de recursos que facilitan el afrontamiento de situaciones de conflicto o estrés. 
SIGN (Scottish Intercollegiate Guidelines Network): se formó en 1993 con el objetivo de elaborar y diseminar guías de práctica clínica con recomendaciones basadas en la mejor evidencia científica disponible.

Suicidio: muerte autoinflingida con evidencia implícita o explícita de que la persona tenía intencionalidad de autoprovocarse la muerte.

SUPRE: programa que lanzó la OMS en 1999 para la prevención del suicidio.

Tamaño del efecto: es una estimación del efecto de un tratamiento cuando se compara con el grupo control (por ejemplo, otro tratamiento activo, no tratamiento o tratamiento habitual). Un ejemplo de tamaño del efecto es el riesgo relativo (empleado para variables dicotómicas) y la diferencia de medias ponderada y estandarizada (ambas para variables continuas).

Terapia cognitivo-conductual: se centra en la modificación de conductas disfuncionales, pensamientos negativos distorsionados asociados a situaciones específicas y actitudes desadaptativas relacionadas con la depresión.

Terapia conductual: es un enfoque de la psicología clínica que se fundamenta en la psicología del aprendizaje para la explicación de los trastornos psicológicos y el desarrollo de estrategias dirigidas al cambio terapéutico. Otra característica es estar basada en el estudio experimental de los principios y leyes del aprendizaje.

Terapia dialéctico-conductual: es un tratamiento psicológico desarrollado específicamente para el tratamiento de personas con trastorno límite de la personalidad, pero que se emplea también para pacientes con otros diagnósticos. La TDC emplea técnicas que se centran en el cambio conductual, con estrategias de aceptación o de validación, subrayando que la aceptación no excluye el cambio (componente dialéctico).

Terapia electroconvulsiva: procedimiento consistente en provocar, con finalidad terapéutica, una crisis comicial generalizada a través de una estimulación eléctrica del sistema nervioso central.

Terapia familiar: hace de las relaciones familiares el foco principal de su intervención, debido a que algunos autores han señalado que existe una fuerte evidencia de asociación entre la depresión infantojuvenil y factores como vínculos afectivos débiles, niveles elevados de criticismo, hostilidad familiar o psicopatología parental.

Terapia interpersonal: aborda las relaciones interpersonales e interviene en el contexto social inmediato del paciente. Asume que los problemas interpersonales pueden activar o exacerbar una depresión, por lo que se 
centra en ellos con la finalidad de favorecer cambios adaptativos y que de esta manera se produzca una mejoría de la sintomatología depresiva.

Terapia no directiva: procedimiento en el que el psicoterapeuta refleja al cliente lo que le dice, como procedimiento para evitar dirigir al cliente. Su característica distintiva sería la actitud del terapeuta, que promueve las condiciones de la relación terapéutica que favorecen los procesos de cambio psicológico.

Terapia de apoyo: intervención basada en el apoyo emocional, resolución de problemas de forma no directiva y revisión del estado del paciente (síntomas depresivos, rendimiento escolar, suicidabilidad, actividades sociales), con la finalidad de valorar la necesidad de intervención por parte de profesionales especializados.

Terapia de solución de problemas: intervención psicológica que se centra en el afrontamiento de áreas problemáticas específicas. Para ello el terapeuta y el paciente trabajan de forma conjunta en la identificación, priorización y manejo de dichas áreas.

Terapia psicodinámica: deriva del psicoanálisis y se basa en la teoría freudiana del funcionamiento psicológico de que la naturaleza de los conflictos puede ser en gran medida inconsciente, por lo que el objetivo terapéutico es resolver estos conflictos.

Tratamiento habitual: es el tratamiento o cuidado normal según el área donde se realice y en el contexto clínico diario. Es empleado habitualmente como grupo de comparación en los estudios experimentales.

Triaje: revisión clínica y sistemática de un conjunto de pacientes con el objetivo de asignar evaluaciones y prioridades de tratamiento mediante una serie de criterios predeterminados y con un método de clasificación que determine el nivel de urgencia. 


\section{Anexo 7. Declaración de intereses}

\section{Coordinadores y miembros del grupo elaborador}

Gerardo Atienza Merino, María José Ávila González, Celia Canedo Magariños, Manuel Castro Bouzas, Jesús Combarro Mato, Elena de las Heras Liñero, Rafael Fernández Martínez, Alejandro García Caballero, Amparo González García, Delia Guitián Rodríguez, Ekaterina Kokoulina Cherevach, Cristina Losada Pérez, María del Carmen Maceira Rozas, Belén Martínez Alonso, José Mazaira Castro, $\mathrm{M}^{\mathrm{a}}$ Luisa Mosteiro Álvarez, Laura Pérez Méndez, Teresa Reijas Ruiz, Águeda Rojo Pantoja, Henar Sancho Diaz y Margarita Tovar, Yolanda Triñanes Pego, declararon ausencia de conflictos de interés.

María Álvarez Ariza declaró haber recibido financiación para reuniones, congresos o asistencia a cursos (Jansen). Ernesto Ferrer Gómez del Valle declaró haber recibido financiación para reuniones, congresos o asistencia a cursos (Jansen). Jesús Combarro Mato declaró haber recibido financiación para reuniones, congresos o asistencia a cursos (Laboratorios Esteve).

\section{Colaboradores expertos}

José Teo Andrés González, José Antonio Couceiro Gianzo, Manuel A. Franco Martín, Susana García-Baquero Borrell, José Ramón García Palacios, Ana Goicoechea Castaño, José Mazaira Castro, Marta Medrano Varela, Daniel Portela Orjales y Carmen Senra Rivera declararon ausencia de conflictos de interés.

Enrique Baca-García declaró haber recibido financiación para investigación y dotación de material para el Servicio.

\section{Revisores externos}

Germán E. Berrios, Julio Bobes García, Mercedes Borda Más, Rosendo Bugarín González, María Consuelo Carballal Balsa, José Antonio Couceiro Gianzo, Ana Díaz Pérez, $\mathrm{M}^{\mathrm{a}}$ Dolores Franco Fernández, Lucas Giner Jiménez, Ana Goicoechea Castaño, Javier Jiménez Pietropaolo, Germán López Cortacáns, Raimundo Mateos Álvarez, Berta Moreno Küstner, Teresa Pacheco Tabuenca, Pablo Pascual Pascual, Manuel Portela Romero, Francisco Rodríguez Pulido, Pilar Alejandra Saiz Martínez, Carmen Senra Rivera y Gustavo Turecki, declararon ausencia de conflictos de interés. 
Enric Aragonés declaró haber recibido financiación para reuniones, congresos o asistencia a cursos (Lilly) y financiación para investigación (Lilly). Manuel Arrojo Romero participó en la elaboración del capítulo "Valoración del intento de suicidio" del Tratatado de Medicina de Urgencias, financiado por Laboratorios Menarini. Mario Páramo participó en la elaboración del documento "Recomendaciones preventivas de manejo de comportamientos suicidas" de la Sociedad Española de Psiquiatría y de la Sociedad Española de Psiquiatría Biológica, financiado por Laboratorios Adamed. Victor Pérez Solá declaró haber recibido financiación como ponente en conferencias y cursos (Lilly, Astracursos (Lilly, Astra-Zeneca, BMS) y por actividades de consultoría para compañías farmacéuticas (Lilly, Astra-Zeneca, BMS). Juan Luis Fernández Hierro de claró haber recibido financiación para reuniones, congresos o asistencia a cursos (Almirall, Bristol-Otsuka, Pfizer, Janssen), honorarios como ponente (Lündbeck y tener intereses económicos en una empresa privada relacionada con la salud (consulta privada de psiquiatría). 


\section{Bibliografía}

1 Scottish Intercollegiate Guidelines Network. Forming guideline recommendations. En: SIGN 50: A guideline developeers' handbook: Edinburgh: SIGN. 2001.

2 Hawton K, van Heeringen K. Suicide. Lancet. 2009;373(9672):1372-81.

3 World report on violence and health. Geneva:WHO;2002 [citado 18 ene 2010]. Disponible en: http://whqlibdoc.who.int/publications/2002/9241545615_chap7_ eng.pdf

4 Preventing Suicide. Program Activities Guide [Internet]. Atlanta (GA): Departament health \& Human Services; [citado 25 ene 2010]. Disponible en: http:/www.cdc.gov/violenceprevention/pdf/PreventingSuicide-a.pdf

5 The state of the Mental Health in the Europe. Commission of the European Communities. European Communities, 2004.

6 Estrategia en salud mental Sistema Nacional de Salud 2009-2013. Madrid: Ministerio de Sanidad, Política Social e Igualdad; 2011.

7 Bille Brahe U. Suicidal behaviour in Europe. The situation in the 1990s. Copenhagen: World Health Organization, Regional Office for Europe; 1998 [citado 31 ene 2011]. Disponible en: http://selvmord.wnm.dk/ filecache/31137/1277884104/e60709whopublicationsuicidalbehaviourineurope bille-brahe1998.pdf

8 Chinchilla A, Correas J, Vega M. Manual de urgencias psiquiátricas. Barcelona: Masson; 2003.

9 Meyer RE, Salzman C, Youngstrom EA, Clayton PJ, Goodwin FK, Mann JJ, et al. Suicidality and risk of suicide--definition, drug safety concerns, and a necessary target for drug development: a consensus statement. J Clin Psychiatry. 2010;71(8):e1-e21.

10 Diekstra RFW. The epidemiology of suicide and parasuicide. Acta Psychiatr Scand. 1993;371:9-20.

11 O’Carroll PW, Berman AL, Maris RW, Moscicki EK, Tanney BL, Silverman M. Beyond the Tower of Babel: a nomenclature for suicidology. Suicide Life Threat Behav. 1996;26(3):237-52.

12 Silverman MM, Berman AL, Sanddal MD, O'Carroll PW, Joiner TE. Rebuilding the Tower of Babel: A Revised Nomenclature for the Study of Suicide and Suicidal Behaviors. Part 1: Background, Rationale, and Methodology. Suicide Life Threat Behav. 2007;37(3):248-63.

13 Silverman MM, Berman AL, Sanddal MD, O'Carroll PW, Joiner TE. Rebuilding the Tower of Babel: A Revised Nomenclature for the Study of Suicide and Suicidal Behaviors. Part 2: Suicide-Related Ideations, Communications, and Behaviors. Suicide Life Threat Behav. 2007;37(3):264-77.

14 De Leo D, Bertolote JM, Lester D. Self-directed violence. En: Krug EG, Dahlberg LL, Mercy JA, Zwi AB, Lozano R, eds. World Report on violence and health. Geneva: World Health Organization; 2002. p. 183-212.

15 Organización Mundial de la Salud. Prevención del suicidio: un instrumento para trabajadores de atención primaria de salud [Internet]. Ginebra: Departamento de Salud Mental y Toxicología, Organización Mundial de la Salud;2000 [citado 10 may 2010]. Disponible en: www.who.int/entity/mental_health/media/ primaryhealthcare_workers_spanish.pdf 
Arsenault-Lapierre G, Kim C, Turecki G. Psychiatric diagnoses in 3275 suicides: a meta-analysis. BMC Psychiatry. 2004;4(37):1-11. Suicidal Behavior. Epidemiol Rev. 2008;30(1):133-54.

Sullivan GR, Bongar B. Assessing suicide risk in the adult patient. En: Kleespies PM, ed. Behavioral Emergencies An evidence-based resource for evaluating and managing risk of suicide, violence, and victimization. Washington (DC): American Psychological Association; 2009.

Oquendo M, Currier D, Posner K. Reconceptualización de la nosología psiquiátrica: el caso de la conducta suicida. Rev Psiquiatr Salud Ment (Barc). 2009;2(2):63-5.

20 Haro JM, Palacín C, Vilagut G, Martínez M, Bernal M, Luque I, et al. Prevalencia de los trastornos mentales y factores asociados: resultados del estudio ESEMeD-España. Med Clin (Barc). 2006;126(12):445-51.

21 López-Ibor JJ, Alonso J, Haro JM. Estudio Europeo de la Epidemiología de los Trastornos Mentales (ESEMeD): aportaciones para la salud mental en España. Actas Esp Psiquiatr. 2007;35(suppl. 2):1-3.

Mladovsky P, Allin S, Masseria C, Hernández-Quevedo C, McDaid D, Mossialos E. Health in the European Union. Trends and analysis. Copenhagen: European Observatory on Health Systems and Policies; 2009 [citado 8 feb 2010]. Disponible en: http://www.euro.who.int/Document/E93348.pdf

Kann L, Kinchen SA, Williams BL, Ross JG, Lowry R, Grunbaum JA, et al. Youth risk beavior surveillance-United States, 1999. State and local YRBSS Cordinators. J Sch Health. 2000;70:271-85.

Bertolote JM, Fleischmann A. A global perspective in the epidemiology of suicide. Suicidologi. 2002;7(2):6-8.

Vega Piñeiro M, Blasco Fontecilla H, Baca García E, Díaz Sastre C. El suicidio. Salud Global Salud Mental. 2002;4:2-15.

26 Instituto Nacional de Estadística. Defunciones según la Causa de Muerte. Año 2010. Datos provisionales Notas de prensa [Internet]. Madrid: INE; 2012 [actualizado 2012; citado 05 jun 2012]. Disponible en: http://www.ine.es/prensa/ np703.pdf

27 Chishti P, Stone DH, Corcovan P, Williamson E, Petridou E. Suicide mortality in the European Union. Eur j Public Health. 2003;13:108-14.

Ruiz Pérez I, Orly de Labry Lima A. El suicidio en la España de hoy. Gac Sanit. 2006;20(1):25-31.

29 Instituto Nacional de Estadística. Salud. Defunciones según la causa de muerte Madrid: Instituto Nacional Estadística; 2011 [citado 24 jun 2011]. [aprox. 2 pantallas]. Disponible en: http://www.ine.es/jaxi/menu.do?type=pcaxis\&path=/ $\mathrm{t} 15 / \mathrm{p} 417 \&$ file $=$ inebase $\& \mathrm{~L}=0$

30 Instituto Nacional de Estadistica. Salud. Defunciones según la causa de muerte 2010. Madrid: Instituto Nacional Estadística; 2012 [actualizado 12 mar 2012; citado Disponible en: http://www.ine.es/jaxi/tabla.do?path=/t15/p417/a2010/ $10 / \&$ file $=06001 . p x \&$ type $=$ pcaxis $\& \mathrm{~L}=0$

31 Fernández Egido C, García Herrero G, Romero García R, Marquina Santos AJ. Intoxicaciones agudas en las urgencias extrahospitalarias. Emergencias. 2008;20:328-31.

32 Caballero Vallés PJ, Dorado Pombo S, Jerez Basurco B, Medina Sampedro M, Brusínt Olivares B. Vigilancia epidemiológica de la intoxicación aguda en el 
Área Sur de la Comunidad de Madrid: Estudio VEIA 2000. An Med Interna. 2004;21(2):62-8.

33 American Psychiatric Association. Practice guideline for the Assessment and Treatment of Patients with Suicidal Behaviors:American Pychiatric Association; 2003 [citado 02 mar 2010]. Disponible en: http://www.psychiatryonline.com/ pracGuide/pracGuideChapToc_14.aspx

Pérez Barrero SA, Mosquera D. El suicidio: prevención y manejo. Memorias de un curso necesario. Madrid: Ediciones Pléyades; 2006.

Yoshimasu K, Kiyohara C, Miyashita K. Suicidal risk factors and completes suicide: meta-analyses based on psychological studies. Environ Health Prev Med. 2008;13:243-56.

Beautrais AL, Collings SCD, Ehrhardt P. Suicide Prevention: A review of evidence of risk and protective factors, and points of effective intervention. Wellington: Ministry of Health; 2005.

37 Sakinofsky I. Treating Suicidality in Depressive Illness. Part I: Current Controversies. Can J Psychiatry. 2007;52(6S1):71S-84S.

38 López P, González-Pinto A, Mosquera F, Aldama A, González C, Fernández de Corres B, et al. Estudio de los factores de riesgo de la conducta suicida en pacientes hospitalizados. Análisis de la atención sanitaria. Investigación Comisionada. Vitoria-Gasteiz: Gobierno Vasco, Departamento de Sanidad; 2007. Informe $\mathrm{N}^{\circ}$.: Osteba D-07-02.

39 Guo B, Harstall C. Efficacy of suicide prevention programs for children and youth. Edmonton (AB): Alberta Heritage Foundation for Medical Research. Health Technology Assessment; 2002. Informe $\mathrm{N}^{0} .: 26$.

40 Yang CY.Association between parity and risk of suicide among parous women. CMAJ. 2010;182(6):569-72.

41 Kapur N, House A, May C, Creed F. Service provision and outcome for deliberate self-poisoning in adults-results from a six centre descriptive study. Soc Psychiatry Psychiatr Epidemiol. 2003;38:390-5.

42 Kapur N, Murphy E, Cooper J, Bergen H, Hawton K, Simkin S, et al.Psychosocial assessment following self-harm: results from the multi-centre monitoring of self-harm project. J Affect Disord. 2008;106(3):285-93.

43 Nordentoft M, Sogaard M. Registration, psychiatric evaluationand adherence to psychiatric treatment after suicide attempt. Nord J Psychiatry. 2005;59:213-6.

44 Schechter M, Maltsberger JT. The clinician interview as a method in suicide risk assesment. En: Wasserman D, Wasserman C, eds. Suicidology and Suicide Prevention A global Perspective. New York: Oxford University Press Inc; 2009.

45 Motto JA. An integrated approach to estimating suicide risk. En: Maris RW, Berman AL, Maltsberger JT, Yufit RI, eds. Assessment and prediction of suicide. New York: Guilford; 1992. p. 625-39.

46 Taylor TL, Hawton K, Fortune S, Kapur N. Attitudes towards clinical services among people who self-harm: systematic review. Br J Psychiatry. 2009;194:10410 .

47 Canadian Coalition for Seniors' Mental Health. The Assessment of Suicide Risk and Prevention of Suicide. Toronto: Canadian Coalition for Seniors' Mental Health; 2006.

48 Brown GK. A Review of Suicide Assessment Measures for Intervention Research With Adults and Older Adults. Rockville (MD): National Institute of 
Mental Health; 2002 [citado 12 abr 2010]. Disponible en: http://www.nimh.nih. gov/research/adultsuicide.pdf

Beck AT, Weissman A, Lester D, Trexler L. The measurement of pessimism: the hopelessness scale. J Consult Clin Psychol. 1974;42:861-5.

50 Beck AT, Kovacs M, Weissman A. Assessment of suicidal intention: the Scale for Suicide Ideation. J Consult Clin Psychol. 1979;47(2):343-52.

Beck RW, Morris JB, Beck AT. Cross-validation of the Suicidal Intent Scale. Psychol Rep. 1974;34(2):445-46.

Beck AT, Steer RA, Brown GK. BDI-II, Beck depression inventory: Manual. 2a ed. San Antonio, Texas: Harcourt; 1996.

Hamilton M. A rating scale for depression. Journal of Neurology, Neurosurgery and Psychiatry. 1960;23:56-62.

Patterson WM, Dohn HH, Bird J, Patterson GA. Evaluation of suicidal patients: the SAD PERSONS scale. Psychosomatics. 1983;24(4):348-9.

Berman A. Risk assessment, treatment planning, and management of the at-risk-for suicide client: The "how to" aspects of assesing suicide risk and formulating treatment plans. Family Therapy Magazine. 2006;5(4):7-10.

Kerr PL, Muehlenkamp JJ, Turner JM. Nonsuicidal self-injury: a review of current research for family medicine and primary care physicians. J Am Board Fam Med. 2010;23(2):240-59.

Farand L, Renaud J, Chagnon F. Adolescent suicide in Quebec and prior utilization of medical services. Can J Public Health. 2004;95(5):357-60.

Luoma JB, Martin CE, Pearson JL. Contact with mental health and primary care providers before suicide: a review of the evidence. Am J Psychiatry. 2002;159(6):909-16.

Lastra I, y cols. Prevención de las conductas suicidas. En: Vázquez-Barquero JL, ed. Psiquiatría en Atención Primaria. Madrid: Aula Médica; 1998. p. 753-70.

National Collaborating Centre for Mental Health. Self-harm. The short-term physical and psychological management and secondary prevention of selfharm in primary and secondary care. London: National Institute for Clinical Excellence; 2004. Informe $\mathrm{N}^{\circ} .: 16$.

61 Haste F, Charlton J, Jenkins R. Potential for suicide prevention in primary care? An analysis of factors associated with suicide. Br J Gen Pract. 1998;48:1759-63. Grupo de trabajo de Salud Mental del Programa de Actividades Preventivas y de Promoción de la Salud (PAPPS). Guía de Salud Mental en Atención Primaria. Barcelona: Sociedad Española de Medicina de Familia y Comunitaria (semFYC); 2001 [citado 27 abr 2010]. Disponible en: http://www.papps.org/ upload/file/publicaciones/guiaRevisada2008-salud-mental.pdf

Organización Mundial de la Salud. Prevención del suicidio: un instrumento para médicos generalistas. Ginebra: Organización Mundial de la Salud, Departamento de Salud Mental y Toxicología; 2000 [citado 10 may 2010]. Disponible en: http://www.who.int/publications/list/prevention_sucide_ medecins/es/index.html

64 Protocolos de intervención en urgencias extrahospitalarias 061. Santiago de Compostela: Xunta de Galicia; 2008.

65 Miller TR, Taylor DM. Adolescent suicidality: who will ideate, who will act? Suicide Life Threat Behav. 2005;35(4):425-35.

66 Nordentoft M. Prevention of suicide and attempted suicide in Denmark. Dan Med Bull. 2007;54(4):306-68. 
67 Larkin GL, Beautrais AL. Emergency departments are underutilized sites for suicide prevention. Crisis. 2010;31(1):1-6.

68 Gómez Jiménez J. Clasificación de pacientes en los servicios de urgencias y emergencias: Hacia un modelo de triaje estructurado de urgencias y emergencias. Emergencias. 2003;15:165-74.

69 Horowitz LM, Wang PS, Koocher GP, Burr BH, Smith MF, Klavon S, et al. Detecting suicide risk in a pediatric emergency department: development of a brief screening tool. Pediatrics. 2001;107(5):1133-7.

70 Folse VN, Hahn RL. Suicide risk screening in an emergency department: engaging staff nurses in continued testing of a brief instrument. Clin Nurs Res. 2009;18(3):253-71.

71 Robles R, Paéz F, Ascencio M, Mercado E, Hernández L. Evaluación del riesgo suicida en niños: propiedades psicométricas de la versión en castellano del Cuestionario de Riesgo Suicida (RSQ). Actas Esp Psiquiatr. 2005;33(5):292-7.

72 Robles Garcia R, Agraz Páez A, Ascencio Guirado M, Mercado Salcedo E, Hernández Múñoz L. Evaluation of suicide risk in children: psychometric properties of the Spanish version of the Risk of Suicide Questionnaire (RSQ). Actas Esp Psiquiatr. 2005;33:292-97.

73 Mitchell AJ, Dennis M. Self harm and attempted suicide in adults: 10 practical questions and answers for emergency department staff. Emerg Med J. 2006;23(4):251-5.

74 Miret M,Nuevo R,Ayuso-Mateos JL. Documentation of suicide risk assessment in clinical records. Psychiatr Serv. 2009;60(7):994.

75 Cooper J, Kapur N, Dunning J, Guthrie E, Appleby L, Mackway-Jones K. A clinical tool for assessing risk after self-harm. Annals of emergency medicine. 2006;48(4):459-66.

76 Cooper J, Kapur N, Mackway-Jones K. A comparison between clinicians' assessment and the Manchester Self-Harm Rule: a cohort study. Emerg Med J. 2007;24(10):720-1.

77 Crawford MJ, Turnbull G, Wessely S. Deliberate self harm assessment by accident and emergency staff: an intervention study. J Accid Emerg Med. 1998;15(1):18-22.

78 New Zealand Guidelines Group (NZGG). The assessment and management of people at risk of suicide. Wellington (NZ): New Zealand Guidelines Group (NZGG); 2003.

79 Wenzel A, Brown GK, Beck AT, editors. Cognitive Therapy for Suicidal Patients. Scientific and Clinical Applications. Washington: American Psychological Association; 2009.

80 Tarrier N, Taylor K, Gooding P. Cognitive-behavioral interventions to reduce suicide behavior: A systematic review and meta-analysis. Behavior modification. 2008;32(1):77-108.

81 Wood A, Trainor G, Rothwell J, Moore A, Harrington R. Randomized trial of group therapy for repeated deliberate self-harm in adolescents. J Am Acad Child Adolesc Psychiatry. 2001;40:1246-53.

82 Green JM, Wood AJ, Kerfoot MJ, Trainor G, Roberts C, Rothwell J, et al. Group therapy for adolescents with repeated self harm: randomised controlled trial with economic evaluation. BMJ. 2011;342:d682.

83 Hazell PL, Martin G, McGill K, Kay T, Wood A, Trainor G, et al. Group therapy for repeated deliberate self-harm in adolescents: failure of 
replication of a randomized trial. J Am Acad Child Adolesc Psychiatry. 2009;48(6):662-70.

Unutzer J, Tang L, Oishi S, Katon W, Williams JW, Hunkeler E, et al. Reducing suicidal ideation in depressed older primary care patients. J Am Geriatr Soc. 2006;54(10):1550-6.

March J, Silva S, Petrycki S, Curry J, Wells K, Fairbank J, et al. Fluoxetine, cognitive-behavioral therapy, and their combination for adolescents with depression: Treatment for Adolescents With Depression Study (TADS) randomized controlled trial. JAMA. 2004;292(7):807-20.

Goodyer IM, Dubicka B, Wilkinson P, Kelvin R, Roberts C, Byford S, et al. A randomised controlled trial of cognitive behaviour therapy in adolescents with major depression treated by selective serotonin reuptake inhibitors. The ADAPT trial. Health Technol Assess. 2008;12(14):iii-iv, ix-60.

Davidson K, Norrie J, Tyrer P, Gumley A, Tata P, Murray H, et al. The effectiveness of Cognitive Behavior Therapy for Borderline Personality Disorder: results from de Borderline Personality Disorder Study of Cognitive Therapy (BOSCOT) Trial. J Pers Disord. 2006;20(5):450-65.

Slee N, Garnefski N, van der Leeden R, Arensman E, Spinhoven P. Cognitivebehavioural intervention for self-harm: randomised controlled trial. $\mathrm{Br} \mathrm{J}$ Psychiatry. 2008;192(3):202-11.

89 Bateman K, Hansen L, Turkington D, Kingdon D. Cognitive behavioral therapy reduces suicidal ideation in schizophrenia: results from a randomized controlled trial. Suicide Life Threat Behav. 2007;37(3):284-90.

Clarkin JF, Levy KN, Lenzenweger MF, Kernberg OF. Evaluating Three Treatments for Borderline Personality Disorder: A Multiwave Study. Am J Psychiatry. 2007;164:922-8.

91 Eskin M, Ertekin K, Demir H. Efficacy of a Problem-Solving Therapy for Depression and Suicide Potential in Adolescents and Young Adults. Cogn Ther Res. 2008;32:227-45.

92 Mujoomdar M, Cimon K, Nkansah E. Dialectical behaviour therapy in adolescents for suicide prevention: systematic review of clinical-effectiveness. Otawa: Canadian Agency for Drugs and Technologies in Health; 2009.

93 Guthrie E, Kapur N, MackwayJones K, ChewGraham C, Moorey J, Mendel E, et al. Papers Randomised controlled trial of brief psychological intervention after deliberate self poisoning. BMJ. 2001;323(7305):135-8.

94 Alexopoulos GS, Reynolds CF, 3rd, Bruce ML, Katz IR, Raue PJ, Mulsant $\mathrm{BH}$, et al. Reducing suicidal ideation and depression in older primary care patients: 24-month outcomes of the PROSPECT study. Am J Psychiatry. 2009;166(8):882-90.

95 Tang TC, Jou SH, Ko CH, Huang SY, Yen CF. Randomized study of school-based intensive interpersonal psychotherapy for depressed adolescents with suicidal risk and parasuicide behaviors. Psychiatry Clin Neurosci. 2009;63(4):463-70.

96 Harrington RC, Kerfoot M, Dyer E, McGiven F, Gill J, Harrington V, et al. Randomized trial of a home based family intervention for children who have deliberately poisoned themselves. J Am Acad Child Adolesc Psychiatry. 1998;37:512-8.

97 Gregory RJ, Remen AL, Soderberg M, Ploutz-Snyder RJ. A controlled trial of psychodynamic psychotherapy for co-occurring borderline personality 
disorder and alcohol use disorder: six-month outcome. J Am Psychoanal Assoc. 2009;57(1):199-205.

98 Arnevik E, Wilberg T, Urnes O, Johansen M, Monsen JT, Karterud S. Psychotherapy for personality disorders: short-term day hospital psychotherapy versus outpatient individual therapy - a randomized controlled study. Eur Psychiatry. 2009;24(2):71-8.

99 Bousoño García M, Bobes García J, González-Quirós Corujo P. Tratamiento psicofarmacológico. En: Prevención de las conductas suicidas y parasuicidas. Barcelona: Masson; 1997.

100 Ros Montalbán S, Arranz Martí B, Peris Díaz MD. Aproximaciones terapéuticas preventivas. En: En: Comportamientos suicidas Prevención y tratamiento. Barcelona: Ars medica; 2004.

101 Ernst CL, Goldberg JF. Antisuicide Properties of Psychotropic Drugs: A Critical Review. Harv Rev Psychiatry. 2004;12(1):14-41.

102 Yerevanian BI, Koek RJ, Mintz J, Akiskal HS. Bipolar pharmacotherapy and suicidal behavior. Part 2: The impact of antidepressants. J Affect Disord. 2007;103(1-3):13-21.

103 Ghaemi SN, Rosenquist KJ, Ko JY, Baldassano CF, Kontos NJ, Baldessarini RJ. Antidepressant treatment in bipolar versus unipolar depression. Am J Psychiatry. 2004;161(1):163-5.

104 Baldessarini RJ, Tondo L, Davis P, Pompili M, Goodwin FK, Hennen J. Decreased risk of suicides and attempts during long-term lithium treatment: a meta-analytic review. Bipolar Disord. 2006;8(5 Pt 2):625-39.

105 Baldessarini RJ, Tondo L. Suicidal risk during treatment of bipolar disorder patients with lithium versus anticonvulsants. Pharmacopsychiatry. 2009;42:72-5.

106 Lauterbach E, Felber W, Müller-Oerlinghausen B, Ahrens B, Bronisch T, Meyer $\mathrm{T}$, et al. Adjunctive lithium treatment in the prevention of suicidal behaviour in depressive disorders: a randomised, placebo-controlled, 1-year trial. Acta Psychiatr Scand. 2008;118:469-79.

107 Comité de Consenso de Catalunya en Terapéutica de los Trastornos Mentales. Recomendaciones terapéuticas en los trastornso mentales. Conducta suicida. $3^{\mathrm{a}}$ ed. Barcelona: Ars Medica; 2005.

108 Collins JC, McFarland BH. Divalproex, lithium and suicide among Medicaid patients with bipolar disorder. J Affect Disord. 2008;107(1-3):23-8.

109 Goodwin FK, Fireman B, Simon GE, Hunkeler EM, Lee J, Revicki D. Suicide risk in bipolar disorder during treatment with lithium and divalproex. JAMA. 2003;290(11):1467-73.

110 Sondergard L, López AG, Andersen PK, Kessing LV. Mood-stabilizing pharmacological treatment in bipolar disorders and risk of suicide. Bipolar Disord. 2008;10(1):87-94.

111 Arana A, Wentworth CE, Ayuso-Mateos JL, Arellano FM. Suicide-related events in patients treated with antiepileptic drugs. NEJM. 2010;363(6):542-51.

112 FDA US Food and Drug Administration. Antiepileptic Drugs. Rockville (MD): FDA; 2008 [citado 21 sep 2010]. Disponible en: http://www.fda.gov/Safety/ MedWatch/SafetyInformation/SafetyAlertsforHumanMedicalProducts/ ucm074939.htm 
113 Patorno E, Bohn RL, Wahl PM, Avorn J, Patrick AR, Liu J, et al. Anticonvulsant Medications and the Risk of Suicide, Attempted Suicide, or Violent Death. JAMA. 2010;303(14):1401-9.

114 Meltzer HY, Alphs L, Green AI, Altamura AC, Anand R, Bertoldi A, et al. Clozapine treatment for suicidality in schizophrenia: International Suicide Prevention Trial (InterSePT). Arch Gen Psychiatry. 2003;60(1):82-91.

115 Reeves H, Batra S, May RS, Zhang R, Dahl DC, Li X. Efficacy of risperidone augmentation to antidepressants in the management of suicidality in major depressive disorder: a randomized, double-blind, placebo-controlled pilot study. J Clin Psychiatry. 2008;69(8):1228-336.

116 National Institute of Clinical Excellence. Guidance on the use of Electroconvulsive Therapy. London: NICE; 2003. Informe $\mathrm{N}^{\circ} .: 59$.

117 Royal College of Psychiatrists ECT handbook. The Third Report of the Royal College of Psychiatrists' Special Committee on ECT (Council Report CR128). London: Royal College of Psychiatrists; 2005.

118 The Royal Australian and New Zealand College of Psychiatrists. Clinical Memorandum \#12.Electroconvulsive Therapy. Guidelines on the administration of electroconvulsive therapy (ECT). New Zealand: The Royal Australian and New Zealand College of Psychiatrists; 2005.

119 Stellungnahme zur Elektrokrampftherapie (EKT) als psychiatrische Behandlungsmassnahme. Deutsches Ärzteblatt. 2003(3).

120 Greenhalgh J, Knight C, Hind D, Beverley C, Walters S. Clinical and costeffectiveness of electroconvulsive therapy for depressive illness, schizophrenia, catatonia and mania: Systematic reviews and economic modelling studies. Health Technol Assess. 2005;9(9):94.

121 Patel M, Patel S, Hardy DW, Benzies BJ, Tare V. Should Electroconvulsive Therapy Be an Early Consideration for Suicidal Patients? The journal of ECT. 2006;22(2):113-5.

122 Brådvik L, Berglund M. Long-term treatment and suicidal behavior in severe depression: ECT and antidepressant pharmacotherapy may have different effects on the occurrence and seriousness of suicide attempts. Depress Anxiety. 2006;23(1):34-41.

123 Kellner CH, Fink M, Knapp R, Petrides G, Husain M, Rummans T, et al. Relief of expressed suicidal intent by ECT: a consortium for research in ECT study. Am J Psychiatry. 2005;162(5):977-82.

124 Organización Mudial de la Salud. Prevención del Suicidio. Ginebra: Organización Mudial de la Salud; 1969. Informe $\mathrm{N}^{\circ} .: 35$.

125 van der Feltz-Cornelis CM, Sarchiapone M, Postuvan V, Volker D, Roskar $\mathrm{S}$, Grum AT, et al. Best practice elements of multilevel suicide prevention strategies: a review of systematic reviews. Crisis. 2011;32(6):319-33.

126 Organización Mudial de la Salud. Estudio de intervención multicéntrico sobre comportamientos suicidas SUPRE-MISS: protocolo de SUPREMISS. Ginebra: Organización Mundial de la Salud. Informe No.: WHO/MSD/ $\mathrm{MBD} / 02.1$.

127 World Health Organization. Prevención del suicidio: Un instrumento para los medios de comunicación [Internet]. Geneva: World Health Organization;2000. [citado 9 dic 2011]. Disponible en: http://www.who.int/mental_health/media/ media_spanish.pdf. 
128 Organización Mudial de la Salud. Prevención del suicidio. Recursos para consejeros. Ginebra: Organización Mundial de la Salud; 2006.

129 Organización Mundial de la Salud. Prevención del suicidio. Un instrumento para docentes y demás personal institucional. Ginebra: Organización Mundial de la Salud; 2001.

130 Organización Mundial de la Salud. Prevención del suicidio en cárceles y prisiones. Ginebra: Organización Mundial de la Salud; 2007.

131 Organización Mundial de la Salud. Prevención del suicidio. Un instrumento en el trabajo. Ginebra: Organización Mundial de la Salud; 2006.

132 Organización Mundial de la Salud. Prevención del suicidio. ¿Cómo establecer un grupo de supervivientes? Ginebra: Organización Mundial de la Salud; 2000.

133 Organización mundial de la Salud. Prevención del suicidio. Un instrumento para policías, bomberos y otros socorristas de primera línea. Ginebra: Organización Mundial de la Salud; 2009.

134 Suicide prevention. WHO European Ministerial Conference on Mental Health; Helsinki: World Health Organization; 2005.

135 Mann JJ, Apter A, Bertolote J, Beautrais A, Currier D, Haas A, et al. Suicide prevention strategies: a systematic review. JAMA. 2005;294(16):2064-74.

136 Yip PS. Towards evidence-based suicide prevention programs. Crisis. 2011;32(3):117-20.

137 Beautrais A, Fergusson D, Coggan C, Collings C, Doughty C, Ellis P, et al. Effective strategies for suicide prevention in New Zealand: a review of the evidence. NZMJ. 2007;120(1251):1-13.

138 Leitner M, Barr W, Hobby L. Effectiveness of interventions to prevent suicide and suicidal behaviour: a systematic review. Edinburgh: Scottish Government Social Research; 2008.

139 Hegerl U, Mergl R, Havers I, Schmidtke A, Lehfeld H, Niklewski G, et al. Sustainable effects on suicidality were found for the Nuremberg alliance against depression. Eur Arch Psychiatry Clin Neurosc. 2010;260:401-6.

140 Hegerl U, Althaus D, Schmidtke A, Niklewski G. The alliance against depresssion: 2-year evaluation of a community-based intervention to reduce suicidality. Psychol Med. 2006;36:1225-33.

141 Ayuso-Mateos JL, Baca-García E, Bobes J, Giner J, Giner L, Pérez V, et al. Recomendaciones preventivas y manejo del comportamiento suicida en España. Rev Psiquiatr Salud Ment. 2012;5(1):8-23.

142 Garmezy N. Resilience in children's adaptation to negative life events and stressed environments. Pediatr Ann. 1991;20(9):459-60, 63-6.

143 Lapierre S, Erlangsen A, Waern M, De Leo D, Oyama H, Scocco P, et al. A systematic review of elderly suicide prevention programs. Crisis. 2011;32(2):8898.

144 Steele MM, Doey T. Suicidal behaviour in children and adolescents. Part 1: etiology and risk factors. Can J Psychiatry. 2007;52(6 Suppl 1):21S-33S.

145 Malfent D, Wondrak T, Kapusta ND, Sonneck G. Suicidal ideation and its correlates among elderly in residential care homes. Int J Geriatr Psychiatry. 2010;25:843-9.

146 Peña JB, Kuhlberg JA, Zayas LH, Baumann AA, Gulbas L, Hausmann-Stabile C, et al. Familism, Family Environment, and Suicide Attempts among Latina Youth. Suicide Life Threat Behav. 2011;41(3):330-41. 
147 World Health Organization. Mental Health: Responsible and deglamourized media reporting [Internet]. Geneva: World Health Organization [citado 09 dic 2011]. Disponible en: http://www.who.int/mental_health/mhgap/evidence/ suicide/q9/en/index.html

148 Johnson J, Wood AM, Gooding P, Taylor PJ, Tarrier N. Resilience to suicidality: the buffering hypothesis. Clin Psychol Rev. 2011;31(4):563-91.

149 Wyman PA, Brown CH, LoMurray M, Schmeelk-Cone K, Petrova M, Yu Q, et al. An outcome evaluation of the sources of strength suicide prevention program delivered by adolescent peer leaders in high schools. Am J Public Health. 2010;100(9):1653-61.

150 Tsey K, Whiteside M, Haswell-Elkins M, Bainbridge R, Cadet-James Y, Wilson A. Empowerment and Indigenous Australian health: a synthesis of findings from Family Wellbeing formative research. Health Soc Care Community. 2010;18(2):169-79.

151 Lapierre S, Dubé M, Bouffard L, Alain M. Addressing suicidal ideations through the realization of meaningful personal goals. Crisis. 2007;28(1):16-25.

152 Heisel MJ, Duberstein P, Talbot NL, King DK, Tu X. Adapting interpersonal psychotherapy for older adults at risk for suicide:preliminary findings. Prof Psychol Res Pract. 2009;40:156-64.

153 Judge B, Billick SB. Suicidality in Adolescence: Review and Legal Considerations. Behav Sci Law. 2004;22:681-95.

154 Niederkrotenthaler T, Voracek M, Herberth A, Till B, Strauss M, Etzersdorfer E, et al. Role of media reports in completed and prevented suicide: Werther v. Papageno effects. Br J Psychiatry. 2010;197(3):234-43.

155 King M, Semlyen J, See Tai S, Killaspy H, Osborn D, Popelyuk D, et al. A systematic review of mental disorder, suicide, and deliberate self harm in lesbian, gay and bisexual people. BMC Psychiatry. 2008;8:70.

156 Pirkis J, Blood RW, Beautrais A, Burgess P, Skehans J. Media Guidelines on the Reporting of Suicide. Crisis. 2006;27:82-7.

157 Niederkrotenthaler T, Sonneck G. Assessing the impact of media guidelines for reporting on suicides in Austria: interrupted time series analysis. Aust N Z J Psychiatry. 2007;41(5):419-28.

158 Fu KW, Yip PS. Changes in reporting of suicide news after the promotion of the WHO media recommendations. Suicide Life Threat Behav. 2008;38(5):631-6.

159 Collings SC, Kemp CG. Death knocks, professional practice, and the public good: the media experience of suicide reporting in New Zealand. Soc Sci Med. 2010;71(2):244-8.

160 Durkee T, Hadlaczky G, Westerlund M, Carli V. Internet Pathways in Suicidality: A Review of the Evidence. Int J Environ Res Public Health. 2011;8(10):393852.

161 Biddle L, Donovan J, Hawton K, Kapur N, Gunnell D. Suicide and the internet. BMJ. 2008;12:800-2.

162 Recupero PR, Harms SE, Noble JM. Googling suicide: surfing for suicide information on the Internet. J Clin Psychiatry. 2008;69(6):878-88.

163 McCarthy MJ. Internet monitoring of suicide risk in the population. J Affect Disord. 2010;122(3):277-9.

164 Dunlop SM, More E, Romer D. Where do youth learn about suicides on the Internet, and what influence does this have on suicidal ideation? J Child Psychol Psychiatry. 2011;52(10):1073-80. 
165 Haas A, Koestner B, Rosenberg J, Moore D, Garlow SJ, Sedway J, et al. An interactive web-based method of outreach to college students at risk for suicide. J Am Coll Health. 2008;57(1):15-22.

166 Gilat I, Shahar G. Emotional first aid for a suicide crisis: comparison between Telephonic hotline and internet. Psychiatry. 2007;70(1):12-8.

167 National Collaborating Centre for Mental Health. Self-harm: longer-term management. London: National Institute for Health and Clinical Excellence; 2011. Informe $\mathrm{N}^{\circ} .: 133$.

168 Wasserman D, Rihmer Z, Rujescu D, Sarchiapone M, Sokolowski M, Titelman $\mathrm{D}$, et al. The European Psychiatric Association (EPA) guidance on suicide treatment and prevention. Eur Psychiatry. 2012;27(2):129-41.

169 Zonda T, Lester D. Preventing suicide by educating general practitioners. Omega (Westport). 2006;54(1):53-7.

170 Roskar S, Podlesek A, Zorko M, Tavcar R, Dernovsek MZ, Groleger U, et al. Effects of training program on recognition and management of depression and suicide risk evaluation for Slovenian primary-care physicians: follow-up study. Croat Med J. 2010;51(3):237-42.

171 Taliaferro LA, Borowsky IW. Perspective: Physician education: a promising strategy to prevent adolescent suicide. Acad Med. 2011;86(3):342-7.

172 Pisani AR, Cross WF, Gould MS. The assessment and management of suicide risk: state of workshop education. Suicide Life Threat Behav. 2011;41(3):25576.

173 Kato TA, Suzuki Y, Sato R, Fujisawa D, Uehara K, Hashimoto N, et al. Development of 2-hour suicide intervention program among medical residents: first pilot trial. Psychiatry Clin Neurosci. 2010;64(5):531-40.

174 Chan SW, Chien WT, Tso S. Evaluating nurses' knowledge, attitude and competency after an education programme on suicide prevention. Nurse Educ Today. 2009;29(7):763-9.

175 Walker BL, Harrington SS, Cole CS. The usefulness of computer-based instruction in providing educational opportunities for nursing staff. J Nurses Staff Dev. 2006;22(3):144-9.

176 Tsai WP, Lin LY, Chang HC, Yu LS, Chou MC. The effects of the gatekeeper suicide-awareness program for nursing personnel. Perspect Psychiatr Care. 2011;47(3):117-25.

177 Gask L, Dixon C, Morriss R, Appleby L, Green G. Evaluating STORM skills training for managing people at risk of suicide. J Adv Nurs. 2006;54(6):739-50.

178 Morriss R, Gask L, Webb R, Dixon C, Appleby L. The effects on suicide rates of an educational intervention for front-line health professionals with suicidal patients (the STORM Project). Psychol Med. 2005;35(7):957-60.

179 Gask L, Lever-Green G, Hays R. Dissemination and implementation of suicide prevention training in one Scottish region. BMC Health Serv Res. 2008;8:246.

180 Ramberg IL, Wasserman D. Suicide-preventive activities in psychiatric care: evaluation of an educational programme in suicide prevention. Nord $\mathrm{J}$ Psychiatry. 2004;58(5):389-94.

181 Cailhol L, Allen M, Moncany AH, Cicotti A, Virgillito S, Barbe RP, et al. Violent behavior of patients admitted in emergency following drug suicidal attempt: a specific staff educational crisis intervention. Gen Hosp Psychiatry. 2007;29(1):42-4. 
182 Shim RS, Compton MT. Pilot testing and preliminary evaluation of a suicide prevention education program for emergency department personnel. Community Ment Health J. 2010;46(6):585-90.

183 Horwitz SM, Heinberg LJ, Storfer-Isser A, Barnes DH, Smith M, Kapur R, et al. Teaching physicians to assess suicidal youth presenting to the emergency department. Pediatr Emerg Care. 2011;27(7):601-5.

184 Indelicato NA, Mirsu-Paun A, Griffin WD. Outcomes of a suicide prevention gatekeeper training on a university campus. J Coll Stud Dev. 2011;52(3):350-61.

185 Thompson D, Goebert D, Takeshita J. A program for reducing depressive symptoms and suicidal ideation in medical students. Acad Med. 2010;85(10):1635-9.

186 Tompkins TL, Witt J, Abraibesh N. Does a gatekeeper suicide prevention program work in a school setting? Evaluating training outcome and moderators of effectiveness. Suicide Life Threat Behav. 2009;39(6):671-81.

187 Keller DP, Schut LJA, Puddy RW, Williams L, Stephens RL, McKeon R, et al. Tennessee Lives Count: Statewide gatekeeper training for youth suicide prevention. Prof Psychol Res Pr. 2009;40(2):126-33.

188 Gibbons MM, Studer JR. Suicide awareness training for faculty and staff: a training model for school counselors. Professional School Counseling. 2008;11:272-6.

189 Robinson J, Gook S, Yuen HP, McGorry PD, Yung AR. Managing deliberate self-harm in young people: an evaluation of a training program developed for school welfare staff using a longitudinal research design. BMC Psychiatry. 2008;8:75.

190 Lu YJ, Chang HJ, Tung YY, Hsu MC, Lin MF. Alleviating psychological distress of suicide survivors: evaluation of a volunteer care programme. J Psychiatr Ment Health Nurs. 2011;18(5):449-56.

191 Matthieu MM, Cross W, Batres AR, Flora CM, Knox KL. Evaluation of gatekeeper training for suicide prevention in veterans. Archives of suicide research : official journal of the International Academy for Suicide Research. 2008;12(2):148-54.

192 Tsai WP, Lin LY, Chang WL, Chang HC, Chou MC. The effects of the suicide awareness program in enhancing community volunteers' awareness of suicide warning signs. Arch Psychiatr Nurs. 2010;24(1):63-8.

193 Frankenfield DL, Keyl PM, Gielen A, Wissow LS, Werthamer L, Baker SP. Adolescent patients--healthy or hurting? Missed opportunities to screen for suicide risk in the primary care setting. Arch Pediatr Adolesc Med. 2000;154(2):162-8.

194 Gaynes BN, West SL, Ford CA, Frame P, Klein J, Lohr KN. Screening for suicide risk in adults: a summary of the evidence for the U.S. Preventive Services Task Force. Ann Intern Med. 2004;140(10):822-35.

195 Voros V, Osvath P, Kovacs L, Varga J, Fekete S, Kovacs A. Screening for suicidal behaviour and mental disorders with Prime-MD questionnaire in general practice. Prim Care Community Psychiatr. 2006;11(4):193-6.

196 Pena JB, Caine ED. Screening as an approach for adolescent suicide prevention. Suicide Life Threat Behav. 2006;36(6):614-37.

197 Montalván V, Graver R, María A. Oquendo MA, Baca-García E, Morales M, Mann J. Spanish Adaptation of the Buss-Durkee Hostility Inventory (BDHI). Eur J Psychiat. 2001;15(2):101-12. 
198 Wintersteen MB. Standardized screening for suicidal adolescents in primary care. Pediatrics. 2010;125(5):938-44.

199 Habis A, Tall L, Smith J, Guenther E. Pediatric emergency medicine physicians' current practices and beliefs regarding mental health screening. Pediatr Emerg Care. 2007;23(6):387-93.

200 Asarnow JR, Baraff LJ, Berk M, Grob C, Devich-Navarro M, Suddath R, et al. Pediatric emergency department suicidal patients: two-site evaluation of suicide ideators, single attempters, and repeat attempters. J Am Acad Child Psy 2008;47(8):958-66.

201 King CA, O'Mara RM, Hayward CN, Cunningham RM. Adolescent suicide risk screening in the emergency department. Acad Emerg Med. 2009;16(11):123441.

202 Fein JA, Pailler ME, Barg FK, Wintersteen MB, Hayes K, Tien AY, et al. Feasibility and effects of a Web-based adolescent psychiatric assessment administered by clinical staff in the pediatric emergency department. Arch Pediatr Adolesc Med. 2010;164(12):1112-7.

203 Oyama H, Sakashita T, Ono Y, Goto M, Fujita M, Koida J. Effect of communitybased intervention using depression screening on elderly suicide risk: a metaanalysis of the evidence from Japan. Community Ment Health J.2008;44(5):31120.

204 Oyama H, Sakashita T, Hojo K, Ono Y, Watanabe N, Takizawa T, et al. A community-based survey and screening for depression in the elderly: the shortterm effect on suicide risk in Japan. Crisis. 2010;31(2):100-8.

205 Heisel MJ, Duberstein PR, Lyness JM, Feldman MD. Screening for suicide ideation among older primary care patients. J Am Board Fam Med. 2010;23(2):260-9.

206 Konrad N, Daigle MS, Daniel AE, Dear GE, Frottier P, Hayes LM, et al. Preventing suicide in prisons, part I. Recommendations from the International Association for Suicide Prevention Task Force on Suicide in Prisons. Crisis. 2007;28(3):113-21.

207 Perry AE, Marandos R, Coulton S, Johnson M. Screening tools assessing risk of suicide and self-harm in adult offenders: a systematic review. Int J Offender Ther Comp Criminol. 2010;54(5):803-28.

208 Gould MS, Marrocco FA, Kleinman M, Thomas JG, Mostkoff K, Cote J, et al. Evaluating iatrogenic risk of youth suicide screening programs: a randomized controlled trial. JAMA. 2005;293(13):1635-43.

209 Williams SB, O'Connor EA, Eder M, Whitlock EP. Screening for child and adolescent depression in primary care settings: A systematic evidence review for the US Preventive Services Task Force. Pediatrics. 2009;123(4):e716-e35.

210 Deeley ST, Love AW. Does asking adolescents about suicidal ideation induce negative mood state? Violence Vict. 2010;25(5):677-88.

211 World Health Organization. Mental health: Country reports and charts available. Geneva:WHO; 2011 [citado 21 jun 2011]. Disponible en: http://www. who.int/mental_health/prevention/suicide/country_reports/en/index.html

212 Arán Barés M, Gispert R, Puig X, Freitas A, Ribas G, Puigdefàbregas A. Evolución temporal y distribución geográfica de la mortalidad por suicidio en Cataluña y España (1986-2002). Gac Sanit. 2006;20(6):473-80.

213 Hawton K, Harriss L. Deliberate self-harm by under-15-year-olds: characteristics, trends and outcome. J Child Psychol Psychiatry. 2008;49(4):441-8. 
214 Arán Barés M, Gispert R, Puig X, Freitas A, Ribas G, Puigdefàbregas A. Evolución temporal y distribución geográfica de la mortalidad por suicidio en Cataluña y España (1986-2002). Gac Sanit. 2006;20(6 ):473-80.

215 Evans E, Hawton K, Rodham K. Factors associated with suicidal phenomena in adolescents: a systematic review of population-based studies. Clin Psychol Rev. 2004;24(8):957-79.

216 American Academy of Child and Adolescent Psychiatry. Practice parameter for the assessment and treatment of children and adolescents with suicidal behaviour. J Am Acad Child Adolesc Psychiatry. 2001;40(7 Suppl):24S-51S.

217 Vander Stoep A, Adrian M, Mc Cauley E, Crowell SE, Stone A, Flynn C. Risk for Suicidal Ideation and Suicide Attempts Associated with Co-occurring Depression and Conduct Problems in Early Adolescence. Suicide Life Threat Behav. 2011;41(3):316-29.

218 Schilling EA, Aseltine Jr RH, Glanovsky JL, James A, Jacobs D. Adolescent Alcohol Use, Suicidal Ideation, and Suicide Attempts. J Adolesc Health. 2009;44(4):335-41.

219 Chronis-Tuscano A, Molina BS, Pelham WE, Applegate B, Dahlke A, Overmyer $\mathrm{M}$, et al. Very early predictors of adolescent depression and suicide attempts in children with attention-deficit/hyperactivity disorder. Arch gen Psychiatry. 2010;67(10):1044-51.

220 Wong MM, Brower KJ, Zucker RA. Sleep problems, suicidal ideation, and selfharm behaviors in adolescence. J Psychiatr Res. 2011;45(4):505-11.

221 Goldstein TR, Bridge JA, Brent DA. Sleep disturbance preceding completed suicide in adolescents. J Consult Clin Psychol. 2008;76(1):84-91.

222 Axelson D, Birmaher B, Strober M, Gill MK, Valeri S, Laurel Chiappetta L, et al. Phenomenology of Children and Adolescents With Bipolar Spectrum Disorders. Arch gen Psychiatry. 2006;63:1139-48.

223 Goldstein TR, Birmaher B, Axelson D, Ryan ND, Strober MA, Gill MK, et al. History of suicide attempts in pediatric bipolar disorder: factors associated with increased risk. Bipolar Disord. 2005;7(6):525-35.

224 Patel K, Upthegrove R. Self-harm in first-episode psychosis. Psychiatr Bull R Coll Psychiatr. 2009;33(3):104-7.

225 Witte TK, Merrill KA, Stellrecht NE, Bernert RA, Hollar DL, Schatschneider $\mathrm{C}$, et al. "Impulsive" youth suicide attempters are not necessarily all that impulsive. J Affect Disord. 2008;107(1-3):107-16.

226 Jacobson CM, Marrocco F, Kleinman M, Gould MS. Restrictive emotionality, depressive symptoms, and suicidal thoughts and behaviors among high school students. J Youth Adolesc. 2011;40(6):656-65.

227 O'Connor RC, Rasmussen S, Hawton K. Predicting depression, anxiety and self-harm in adolescents: the role of perfectionism and acute life stress. Behav Res Ther. 2010;48(1):52-9.

228 Speckens AE, Hawton K. Social problem solving in adolescents with suicidal behavior: a systematic review. Suicide Life Threat Behav. 2005;35(4):365-87.

229 Laje G, PaddocK S, Manji H, Rush J, Wilson AF, Charney D, et al. Genetic markers of suicidal ideation emerging during citalopram treatment of major depression. Am J Psychiatry. 2007;164(10):1530-8.

230 Wilcox HC, Arria AM, Caldeira KM, Vincent KB, Pinchevsky GM, O'Grady KE. Prevalence and predictors of persistent suicide ideation, plans, and attempts during college. J Affect Disord. 2010;127(1-3):287-94. 
231 Brunstein Klomek A, Sourander A, Gould M. The association of suicide and bullying in childhood to young adulthood: a review of cross-sectional and longitudinal research findings. Can J Psychiatry. 2010;55(5):282-8.

232 McMahon EM, Reulbach U, Keeley H, Perry IJ, Arensman E. Bullying victimisation, self harm and associated factors in Irish adolescent boys. Soc Sci Med. 2010;71(7):1300-7.

233 Klomek AB, Sourander A, Niemelä S, Kumpulainen K, Piha J, Tamminen T, et al. Childhood bullying behaviors as a risk for suicide attempts and completed suicides: a population-based birth cohort study. J Am Acad Child Adolesc Psychiatry. 2009;48(3):254-61.

234 Hinduja S, Patchin JW. Bullying, Cyberbullying, and Suicide. Arch Suicide Res. 2010;14:206-21.

235 Winterrowd E, Canetto SS, Chavez EL. Friendship factors and suicidality: common and unique patterns in Mexican American and European American youth. Suicide Life Threat Behav. 2011;41(1):50-65.

236 Renaud J, Berlim MT, Begolli M, McGirr A, Turecki G. Sexual orientation and gender identity in youth suicide victims: An exploratory study. Can J Psychiatry. 2010;55(1):29-34.

237 Lucassen MF, Merry SN, Robinson EM, Denny S, Clark T, Ameratunga S, et al. Sexual attraction, depression, self-harm, suicidality and help-seeking behaviour in New Zealand secondary school students. Aust N Z J Psychiatry. 2011;45(5):376-83.

238 Evans E, Hawton K, Rodham K. Suicidal phenomena and abuse in adolescents: a review of epidemiological studies. Child Abuse Negl. 2005;29:45-58.

239 Bruffaerts R, Demyttenaere K, Borges G, Haro JM, Chiu WT, Hwang I, et al. Childhood adversities as risk factors for onset and persistence of suicidal behaviour. Br J Psychiatry. 2010;197(1):20-7.

240 Colucci E, Martin G. Ethnocultural aspects of suicide in young people: a systematic literature review part 2: Risk factors, precipitating agents, and attitudes toward suicide. Suicide Life Threat Behav. 2007;37(2):222-37.

241 Bhatia SK, Bhatia SC. Childhood and adolescent depression. Am Fam Physician. 2007;75(1):73-80.

242 Ougrin D, Zundel T, Ng A, Banarsee R, Bottle A, Taylor E. Trial of Therapeutic Assessment in London: Randomised controlled trial of Therapeutic Assessment versus standard psychosocial assessment in adolescents presenting with selfharm. Archives of Disease in Childhood. 2011;96(2):148-53.

243 Horowitz LM, Wang PS, Koocher GP, Burr BH, Smith MF, Klavon S, et al. Detecting suicide risk in a pediatric emergency department: development of a brief screening tool. Pediatrics. 2001;107(5):1133-7.

244 Aliaga J, Rodríguez L, Ponce C, Frisancho A, Enríquez J. Escala de desesperanza de Beck (BHS): Adaptación y características psicométricas. Revista de Investigación en Psicología. 2006;9(1):69-79.

245 Beck RW, Morris JB, Beck AT. Cross-validation of the Suicidal Intent Scale. Psychol Rep. 1974;34(2):445-6.

246 Kaufman J, Birmaher B, Brent DA. Schedule for Affective Disorders and Schizophrenia for School-Age Children-Present and Lifetime Version (K-SADS-PL): initial reliability and validity data. J Am Acad Child Adolesc Psychiatry. 1997;36:980-8. 
247 Poznanski EO, Grossman JA, Buchbaum Y, Banegas M, Freeman L, Gibbons R. Preliminary studies of the reliability and validity of the Children's Depression Scale. J Am Acad Child Adolesc Psychiatry. 1984;23:191-7.

248 Cusimano MD, Sameem M. The effectiveness of middle and high school-based suicide prevention programmes for adolescents: a systematic review. Inj Prev. 2011;17:43-9.

249 Eggert LL, Thompson EA, Herting JR, Nicholas LJ. Reducing suicide potential among high-risk youth: tests of a school-based prevention program. Suicide Life Threat Behav. 1995;25(2):276-96.

250 Randell BP, Eggert LL, Pike KC. Immediate post intervention effects of two brief youth suicide prevention interventions. Suicide Life Threat Behav. 2001;31(1):41-61.

251 Steele MM, Doey T. Suicidal behaviour in children and adolescents. Part 2: Treatment and Prevention. Can J Psychiatry. 2007;52(6 Suppl 1):35S-45S.

252 Gould MS, Greenberg T, Munfakh JL, Kleinman M, Lubell K. Teenagers' attitudes about seeking help from telephone crisis services (hotlines). Suicide Life Threat Behav. 2006;36(6):601-13.

253 Gould MS, Greenberg T, Velting DM, Shaffer D. Youth suicide risk and preventive interventions: a review of the past 10 years. J Am Acad Child Adolesc Psychiatry. 2003;42(4):386-405.

254 Hagihara A, Miyazaki S, Abe T. Internet suicide searches and the incidence of suicide in young people in Japan. Eur Arch Psychiatry Clin Neurosc. 2011.

255 Szumilas M, Kutcher S. Teen suicide information on the internet: a systematic analysis of quality. Can J Psychiatry. 2009;54(9):596-604.

256 Royal College of Psychiatrists. Self-harm, Suicide and Risk: Helping People who Self-harm. London: Royal College of Psychiatrists; 2010. Informe $N^{\circ}$.: CR158.

257 Conwell Y, Thompson C. Suicidal Behavior in Elders. Psychiatric Clinics of North America. 2008;31(2):333-56.

258 Instituto Nacional de Estadística. Salud. Defunciones según la causa de muerte 2009. Tasas de suicidios por edad y sexo por 100000 habitantes de cada grupo. Madrid: Instituto Nacional Estadística; 2009 [citado 29 jul 2011]. Disponible en: http://www.ine.es/jaxi/tabla.do?path=/t15/p417/a2009/10/\&file=05008.px\&type $=$ pcaxis $\& \mathrm{~L}=0$

259 Chan J, Draper B, Banerjee S. Deliberate self-harm in older adults: a review of the literature from 1995 to 2004. Int J Geriatr Psychiatry. 2007;22:720-32.

260 Miret M, Nuevo R, Morant C, Sainz-Corton E, Jimenez-Arriero MA, LopezIbor JJ, et al. Differences Between Younger and Older Adults in the Structure of Suicidal Intent and Its Correlates. Am J Geriatr Psychiatr. 2010;18(9):839-47.

261 Grek A. Clinical management of suicidality in the elderly: an opportunity for involvement in the lives of older patients. Can J Psychiatry. 2007;52(6 Suppl 1):47S-57S.

262 Wiktorsson S, Runeson B, Skoog I, Ostling S, Waern M. Attempted suicide in the elderly: Characteristics of suicide attempters 70 years and older and a general population comparison group. Am J Geriatr Psychiatr. 2010;18 (1):5767.

263 Dennis MS, Wakefield P, Molloy C, Andrews H, Friedman T. A study of selfharm in older people: mental disorder, social factors and motives. Aging Ment Health. 2007;11(5):520-5. 
264 Tejedor MC. Aspectos clínicos del suicidio en el anciano deprimido. Informaciones Psiquiátricas. 2002;167:45-50.

265 Pfaff JJ, Almeida OP, Witte TK, Waesche MC, Joiner TE, Jr. Relationship between quantity and frequency of alcohol use and indices of suicidal behavior in an elderly Australian sample. Suicide Life Threat Behav. 2007;37(6):616-26.

266 Hirsch JK, Duberstein PR, Unutzer J. Chronic medical problems and distressful thoughts of suicide in primary care patients: mitigating role of happiness. Int J Geriatr Psychiatry. 2009;24(7):671-9.

267 Harwood DM, Hawton K, Hope T, Harriss L, Jacoby R. Life problems and physical illness as risk factors for suicide in older people: a descriptive and case-control study. Psychol Med. 2006;36(9):1265-74.

268 Levy TB, Barak Y, Sigler M, Aizenberg D. Suicide attempts and burden of physical illness among depressed elderly inpatients. Arch Gerontol Geriatr. 2011;52(1):115-7.

269 Voaklander DC, Rowe BH, Dryden DM, Pahal J, Saar P, Kelly KD. Medical illness, medication use and suicide in seniors: a population-based case-control study. J Epidemiol Community Health. 2008;62:138-46.

270 Haw C, Harwood D, Hawton K. Dementia and suicidal behavior: a review of the literature. Int Psychogeriatr. 2009;21(3):440-53.

271 Erlangsen A, Vach W, Jeune B. The effect of hospitalization with medical illnesses on the suicide risk in the oldest old: A population-based register study. J Am Geriatr Soc. 2005;53(5):771-6.

272 Vanderhorst RK, McLaren S. Social relationships as predictors of depression and suicidal ideation in older adults. Aging Ment Health. 2005;9(6):517-25.

273 Yesavage JA, Brink TL, Rose TL, Lum O, Huang V, Adey M, et al. Development and validation of a geriatric depression screening scale: A preliminary report. J Psychiatr Res. 1983;17(1):37-49.

274 Fry PS. Development of a geriatric scale of hopelessness: Implications for counseling and intervention with the depressed elderly. J Couns Psychol. 1984;31(3):322-31.

275 Edelstein BA, Heisel MJ, McKee DR, Martin RR, Koven LP, Duberstein PR, et al. Development and Psychometric Evaluation of the Reasons for Living - Older Adults Scale: A Suicide Risk Assessment Inventory. Gerontologist. 2009;49(6): 736-45.

276 Awata S, Bech P, Koizumi Y, Seki T, Kuriyama S, Hozawa A, et al. Validity and utility of the Japanese version of the WHO-Five Well-Being Index in the context of detecting suicidal ideation in elderly community residents. Int Psychogeriatr. 2007;19(1):77-88.

277 Chen WJ, Chen CC, Ho CK, Lee MB, Chung YT, Wang YC, et al. The suitability of the BSRS-5 for assessing elderly who have attempted suicide and need to be referred for professional mental health consultation in a metropolitan city, Taiwan. Int J Geriatr Psychiatry. 2009;24(10):1151-7.

278 Kjolseth I, Ekeberg O, Steihaug S. Elderly people who committed suicide-their contact with the health service. What did they expect, and what did they get? Aging Ment Health. 2010;14(8):938-46.

279 Instituto Nacional de Estadística. Salud. Defunciones según la causa de muerte 2008. Suicidios por medio empleado, sexo y edad. Madrid: Instituto Nacional Estadística; 2008 [citado 27 jun 2011]. Disponible en: http://www.ine.es/jaxi/ tabla.do?path $=/$ t15/p417/a2008/10/\&file $=05002 . p x \&$ type $=$ pcaxis $\& L=0$ 
280 Casado Blanco M. Suicidios en mayores de 65 años en la provincia de Badajoz: análisis médico legal. Cuad med forense [revista en Internet]. 2002 [citado 28 may 2012]; (28): Disponible en: http://scielo.isciii.es/pdf/cmf/n28/original1.pdf

281 Hawton K, Harriss L. Deliberate self-harm in people aged 60 years and over: characteristics and outcome of a 20-year cohort. Int J Geriatr Psychiatry. 2006;21(6):572-81.

282 De Leo D, Dello Buono M, Dwyer J. Suicide among the elderly: The long-term impact of a telephone support and assessment intervention in northern Italy. Br J Psychiatry. 2002;181:226-9.

283 Oyama H, Watanabe N, Ono Y, Sakashita T, Takenoshita Y, Taguchi M, et al. Community-based suicide prevention through group activity for the elderly successfully reduced the high suicide rate for females. Psychiatry Clin Neurosci. 2005;59(3):337-44.

284 Vannoy SD, Duberstein P, Cukrowicz K, Lin EH, Fan MY, Unützer J. The relationship between suicide ideation and late-life depression. Am J Geriatr Psychiatry. 2007;15(12):1024-33.

285 Bruce ML, Ten Have TR, Reynolds CF, Katz II, Schulberg HC, Mulsant $\mathrm{BH}$, et al. Randomized Controlled Trial in Depressed Older Primary Care Patients: A Reducing Suicidal Ideation and Depressive Symptoms. JAMA. 2004;291(9):1081-91.

286 Chan SS, Leung VP, Tsoh J, Li SW, Yu CS, Yu GK, et al. Outcomes of a twotiered multifaceted elderly suicide prevention program in a Hong Kong chinese community. Am J Geriatr Psychiatry. 2011;19(2):185-96.

287 Fisher BJ, Haythornthwaite JA, Heinberg LJ, Clark M, Reed J. Intención de suicidio en pacientes con dolor crónico. Rev Soc Esp Dolor. 2002;9:146-56.

288 Robson A, Scrutton F, Wilkinson L, MacLeod F. The risk of suicide in cancer patients: a review of the literature. Psychooncology. 2010;19(12):1250-8.

289 Tang NK, Crane C. Suicidality in chronic pain: a review of the prevalence, risk factors and psychological links. Psychol Med. 2006;36(5):575-86.

290 Giannini MJ, Bergmark B, Kreshover S, Elias E, Plummer C, O'Keefe E. Understanding suicide and disability through three major disabling conditions: Intellectual disability, spinal cord injury, and multiple sclerosis. Disabil Health J. 2010;3(2):74-8.

291 Kaplan MS, McFarland BH, Huguet N, Newsom JT. Physical illness, functional limitations, and suicide risk: a population-based study. Am J Orthopsychiatry. 2007;77(1):56-60.

292 Kishi Y, Robinson RG, Kosier JT. Suicidal ideation among patients with acute life-threatening physical illness: patients with stroke, traumatic brain injury, myocardial infarction, and spinal cord injury. Psychosomatics. 2001;42(5):38290.

293 Goodwin RD, Marusic A, Hoven CW. Suicide attempts in the United States: the role of physical illness. Soc Sci Med. 2003;56(8):1783-8.

294 Greydanus D, Patel D, Pratt H. Suicide risk in adolescents with chronic illness: implications for primary care and specialty pediatric practice: a review. Dev Med Child Neurol. 2010;52(12):1083-7.

295 Vera M, Reyes-Rabanillo ML, Huertas S, Juarbe D, Perez-Pedrogo C, Huertas A, et al. Suicide ideation, plans, and attempts among general practice patients with chronic health conditions in Puerto Rico. Int J Gen Med. 2011;4:197-205. 
296 Calandre EP, Vilchez JS, Molina-Barea R, Tovar MI, Garcia-Leiva JM, Hidalgo $\mathrm{J}$, et al. Suicide attempts and risk of suicide in patients with fibromyalgia: a survey in Spanish patients. Rheumatology (Oxford). 2011;50(10):1889-93.

297 Gilbert JW, Wheeler GR, Storey BB, Mick G, Richardson G, Westerfield $\mathrm{G}$, et al. Suicidality in chronic noncancer pain patients. Int $\mathrm{J}$ Neurosci. 2009;119(10):1968-79.

298 Wolfe F, Hassett AL, Walitt B, Michaud K. Mortality in fibromyalgia: a study of 8,186 patients over thirty-five years. Arthritis Care Res (Hoboken). 2011;63(1):94-101.

299 Dennis M, Baillon S, Brugha T, Lindesay J, Stewart R, Meltzer H. The influence of limitation in activity of daily living and physical health on suicidal ideation: results from a population survey of Great Britain. Soc Psychiatry Psychiatr Epidemiol. 2009;44(8):608-13.

300 Everett Jones S, Lollar DJ. Relationship between physical disabilities or longterm health problems and health risk behaviors or conditions among US high school students. J Sch Health. 2008;78(5):252-7.

301 Gadalla T. Association of comorbid mood disorders and chronic illness with disability and quality of life in Ontario, Canada. Chronic Dis Can. 2008;28(4):148-54.

302 Jurisic B, Marusic A. Suicidal ideation and behavior and some psychological correlates in physically disabled motor-vehicle accident survivors. Crisis. 2009;30(1):34-8.

303 Zochling J, Braun J. Mortality in ankylosing spondylitis. Clin Exp Rheumatol. 2008;26(5 Suppl 51):S80-4.

304 Catalan J, Harding R, Sibley E, Clucas C, Croome N, Sherr L. HIV infection and mental health: suicidal behaviour--systematic review. Psychol Health Med. 2011;16(5):588-611.

305 Bill-Axelson A, Garmo H, Lambe M, Bratt O, Adolfsson J, Nyberg U, et al. Suicide Risk in Men with Prostate-Specific Antigen-Detected Early Prostate Cancer: A Nationwide Population-Based Cohort Study from PCBaSe Sweden. Eur Urol. 2009;57:390-5.

306 Giner L. Diferencias en la conducta suicida. Madrid: Universidad Autónoma de Madrid; 2011.

307 Lago Canzobre S, Debén Sánchez M. Cuidados del cuidador del paciente con Demencia. Barcelona: Elsevier; [citado 14 jun 2011]. Disponible en: http:// www.fisterra.com/guias2/cuidador.asp

308 Zabalegui Yárnoz A, Navarro Díez M, Cabrera Torres E, Gallart FernándezPuebla A, Bardallo Porras D, Rodríguez Higueras E, et al. Eficacia de las intervenciones dirigidas a cuidadores principales de personas dependientes mayores de 65 años. Una revisión sistemática. Rev Esp Geriatr Gerontol. 2008;43(3):157-66.

309 Mizuno E, Hosak T, Ogihara R, Higano H, Mano Y. Effectiveness of a stress management program for family caregivers of the elderly at home. J Med Dent Sci. 1999;46(4):145-53.

310 Hernández-Viadel M, Guillem-Miralles JL, Pérez-Prieto JF, Leal-Cercos C. Homicidio-suicidio en el anciano: ¿por qué el cuidador mata a su pareja con enfermedad de Alzheimer y después se suicida? Psiq Biol. 2006;13(1):30-4. 
311 McLean J, Maxwell M, Platt S, Harris F, Jepson R. Risk and protective factors for suicide and suicidal behaviour: A literature review. Edinburgh: Scottish Government Social Research; 2008.

312 Magellan Behavioral Health: Clinical Practice Guideline for Assessing and Managing the Suicidal Patient. 6/08 v.2: Magellan Health Services; 2008 [citado 16 mar 2010]. Disponible en: http://www.magellanprovider.com/MHS/MGL/ providing_care/clInical_guidelines/clin_prac_guidelines/suicide.pdf

313 Andersen K, Hawgood J, Klieve H, Kolves K, De Leo D. Suicide in selected occupations in Queensland: evidence from the State suicide register. Aust N Z J Psychiatry. 2010;44(3):243-9.

314 Platt B, Hawton K, Simkin S, Mellanby RJ. Systematic review of the prevalence of suicide in veterinary surgeons. Occup Med (Lond). 2010;60(6):436-46.

315 Pompili M, Innamorati M, Narciso V, Kotzalidis GD, Dominici G, Talamo A, et al. Burnout, hopelessness and suicide risk in medical doctors. Clin Ter. 2010;161(6):511-4.

316 Schwenk TL, Davis L, Wimsatt LA. Depression, stigma, and suicidal ideation in medical students. JAMA. 2010;304(11):1181-90.

317 Dyrbye LN, Thomas MR, Massie FS, Power DV, Eacker A, Harper W, et al. Burnout and suicidal ideation among U.S. medical students. Ann Intern Med. 2008;149(5):334-41.

318 Bagley SC, Munjas B, Shekelle P. A systematic review of suicide prevention programs for military or veterans. Suicide Life Threat Behav. 2010;40(3):25765.

319 Knox KL, Pflanz S, Talcott GW, Campise RL, Lavigne JE, Bajorska A, et al. The US Air Force suicide prevention program: implications for public health policy. Am J Public Health. 2010;100(12):2457-63.

320 Levenson RL, Jr., O'Hara AF, Clark R, Sr. The Badge of Life Psychological Survival for Police Officers Program. Int J Emerg Ment Health. 2010;12(2):95101.

321 Takada M, Shima S. Characteristics and effects of suicide prevention programs: comparison between workplace and other settings. Ind Health. 2010;48(4):41626.

322 Violanti JM. Police suicide: a national comparison with fire-fighter and military personnel. An International Journal of Police Strategies \& Management. 2009;33(2):270-86.

323 Bobes García J, Giner Ubago J, Daiz J. Suicidio y Psiquiatría. Recomendaciones preventivas y de manejo del comportamiento suicida. Madrid:Triacastela;2011.

324 Centers for Disease Control and Prevention. Study looks at suicide rates from 1928-2007. CDC Study Finds Suicide Rates Rise and Fall with Economy [revista en Internet]. 2011 [citado 28 may 2012]: Disponible en: http://www.cdc. gov/media/releases/2011/p0414_suiciderates.html

325 Rehkopf DH, Buka SL. The association between suicide and the socioeconomic characteristics of geographical areas: A systematic review. Psychol Med. 2006;36(2):145-57.

326 Pompili M, Lester D, Innamorati M, De Pisa E, Iliceto P, Puccinno M, et al. Suicide risk and exposure to mobbing. Work. 2008;31(2):237-43.

327 Yildirim A, Yildirim D. Mobbing in the workplace by peers and managers: mobbing experienced by nurses working in healthcare facilities in Turkey and its effect on nurses. J Clin Nurs. 2007;16(8):1444-53. 
328 Yildirim D, Yildirim A, Timucin A. Mobbing behaviors encountered by nurse teaching staff. Nurs Ethics. 2007;14(4):447-63.

329 Balducci C, Alfano V, Fraccaroli F. Relationships between mobbing at work and MMPI-2 personality profile, posttraumatic stress symptoms, and suicidal ideation and behavior. Violence Vict. 2009;24(1):52-67.

330 Leymann H. The content and development of mobbing at work. European Journal of Work and Organizational Psychology. 1996;5(2):165-84.

331 Long B. Psychologic aspects of the hostile workplace: Harassment and bullying. Clin Occup Environ Med. 2003;3(4):803-20.

332 International Labour Office. Sexual harassment at work. Genève: International Labour Organization; 2007.

333 Merino J, Cruceta G. El acoso sexual en el trabajo en Catalunya. Estudio de casos. Rev d'estudis de la violencia [revista en Internet]. 2009 [citado 28 may 2012]; 7(1er trimestre): Disponible en: http://www.navarra.es/NR/rdonlyres/D91FE4994898-4EDD-AA09-213A8AF122EA/153600/ICEV_Acoso_sexual.pdf

334 Golding JM. Intimate Partner Violence as a Risk Factor for Mental Disorders: A Meta-Analysis. J Fam Violence. 1999;14(2):99-132.

335 Renner LM, Markward MJ. Factors associated with suicidal ideation among women abused in intimate partner relationships. Smith Coll Stud Soc Work. 2009;79(2):139-54.

336 Espinoza-Gomez F, Zepeda-Pamplona V, Bautista-Hernández V, HernándezSuárez CM, Newton-Sánchez OA, Plasencia-García GR. Violencia doméstica y riesgo de conducta suicida en universitarios adolescentes. Salud Publica Mex. 2010;52:213-9.

337 Dirección General de Instituciones Penitenciarias. Programa marco de prevención de suicidios. Madrid; 2005.

338 Pompili M, Lester D, Innamorati M, Del Casale A, Girardi P, Ferracuti S, et al. Preventing suicide in jails and prisons: suggestions from experience with psychiatric inpatients. J Forensic Sci. 2009;54(5):1155-62.

339 Dyregrov K. What Do We Know About Needs for Help After Suicide in Different Parts of the World? Crisis. 2011;6:1-9.

340 Sakinofsky I. The Aftermath of Suicide: Managing Survivors' Bereavement. Can J Psychiatry. 2007;52(10S1):129S-36S.

341 Aguirre RTP, Slater H. Suicide postvention as suicide prevention: improvement and expansion in the United States. Death Studies. 2010;34:529-40.

342 Cvinar JG. Do suicide survivors suffer social stigma: a review of the literature. Perspect Psychiatr Care. 2005;41(1):14-21.

343 Maple M, Edwards H, Plummer D, Minichiello V. Silenced voices: hearing the stories of parents bereaved through the suicide death of a young adult child. Health Soc Care Community. 2010;18(3):241-8.

344 Dyregrov K. The important role of the school following suicide in Norway. What support do young people wish that school could provide? Omega (Westport). 2009;59(2):147-61.

345 Andriessen K. Can Postvention Be Prevention? Crisis. 2009;30(1):43-7.

346 Szumilas M, Kutcher S. Post-suicide intervention programs: a systematic review. Can J Public Health. 2011;102(1):18-29.

347 McDaid C, Trowman R, Golder S, Hawton K, Sowden A. Interventions for people bereaved through suicide: systematic review. $\mathrm{Br} \mathrm{J}$ Psychiatry. 2008;193(6):438-43. 
348 Wurst FM, Kunz I, Skipper G, Wolfersdorf M, Beine KH, Thon N. The therapist's reaction to a patient's suicide: Results of a survey and implications for health care professionals' well-being. Crisis. 2011;32(2):99-105.

349 Pallin V. Supporting staff and patients after a suicide. En: Duffy D, Ryan T, eds. New approaches to preventing suicide A manual for practitioners. London: Jessica Kingsley Publishers; 2004.

350 Hendin H, Haas AP, Maltsberger JT, Szanto K, Rabinowicz H. Factors Contributing to Therapists' Distress After the Suicide of a Patient. Am J Psychiatry. 2004;161:1442-6.

351 Thomyangkoon P, Leenaars A. Impact of death by suicide of patients on Thai psychiatrists. Suicide Life Threat Behav. 2008;38(6):728-40.

352 Alexander DA, Klein S, Gray NM, Dewar IG, Eagles JM. Suicide by patients: Questionnaire study of its effect on consultant psychiatrists. BMJ. 2000;320(7249):1571-4.

353 Ellis TE, Dickey ITO, Jones EC. Patient suicide in psychiatry residency programs: A national survey of training and postvention practices. Acad Psychiatry. 1998;22(3):181-9.

354 Bartels SJ. The aftermath of suicide on the psychiatric inpatient unit. Gen Hosp Psychiatry. 1987;9:189-97.

355 Yousaf F, Hawthorne M, Sedgwick P. Impact of patient suicide on psychiatric trainees. Psychiatr Bull R Coll Psychiatr. 2002;26(2):53-5.

356 Pedreira Crespo V. Desarrollos recientes en salud mental comunitaria en Galicia. Psilogos - Revista do Serviço de Psiquiatria do Hospital Prof Doutor Fernando Fonseca [revista en Internet]. 2008 [citado; 6(1): Disponible en: http://www.psilogos.com/Revista/Vol6N1/Indice9_ficheiros/Crespo\%20_\%20 P77-97.pdf

357 Pedreira Crespo V, (coord). Plan Estratéxico de Saúde Mental. Galicia 20062011. Santiago de Compostela: Xunta de Galicia. Sergas; 2007.

358 Tejedor MC, Díaz A, Faus G, Pérez V, Solà I. Resultados del programa de prevención de la conducta suicida. Distrito de la Dreta de l'Eixample de Barcelona. Actas Esp Psiquiatr. 2011;39(5):280-7.

359 Palao DJ. Programa de intervención multinivel para la prevención de la depresión y el suicidio (Corporació Sanitària i Universitària Parc Taulí de Sabadell (Barcelona). Comunicación personal.

360 Informe anual del Sistema Nacional de Salud 2007. Castilla y León. Madrid: Ministerio de Sanidad y Consumo; 2007.

361 Código penal, Ley Orgánica 10/1995. Boletín Oficial del Estado, N² 281, (24 de noviembre de 1995).

362 Ley básica reguladora de la autonomía del paciente y de derechos y obligaciones en materia de información y documentación clínica, Ley 41/2002. Boletín Oficial del Estado, No 274, (15 de noviembre de 2002).

363 Carrasco Gómez JJ. Responsabilidad médica y psiquiatría. Madrid: Colex; 1990.

364 Bobes García J, Sáiz Martínez PA, Bascarán Fernández T, Bousoño García M. Comportamientos suicidas. Prevención y tratamiento. Barcelona: Ars Medica; 2004.

365 Fuertes Rocañín JC, Cabrera Forneiro J. La Salud Mental en los Tribunales. Madrid: Arán Ediciones; 2007. 


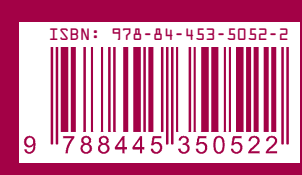

P.V.P.: 10 euros

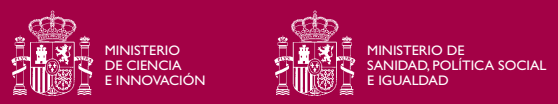

